SJ Quinney College of Law, University of Utah Utah Law Digital Commons

2019

Visibility Protection Under the Clean Air Act

Arnold W. Reitze Jr.

Follow this and additional works at: https://dc.law.utah.edu/scholarship

Part of the Environmental Law Commons 


\section{Visibility Protection Under the Clean Air Act}

Professor Arnold W. Reitze, Jr.*

Copyright January 9, 2018

* Professor of Law, S.J. Quinney College of Law, The University of Utah. Member of the Utah Air Quality Board. Research assistance was provided by J.D. candidate Angeline Portel.. 
Table of Contents

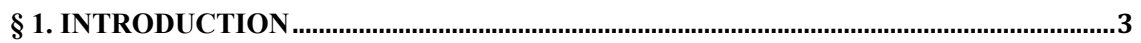

§ 2. VISIBILITY CONTROLS ON SPECIFIC EMISSION SOURCES ...................................

$\S 2$ (A). REASONABLE PROGRESS................................................................................................................

§ 2(a)(1). State of North Dakota v. EPA (Reasonable Progress Issues)...................................... 8

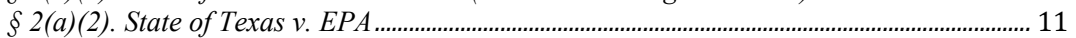

§ 2(B). INTERSTATE TRANSPORT OF POLLUTANTS .............................................................................15

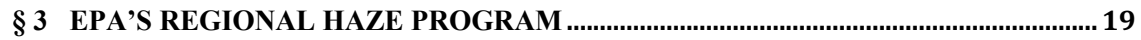

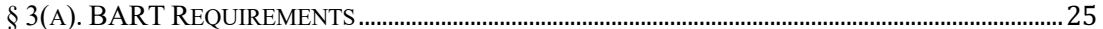

$\S 3(a)(1)$. North Dakota v. EPA. ................................................................................................... 27

§ 3(a)(2). National Parks Conservation Ass'n v. EPA.................................................................. 30

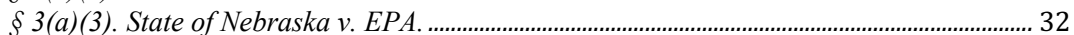

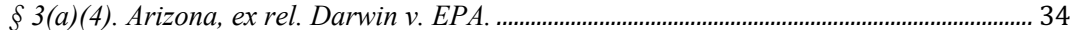

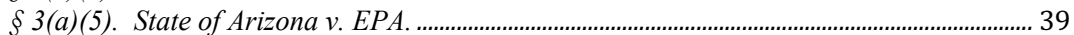

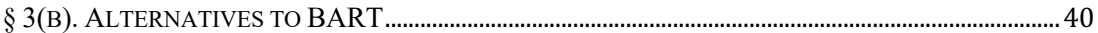

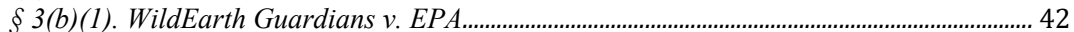

$\S 3(b)(2)$. National Parks Conservation Association v. McCarthy .......................................... 45

§ 3(C). THE 2017 REVISIONS TO THE HAZE RULE..................................................................................... 45

§ 4. VISIBILITY IN GRAND CANYON NATIONAL PARK ….......................................47

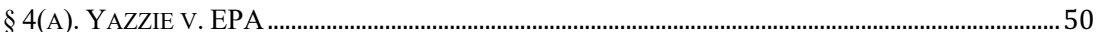

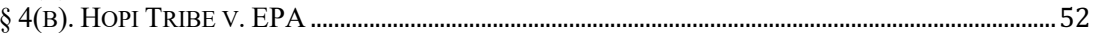

§ 4(C). DEVELOPMENTS IN 2017 .................................................................................................. 53

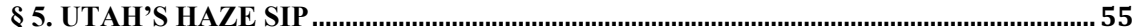

§ 5(A). EPA'S RESPONSE TO UTAH'S HAZE SIP REVISIONS .......................................................... 58

§ 5(B). DEVELOPMENTS IN 2017..................................................................................................... 63

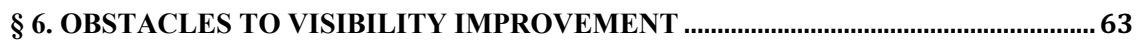




\section{$\S 1$. Introduction}

The Clean Air Act's ("CAA") visibility program was created in 1977 to protect and enhance visibility in the 156 Federal Class I areas, which include national parks and wilderness areas as specified in the CAA. ${ }^{1}$ Visibility can be affected by emissions from specific sources that are called plume blight. Visibility also can be affected by emissions from myriad sources that create regional haze. The CAA in 1977 provides for the protection of visibility in Federal Class I areas by requiring major stationary sources that were in existence on August 7, 1977, and had been in operation for not more than fifteen years, to be subject to emission reduction requirements that are incorporated into state implementation plans (“SIPs”). ${ }^{2}$ In addition, SIPs must include measures necessary to make reasonable progress toward meeting the national visibility goals including a longterm (ten to fifteen years) strategy for making reasonable progress. ${ }^{3}$ Any SIP or SIP revision must be submitted to EPA, where it is approved or disapproved, an action that is subject to judicial review. ${ }^{4}$ If a SIP or a SIP revision is rejected, the Agency must promulgate a Federal Implementation Plan ("FIP"). ${ }^{5}$ The CAA Amendments of 1990 expanded the visibility program to address regional haze caused by interstate transport of pollutants that reduce visibility in Class I areas. ${ }^{6}$

EPA promulgated regulations in 1980 to address visibility impairment reasonably attributable to one or a small group of sources. ${ }^{7}$ Regional haze was not addressed until a regulation was promulgated on July $1,1999 .{ }^{8}$ Visibility deterioration is caused by light extinction resulting from particulates scattering and absorbing light. In addition to reducing visibility, fine particulate matter ("PM 2.5 ") may include sulfates, nitrates, organic carbon, elemental carbon, and soil dust that can create serious health effects as well as contribute to adverse environmental impacts, including acid deposition and eutrophication. ${ }^{9}$ An important cause of visibility reduction is sulfate ("SO 4 "), a secondary pollutant formed in the atmosphere from sulfur oxides that are primarily released from burning fossil fuels by power plants and other industrial facilities. ${ }^{10}$ Copper smelting is also a significant contributor. ${ }^{11}$ Sulfates contribute somewhere between " $45-90$ percent of light extinction

\footnotetext{
${ }^{1}$ See Clean Air Act $\S \S 162,169,42$ U.S.C. $\S \S 7472,7479$ (2012).

${ }^{2} I d$. $\$ 7491$.

${ }^{3} I d . \S 7491(\mathrm{~b})(2),(\mathrm{b})(2)(\mathrm{B})$.

${ }^{4}$ See, e.g., National Parks Conservation Ass'n v. EPA, 803 F.3d 151 (3d. Cir. 2015).

${ }^{5} 42$ U.S.C. $\S 7410$ (c) (2012).

${ }^{6}$ Id. $\S 7492$.

${ }^{7}$ Visibility Protection for Federal Class I Areas, 45 Fed. Reg. 80,084 (Dec. 2, 1980) (to be codified at 40

C.F.R. pt. 51).

${ }^{8}$ Regional Haze Regulations, 64 Fed. Reg. 35,714 (July 1,1999) (to be codified at 40 C.F.R. pt. 51).

${ }^{9} \mathrm{Id}$. at 35,716 .

${ }^{10}$ Approval, Disapproval, and Promulgation of Air Quality Implementation Plans, 81 Fed. Reg. 2004, 2018

(proposed Jan. 14, 2016) (to be codified at 40 C.F.R. pt. 52).

${ }^{11}$ Utah Dep't of Health, Air Pollution and Public Health in Utah 23 (2015),

http://health.utah.gov/enviroepi/healthyhomes/epht/AirPollution_PublicHealth.pdf.
} 
due to aerosols on the $20 \%$ most impaired days." 12 Ammonium sulfate is an important visibility reducing substance. ${ }^{13}$

Another important contributor to visibility impairment is organic pollutants, which are emitted from natural sources (bioemissions) as well as carbon (soot) from stationary and mobile sources. Natural organic particulates are produced as primary pollutants from wildfire smoke, plant waxes, and from conversion of the emissions of natural volatile organic compounds ("VOCs"). ${ }^{14}$ Mineral dust is produced from the action of wind on soil. ${ }^{15}$ On an annual basis the concentrations of anthropogenic particles dominate, but natural particles from wildfires and windblown dust can be important at certain times. Fine particulates are the primary anthropogenic contributor to haze, but coarse particulates from soil dust and gaseous nitrogen dioxide ("NO 2 ") are also contributors. ${ }^{16}$ The anthropogenic substances that impair visibility are primarily sulfates, organics, elemental carbon, soil dust, and nitrates created by ammonia and nitrogen oxide precursors. ${ }^{17}$

\section{§ 2. Visibility Controls on Specific Emission Sources}

The visibility program created by CAA sections 169A \& B was initially aimed at existing major sources. A major source is defined as a listed category of stationary sources with the potential to emit 250 tons or more of any pollutant. ${ }^{18}$ Major stationary sources that had not been in operation for more than fifteen years on August 7, 1977, and that emit any air pollutant that may cause or contribute to visibility impairment are required to install and operate the Best Available Retrofit Technology ("BART"). ${ }^{19}$ EPA, however, may exempt sources that have emissions with no significant impairment on visibility. ${ }^{20}$ Sources reconstructed after 1977 are exempt only if they are subject to the prevention of significant deterioration (PSD permit program. ${ }^{21}$

A haze SIP must be developed by each state with one or more BART-eligible sources and must include a determination of BART for each eligible source. ${ }^{22}$ However, a "State is not required to make a determination of BART for sulfur dioxide (" $\mathrm{SO}_{2}$ ") or for nitrogen oxides ("NO" ${ }_{x}$ ") if a BART-eligible source has the potential to emit less than 40 tons per year of such pollutant(s), or for $\mathrm{PM}_{10}$ if a BART-eligible source has the potential

\footnotetext{
${ }^{12}$ Regional Haze Regulations, 64 Fed. Reg. at 35,722.

13 Dan Binkley et al., Colo. State U. \& Nat'L Park Serv., Status of Air Quality and Related Values in Class I National Parks and Monuments of the Colorado Plateau 13 (1997). See also U.S. Envtl. Protection Agency, EPA-450/5-79-008, Protecting Visibility, An EPA Report to CONGRESS 6-18 (1979).

${ }^{14}$ Nat. Res. Council et Al., Protecting Visibility In National Parks and Wilderness Areas 50 (1993).

${ }^{15} \mathrm{Id}$.

${ }^{16} \mathrm{Id}$. at 58 .

${ }^{17} I d$. at 51,54

1842 U.S.C. $\$ 7491(\mathrm{~g})(7)$ (2012).

${ }^{19}$ Id. $\S 7491(\mathrm{~b})(2)(\mathrm{A}) ; 40$ C.F.R. $\S 51.301(2017)$.

${ }^{20} 42$ U.S.C. $\$ 7491$ (c)(1).

${ }^{21}$ Phoenix Cement Co. v. EPA, 647 F. App'x. 702, 705 (9th Cir. 2016)

2240 C.F.R. $\S 51.308(\mathrm{e})(1)(2017)$.
} 
to emit less than 15 tons per year of such pollutant." ${ }^{23}$ If the imposition of an emission standard is not feasible, a design, equipment, work practice, or other operational standard may be imposed. ${ }^{24}$

BART must be based on an analysis of the best system of continuous emission control technology available after considering five factors: "the technology available, the costs of compliance, the energy and nonair quality environmental impacts of compliance, any pollution control equipment in use at the source, the remaining useful life of the source, and the degree of improvement in visibility which may reasonably be anticipated to result from the use of such technology." 25 Fossil fuel fired electric power plants having a total generating capacity in excess of 750 megawatts are subject to a specific CAA mandate that emission limits are to be determined pursuant to guidelines promulgated by EPA's Administrator. ${ }^{26}$ These BART-eligible sources must have the appropriate emissions control technology determined by the state, which are based on Appendix Y of the BART guidelines. ${ }^{27}$ To avoid visibility-based emission requirements, the owner or operator of the plant must demonstrate to the satisfaction of the Administrator that the plant, by itself or in combination with other sources, does not have a significant impact on the visibility of a protected mandatory Class I area. ${ }^{28}$

EPA's Administrator is required to promulgate a list of mandatory Class I areas where visibility is an important value. ${ }^{29}$ EPA identified 156 of the 158 mandatory Class I areas where visibility is deemed to be important value. ${ }^{30}$ Rainbow Lake Wilderness Area in Wisconsin and Bradwell Bay Wilderness Area in Florida were not included because they had no vistas extending outside their boundaries and did not meet other criteria used to determine the importance of visual values. ${ }^{31}$

Thirty-five states and the Virgin Islands have Class I areas listed for visibility protection. ${ }^{32}$ Each state that contained, or impaired, any area with visibility values was to revise its SIP to utilize emission limits, schedules of compliance, and other measures necessary to make reasonable progress toward remedying existing or future visibility impairment. ${ }^{33}$ The states had to make reasonable progress toward preventing visibility impairment and protect any "integral vista," which is the view looking out from a listed Class I area. ${ }^{34}$ EPA promulgated Visibility Protection for Federal Class I Areas on December 2, 1980, based on CAA $§ 169$ A, which adopted a "phased approach to visibility

\footnotetext{
${ }^{23} \mathrm{Id}$ § 51.308(e)(1)(C).

${ }^{24}$ Id. $\$ 51.308(\mathrm{e})(1)(\mathrm{C})(\mathrm{iii})$.

2542 U.S.C. $\$ 7491(\mathrm{~g})(2)(2012) ; 40$ C.F.R. $\$ 51.308(\mathrm{e})(1)(\mathrm{A})(2017)$.

${ }^{26} 42$ U.S.C. $\$ 7491(\mathrm{~b})(2)(\mathrm{A})(2012)$.

2740 C.F.R. $\S 51.308(\mathrm{e}) \&$ Part 51, App. Y (2017).

2842 U.S.C. $\S 7491(c)(2)(2012) ; 40$ C.F.R. § 51.303(a)(2) (2017).

${ }^{29} 42$ U.S.C. $\$ 7491(\mathrm{a})(2)(2012)$.

${ }^{30}$ National Visibility Goal for Federal Class I Areas; Identification of Mandatory Class I Federal Areas

Where Visibility is an Important Value, 44 Fed. Reg. 69,122 (Nov. 30, 1979) (codified at 40 C.F.R. pt. 81).

${ }^{31} I d$. at 69,123 .

${ }^{32} \mathrm{Id}$.

${ }^{33} 42$ U.S.C. $\$ 7491(b)(2)$ (2012).

${ }^{34} 40$ C.F.R. $\$ 51.301$ (2017).
} 
protection." ${ }^{35}$ Phase I controlled "reasonably attributable" impairment from a single existing stationary facility or small group of existing stationary facilities, which is defined at 40 C.F.R. $\S 51.301$. EPA deferred addressing regional haze.

The first phase of the haze program applied to the years 2008-2018 and required the development of haze SIPs to reduced emissions that affect visibility. This phase focused primarily on a one-time imposition of BART requirements at eligible facilities. The second phase requires SIPs to reduce emissions during 2018-2028 by focusing on reasonable progress goals from a much larger group of sources. EPA, however, delayed the submission deadline until July $31,2021 .^{36}$

EPA's "Phase I" regulations require the thirty-five affected states and the Virgin Islands to develop haze SIPs while coordinating with the appropriate federal land manager ("FLM"). States are to identify existing sources "which may reasonably be anticipated to cause or contribute" to any impairment of visibility. ${ }^{37}$ The regulations define the term "visibility impairment" as "any humanly perceptible change in visibility (visual range, contrast, coloration) from that which would have existed under natural conditions." 38 The term "reasonably attributable" is defined as "attributable by visual observation or any other technique the State deems appropriate." 39

Once a source is identified, the affected state is to take measures to attain "reasonable progress" toward section 169A's national visibility goal. ${ }^{40}$ Measures generally include the determination of emissions limitations for that source based on the BART and the development of a long-term strategy. ${ }^{41}$ BART is required for any major stationary source constructed between 1962 and 1977 that falls within one or more of twenty-six specifically listed sources with the potential to emit 250 tons per year of any air pollutant and which "emits any air pollutant which may reasonably be anticipated to cause or contribute to any impairment of visibility" in any Class I area. ${ }^{42}$

\section{$\S 2$ (a). Reasonable Progress}

The states must impose reasonable progress controls that are based on the mandate in CAA $\S 169 \mathrm{~A}(\mathrm{~b})(2)$ to make "reasonable progress" toward meeting the visibility goal. ${ }^{43}$

\footnotetext{
${ }^{35}$ Visibility Protection for Federal Class I Areas, 45 Fed. Reg. 80,084 (Dec. 2, 1980) (codified at 40 C.F.R. pt. 51).

${ }^{36}$ Protection of Visibility: Amendments to Requirements for State Plans, 82 Fed. Reg. 3,078, 3,080 (Jan.

10, 2017) (codified at 40 C.F.R. pt. 51, 52).

${ }^{37} 40$ C.F.R. $\S 51.300(a),(b)(1)$ (2017).

${ }^{38} I d . \S 51.301$.

${ }^{39} \mathrm{Id}$.

${ }^{40} I d . \S 51.300(\mathrm{a})$.

${ }^{41}$ Id. $\S \S 51.302(\mathrm{c})(2), 51.306$

${ }^{42} I d . \$ 51.301$.

${ }^{43}$ See 42 U.S.C. § 7491(b)(2) (2012); see also Arizona ex rel. Darwin v. EPA, 852 F.3d 1148, 1153 (9th Cir. 2017).
} 
EPA has construed and expanded that mandate in its regional haze rule. ${ }^{44}$ The rule requires reductions each year that will achieve natural, pristine conditions by the year $2064 .{ }^{45}$ If a state is unable to meet the year-to-year reduction rate it must explain in its SIP why efforts to achieve the reductions are not reasonable and propose reasonable progress plans that are. ${ }^{46}$ The rule also provides guidance concerning the implementation of the reasonable progress in the development of a SIP. ${ }^{47}$ These controls apply to all pollutant-emitting stationary sources and fill a regulatory gap that would exist if the EPA were not able to regulate BART-ineligible sources threatening to deteriorate visibility. ${ }^{48}$ When a state develops its haze SIP it must determine the effect of BART, other existing control measures, and visibility control efforts under other CAA programs. If their combined effect does not project reasonable progress it must consider four factors to determine what additional measures are needed. ${ }^{49}$ These factors are: "[1] the costs of compliance, [2] the time necessary for compliance, and [3] the energy and non-air quality environmental impacts of compliance, and [4] the remaining useful life of any existing source subject to such requirements." ${ }^{50}$

In 2002, industry petitioners in American Corn Growers claimed the CAA's nondegradation requirement conflicted with section $169 \mathrm{~A}(\mathrm{~g})(1)$ 's list of factors that must be considered to determine reasonable progress. ${ }^{51}$ The court dismissed this argument, holding the states will be able to comply with the no degradation requirement while applying section $169 \mathrm{~A}(\mathrm{~g})(1)$ 's criteria. ${ }^{52}$ The Sierra Club also attacked the regulations, claiming the reasonable progress requirements were not stringent enough. ${ }^{53}$ However, the court held this challenge was not yet ripe for disposition. ${ }^{54}$ The court, in remanding the rule, indicated its belief that extending a deadline for certain areas, as EPA had done in the haze rule, was beyond the Agency's authority. ${ }^{55}$ Judge Garland wrote a separate opinion, concurring in part and dissenting in part. ${ }^{56} \mathrm{He}$ would have allowed EPA to group sources to determine appropriate BART controls based on the court's appellate review standard under Chevron, which allows considerable deference to EPA's discretion. ${ }^{57}$

In 2011, Arizona submitted a SIP revision to EPA outlining its reasonable progress goals and described the steps it intended to take to limit air pollution within its state, but

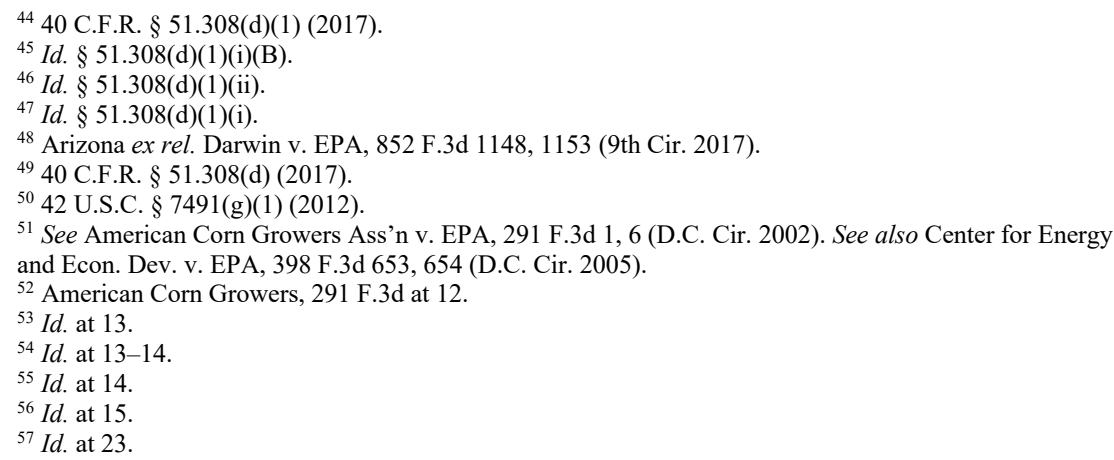


EPA deemed several portions of the SIP inadequate and issued a FIP. ${ }^{58}$ Litigation followed. In Arizona v. EPA, the Ninth Circuit reviewed the steps the EPA took in preparing the FIP and upheld its validity. ${ }^{59}$ The case's substantive issues are discussed in Section 3(a) of this Article, however, this case also interpreted reasonable progress goals ("RPG"). ${ }^{60}$ The court held that RPGs, although not mentioned in section 169A, are an outgrowth of Congress's mandate to make "reasonable progress toward meeting the national [visibility] goal." 61 EPA, therefore, requires each regulated state to establish RPGs based on how much of that state's current haze would have to be eliminated each year to achieve natural, pristine conditions by the year $2064 .{ }^{62}$ If a state is unable to meet the year-to-year reduction rateor the "glidepath," its SIP must explain why achieving the rate is not reasonable, while its proposed RPGs are reasonable. ${ }^{63}$

After a state calculates its RPGs, it must determine whether to implement reasonable progress controls to reach those RPGs after it considers existing control measures - including BART - as well as the visibility impact of controls established through other programs under the CAA. If the existing control measures do not meet RPGs, the state must consider four factors to determine whether additional measures are warranted. Should a state fail to conduct an accurate balancing, the EPA can correct the state's errors in an FIP. ${ }^{64}$ Reasonable progress controls apply to all pollutant-emitting stationary sources that impede reasonable progress. ${ }^{65}$ Thus, a source not be subject to BART might nonetheless be required to adopt additional measures because limiting its pollution would help achieve RPGs. ${ }^{66}$ Thus, reasonable progress controls fill a regulatory gap that would exist if EPA were not able to regulate BART-ineligible emission sources threatening to deteriorate visibility. ${ }^{67}$

\section{§ 2(a)(1). State of North Dakota v. EPA (Reasonable Progress Issues).}

On September 23, 2013, the Eighth Circuit decided State of North Dakota v. EPA. ${ }^{68}$ North Dakota, Great River Energy, and environmental groups challenged EPA's final rule, ${ }^{69}$ which approved in part and disapproved in part two SIPs submitted by the State to

\footnotetext{
${ }^{58}$ Promulgation of Air Quality Implementation Plans; Arizona; Regional Haze and Interstate Visibility Transport Federal Implementation Plan, 79 Fed. Reg. 52,420, 52,422 (Sept. 3, 2014) (to be codified at 40 C.F.R. pt. 52).

${ }^{59}$ Arizona ex rel. Darwin v. EPA, 852 F.3d 1148, 1151-52 (9th Cir. 2017).

${ }^{60} \mathrm{Id}$. at 1153 .

${ }^{61} I d$. (citing Clean Air Act $\S 169 A(b)(2), 42$ U.S.C. $\S 7491(b)(2)$ (2012)).

${ }^{62} \mathrm{Id}$.

${ }^{63} \mathrm{Id}$.

${ }^{64} \mathrm{Id}$.

${ }^{65} \mathrm{Id}$.

${ }^{66} \mathrm{Id}$

${ }^{67} \mathrm{Id}$.

${ }^{68}$ North Dakota v. EPA, 730 F.3d 750 (8th Cir. 2013).

${ }^{69}$ Approval and Promulgation of Implementation Plans; North Dakota; Regional Haze State Implementation Plan; Federal Implementation Plan for Interstate Transport of Pollution Affecting Visibility and Regional Haze, 77 Fed. Reg. 20,894 (Apr. 6, 2012) (codified at 40 C.F.R. pt. 52).
} 
address haze issues. ${ }^{70}$ EPA also promulgated a FIP to address issues that it had disapproved. The court granted in part and denied in part the State's and Great River Energy's petitions for review, and it denied the environmental groups' petition for review. ${ }^{71}$

Under the regional haze regulations, a state must establish a visibility goal and must determine the rate of progress necessary to achieve natural visibility conditions in the mandatory Class I Federal areas by the year 2064 through a uniform rate of improvement in visibility based on emission reduction measures needed for reasonable progress over the period covered by the implementation plan. ${ }^{72}$ Visibility is measured in "deciviews," which is an atmospheric haze index applicable to pristine to very impaired conditions. ${ }^{73}$."A one deciview change is a small but noticeable change in haziness under most circumstances when viewing scenes in mandatory Class I Federal areas."74

The State of North Dakota challenged both EPA's disapproval of its reasonable progress determination for Antelope Valley Station's Units 1 and 2 and its promulgation of a FIP. The State concluded that the rate of progress necessary for the SIP to attain natural conditions by 2064 was not reasonable. This allowed the State to implement a slower rate of progress, but it also obligated the State to demonstrate that its reasonable progress goals were reasonable based on an evaluation using the four statutory factors. ${ }^{75}$ The State determined that additional pollution control technologies for Antelope Valley Station Units 1 and 2 were unnecessary to achieve reasonable progress after it examined the four statutory factors. ${ }^{76}$

North Dakota used its own cumulative source visibility model, which employs the current degraded background visibility conditions as its baseline, which led to the conclusion that the maximum combined improvement for the average of the $20 \%$ worst days was 0.11 deciviews at the Lostwood Wilderness Area and 0.03 deciviews at Theodore Roosevelt National Park. ${ }^{77}$ The State then evaluated the cost effectiveness of additional controls at Antelope Valley using the dollar-per-deciview of improvement metric, "which resulted in a finding that the cost effectiveness of additional controls would be 618 million dollars-per-deciview of improvement at the Lostwood Wilderness Area and 2.3 billion dollars-per-deciview of improvement at Theodore Roosevelt National Park." ${ }^{78}$ This was considered excessive by the State, which determined that requiring additional controls at the Antelope Valley Station was not reasonable. ${ }^{79}$

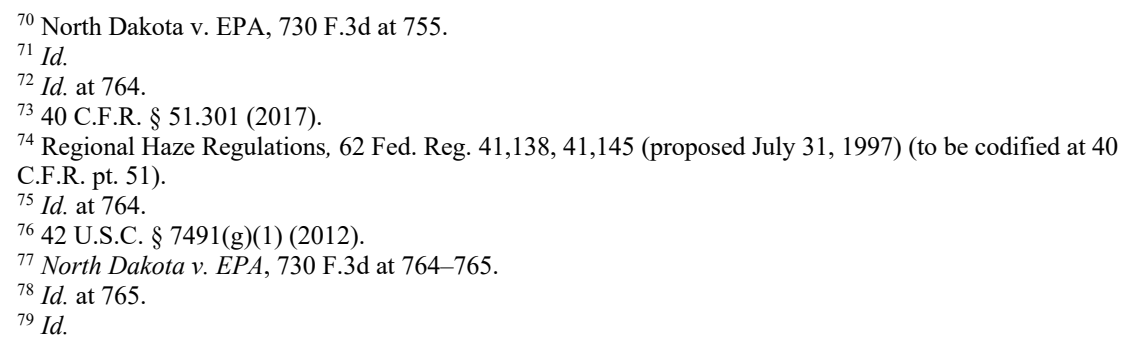


EPA considered the State's decision not to install additional controls as unreasonable because it meant the State could not meet the uniform rate of progress to restore natural visibility in Class I Federal areas by 2064. EPA objected to the State's incremental visibility improvement analysis and the State's cost effectiveness analysis because they were based on the State's cumulative source visibility modeling, which EPA found understated the visibility improvement that would be realized. EPA did not object to the State considering visibility improvement as an additional factor in a reasonable progress analysis, but argued it was not appropriate to assume the degraded background conditions used by the State. Using degraded rather than natural background in the modeling produces estimates that underestimate the benefits of potential control options and over estimates the cost per deciview of improvement. ${ }^{80}$

EPA proposed to promulgate a FIP requiring separated overfire air plus low $\mathrm{NO}_{\mathrm{x}}$ burners ("SOFA + LNB") with an emission limit of $0.17 \mathrm{lbs} / \mathrm{MMBtu}$ on a thirty-day rolling average, which would represent reasonable progress for Units 1 and 2. EPA estimated this technology would cost approximately $\$ 586$ and $\$ 661$ per-ton-of- $\mathrm{NO}_{\mathrm{x}}$ removed at Units 1 and 2 respectively and would remove approximately 3,500 tons of $\mathrm{NO}_{\mathrm{x}}$ per unit per year. The State argued that because this was a reasonable progress determination it was not obligated to use the single source visibility model required under the BART guidelines, but it could utilize its own visibility model. ${ }^{81} \mathrm{EPA}$, however, concluded that the cumulative source visibility model employing the current degraded conditions as its baseline was not consistent with the CAA. ${ }^{82}$

The court deferred to EPA because the matter involved technical matters within its area of expertise. ${ }^{83}$ The State's determination that no additional $\mathrm{NO}_{\mathrm{x}}$ controls were necessary for Antelope Valley Station Units 1 and 2 was based primarily on the use of its cumulative source visibility modeling. The court held that the State was free to use its own visibility model, but it was not free to do so in a manner that was inconsistent with the CAA ${ }^{84}$ Because EPA demonstrated that the visibility model used by the State would maintain current degraded conditions, the court concluded that EPA properly disapproved the State's reasonable progress determination. Moreover, because the State's objection to the FIP was predicated on its claim that EPA improperly rejected the State's reasonable progress determination, the FIP-based claim was also rejected. ${ }^{85}$

EPA's approval of the $0.50 \mathrm{lbs} / \mathrm{MMBtu}$ emission limit as reasonable progress for the Coyote Power Plant was challenged by environmental groups. ${ }^{86}$ North Dakota had evaluated several pollution control technologies, including advanced separated overfire air ("ASOFA"), which could reduce $\mathrm{NO}_{x}$ emissions by $40 \%$ at a cost of $\$ 246$ per ton. However, the State decided that an ASOFA analysis based on the cost per-deciview of

\footnotetext{
${ }^{80} \mathrm{Id}$.

${ }^{81} \mathrm{Id}$.

${ }^{82} I d$. at 766 .

${ }^{83} \mathrm{Id}$.

${ }^{84} \mathrm{Id}$.

${ }^{85} \mathrm{Id}$.

${ }^{86} \mathrm{Id}$. at 767.
} 
improvement would be more useful. This cost ranged from $\$ 618$ million per-deciview of improvement at two of the Class I areas to $\$ 2.3$ billion per-deciview of improvement at other Class I areas. Therefore, the State decided that additional $\mathrm{NO}_{\mathrm{x}}$ controls were not reasonably necessary at the Coyote facility. ${ }^{87}$ The State negotiated an agreement with the Coyote plant that made the facility subject to an $\mathrm{NO}_{\mathrm{x}}$ emission limit of $0.50 \mathrm{lb} / \mathrm{MMBtu}$ on a thirty-day rolling average, which represents an approximate $32 \%$ decrease in emissions from the station's 2000-2004 baseline.

This emissions limit would be satisfied through the installation of additional pollution controls, assumed to be SOFA, that would remove approximately 4,213 tons of $\mathrm{NO}_{\mathrm{x}}$ "[T] $[\mathrm{Tis}$ agreement was made enforceable through a permit for construction at the Coyote Station and was submitted with the State's SIP." 88 EPA concluded that the State's proposed $0.50 \mathrm{lbs} / \mathrm{MMBtu}$ emission limit was not unreasonable, even though the State had disqualified ASOFA as economically infeasible because the CAA requires only that a state establish reasonable progress, not the most reasonable progress. ${ }^{89}$ The court then decided that EPA's conclusion that ASOFA installation would represent reasonable progress and its ultimate determination that the $0.50 \mathrm{lbs} / \mathrm{MMBtu}$ emission limit contained in the SIP also represented reasonable progress was not arbitrary, capricious, or an abuse of the Agency's discretion. ${ }^{90}$ Subsequently, the environmental groups' petition for review of this issue was denied. ${ }^{91}$

\section{§ 2(a)(2). State of Texas v. EPA}

On July 15, 2016, the Fifth Circuit decided State of Texas v. EPA. ${ }^{92}$ The State of Texas and numerous energy companies, power plants, steel mills, consumer organizations, state regulators, and a labor union in Texas challenged EPA's disapproval of Oklahoma's and Texas's plans for controlling regional haze in two national parks and a wildlife refuge and EPA's issuance of a FIP. ${ }^{93}$ Petitioners moved for stay, and EPA moved to dismiss or transfer the petition. The court granted a stay in an opinion that focuses on the Regional Haze Rule's requirement for demonstrating reasonable progress. ${ }^{94}$ Then the four factors, previously discussed, are considered. ${ }^{95}$ Once a state has adopted a reasonable progress goal, the measures adopted to meet the goal are enforceable. ${ }^{96}$

This case concerned visibility at the 801,000 acre Wichita Mountains Wildlife Refuge in southwestern Oklahoma and the Guadalupe Mountains National Park in west Texas. ${ }^{97}$ In 2016, nearly seven years after Texas submitted its implementation plan and

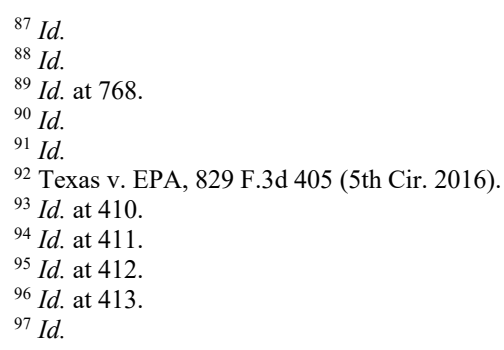


nearly six years after Oklahoma submitted its implementation plan, EPA partially approved and partially disapproved the Texas and Oklahoma plans, and it promulgated a FIP for portions of the state plans. ${ }^{98}$ The FIP imposed reasonable progress goals for the wildlife refuges and national parks in Texas and Oklahoma but only required emission controls in Texas. No Oklahoma emission sources were affected. ${ }^{99}$

Texas concluded that using a linear rate was unreasonable and set alternative reasonable progress goals. Texas determined that actual visibility conditions in the covered areas were already better than the reasonable progress goals it set for 2018. Consequently, any additional retrofit technologies would impose more costs than benefits. ${ }^{100}$ EPA approved Texas's measurements of current visibility conditions in Big Bend, the Guadalupe Mountains, and the Wichita Mountains, which showed that visibility at all three wildernesses was better than the reasonable progress goals. ${ }^{101}$

EPA agreed that the linear rate was unreasonable, but it disapproved Texas's alternative reasonable progress goals on the grounds that Texas's analysis "was not appropriately refined, targeted, or focused on those sources having the most significant and potentially cost-effective visibility benefits." EPA also disagreed over the amount of naturally occurring dust in the protected regions. EPA further disapproved Texas's longterm strategy because the State did not conduct source-specific analysis. ${ }^{102}$

EPA also disapproved Oklahoma's plan because of the effects of Texas emissions on the Wichita Mountains Wildlife Refuge in Oklahoma, which EPA based on its conclusion that Texas had not conducted a source-specific analysis and imposed restrictions on specific sources in Texas. ${ }^{103}$ EPA then imposed a FIP after analyzing emissions and imposed controls on fifteen electrical generating units with the greatest impact on the protected areas. The FIP required scrubber upgrades or scrubber retrofits for these sources without consideration of other controls at other sources. ${ }^{104}$ The Petitioners argued that EPA was targeting coal-fired power plants, and the proposed changes would cost $\$ 2$ billion, rendering them uneconomical and forcing the plants to close. Petitioners also argued that Texas could face power shortages and grid failures because the FIP did not include an exemption for grid reliability. ${ }^{105}$ EPA then moved to dismiss or transfer this petition for review arguing that jurisdiction lies only in the D.C. Circuit. ${ }^{106}$ However, the court concluded that venue was proper in the Fifth Circuit. ${ }^{107}$

\footnotetext{
${ }^{98}$ Id. at 414 (citing Approval and Promulgation of Implementation Plans; Texas and Oklahoma; Regional Haze State Implementation Plans; Interstate Visibility Transport State Implementation Plan to Address Pollution Affecting Visibility and Regional Haze; Federal Implementation Plan for Regional Haze, 81 Fed. Reg. 296 (Jan. 5, 2016) (codified at 40 C.F.R. 52)).

${ }_{99} I d$.

${ }^{100} I d$. at 415 .

${ }^{101} I d$.

${ }^{102} I d$.

${ }^{103} I d$.

${ }^{104} I d$. at 416 .

${ }^{105} \mathrm{Id}$.

${ }^{106} \mathrm{Id}$. at 417 .

${ }^{107} I d$. at 418 .
} 
The Regional Haze Rule grants states considerable flexibility to estimate the degree of visibility impairment existing under natural conditions for the most impaired days and least impaired days. ${ }^{108}$ Nevertheless, EPA disapproved Texas's estimates because the State assumed that natural factors such as dust storms and wildfires contributed $100 \%$ of coarse mass and soil to the air on the $20 \%$ of days with the most visibility impairment and substituted its own estimate using an $80 \%$ contribution from natural factors. ${ }^{109}$ Both EPA and Texas agreed that the regulatory changes necessary to achieve natural visibility by 2064 were unreasonable. The State, therefore, proposed an alternative set of reasonable progress goals that considered emissions from a broad range of sources in Texas. ${ }^{110}$ However, EPA determined that approach was unreasonable and substituted its own sourcespecific analysis. The outcome was that EPA's reasonable progress targets were less than $1 \%$ lower than the Texas goals that EPA found inadequate, although current visibility conditions were exceeding formerly established reasonable progress goals. ${ }^{111}$ EPA's reasonable progress goals would have required costly changes including installation of sulfur dioxide scrubbers at seven electrical generating units and upgrades of existing scrubbers at seven other electrical generating units. ${ }^{112}$ Additionally, EPA's requirement that Texas conduct a source-specific analysis was not supported by the CAA or the Regional Haze Rule. ${ }^{113}$

By statute, EPA must defer to Texas's goals so long as the Texas goals comply with the Act. ${ }^{114}$ The court stated that Petitioners were likely to succeed in showing that EPA improperly failed to defer to Texas's application of the statutory factors and EPA improperly required a source-specific analysis that is not required by the CAA or the Regional Haze Rule. ${ }^{115}$ Neither the CAA nor the Regional Haze Rule require upwind states to provide downwind states with source-specific emission control analysis. Because EPA has never disapproved consultation between states, the court indicated that the Petitioners had a strong likelihood of showing that EPA's disapproval of the consultation between Oklahoma and Texas was arbitrary and capricious. ${ }^{116}$

A haze implementation plan covers a ten-year period, and before the plan ends the state must submit a comprehensive revision to cover the next ten-year period. ${ }^{117}$ The first comprehensive revision is due July 31, 2018. ${ }^{118}$ Each SIP must achieve reasonable progress during the time covered by the plan. Therefore, the emissions controls included in a state implementation plan, must be those designed to achieve the reasonable progress goal for the period covered by the plan. ${ }^{119}$ The FIP in Texas $v$. EPA required reasonable progress

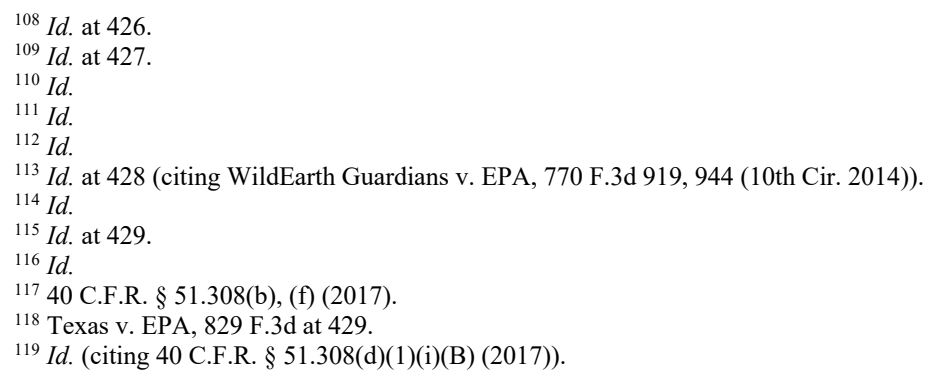


goals to be achieved by installing scrubbers in 2019 and 2021, but the plans in controversy only cover the years up to 2018. The court indicated that it did not believe EPA's interpretation was reasonable because when it promulgated the Regional Haze Rule, it limited its authority to ten years. ${ }^{120}$ EPA subsequently proposed amendments to the Regional Haze Rule to remove the language "for the period covered by the implementation plan" from the requirements for reasonable progress. ${ }^{121}$

EPA is required to consider the energy impacts of compliance with the emission controls in a SIP or FIP. ${ }^{122}$ The court opined that Petitioners had a strong likelihood of success on this issue because the FIP made several of the affected electrical generating units uneconomical and further did not detail why the mandated emissions controls would not endanger reliability or cause the closure of up to 8,400 MW of generating capacity. Moreover, the deference owed to an agency's conclusions is substantially diminished when the subject matter lies beyond the agency's expertise, and EPA has no expertise concerning grid reliability. Therefore, EPA must support its arguments more thoroughly than when dealing with issues in which it has expertise. ${ }^{123}$ "EPA's truncated discussion of grid reliability indicates that the agency may not have fulfilled its statutory obligation to consider the energy impacts of the FIP." 124 The court concluded by issuing a stay of EPA's rule in its entirety, including the emissions control requirements, pending the outcome of this petition for review. ${ }^{125}$

After the Fifth Circuit's decision, the deadline for EPA to impose a FIP or approve a Texas haze SIP was extended several times by mutual consent. However, on August 31, 2017, the U.S. District Court for the District of Columbia refused to extend the September 9, 2017 deadline. ${ }^{126}$ This gave EPA little time to complete a haze rule. ${ }^{127}$ On September 3, 2017, however, EPA's Administrator, Scott Pruitt, signed a regulation that now allows eight coal-fired power plants in Texas to use an emissions trading program to meet haze reduction requirements rather than requiring pollution controls to reduce $\mathrm{SO}_{2}$ emissions This was expected to save one of the electric power companies, Luminant, \$3 billion, ${ }^{128}$ which is praised by the management of the Texas power plants. ${ }^{129}$ After EPA promulgated the emissions trading plan as a final rule on September 30, 2017, Luminant announced

\footnotetext{
${ }^{120}$ Texas v. EPA, 829 F.3d at 429-430.

${ }^{121} \mathrm{Id}$. at 430

12242 U.S.C. $\$ 7491(\mathrm{~g})(1)(2012)$.

123 Texas v. EPA, 829 F.3d at 432

${ }^{124} \mathrm{Id}$. at 433.

${ }^{125} \mathrm{Id}$. at 434 .

${ }^{126}$ Nat'l. Parks Conservation Ass'n. v. EPA, No. 1:11-cv-01548 (ABJ) (D.D.C. Aug. 31, 2017). See Federal District Court Rejects EPA Bid for Texas Haze Plan Deadline Extension, 28 Clean Air Rep. (Inside EPA) No. 18 (Sept. 7, 2017).

${ }^{127}$ Tiffany Stecker, Court Denies Extension of National Parks Air Pollution Deadline, 48 Env't Rep. (BNA) 1429 (Sept. 1, 2017).

${ }^{128}$ Nushin Huq, EPA Opts for Pollution Trading Over Emission Control in Texas, BLOOMBERG ENVIRONMENT \& ENERGY REP. (Oct. 3, 2017), https://news.bloombergenvironment.com/environment-andenergy/epa-opts-for-pollution-trading-over-emissions-controls-in-texas. .

${ }^{129}$ Nushin Huq, Texas Power Plants Praise Once-Loathed Pollution Trading Plan, BLoOMBERG ENVIRONMENT \& ENERGY REP. (Nov. 7, 2017), https://bnanews.bna.com/environment-and-energy/texaspower-plants-praise-once-loathed-pollution-trading-plan/.
} 
plans to retire its Monticello plant in January 2018 because operating the plant is no longer an economically viable option. ${ }^{130}$ In the first quarter of 2017 , nearly $32 \%$ of Texas's electricity was wind generated, which is displacing coal-fired generation. ${ }^{131}$

\section{$\S 2$ (b). Interstate Transport of Pollutants}

On March 10, 2005, EPA issued the Clean Air Interstate Rule ("CAIR”), which required emission reductions of $\mathrm{SO}_{2}$ and $\mathrm{NO}_{\mathrm{x}}$ from electric generating units ("EGUs") in twenty-eight eastern states and the District of Columbia. ${ }^{132}$ For sources subject to CAIR, the emissions control required by CAIR could be substituted for BART controls because EPA concluded CAIR controls were "better than BART." 133 The CAIR rule allows emissions trading while the Haze Rule imposes source specific emission standards including BART. The permissibility of a state's decision to follow CAIR rather than imposing BART is an issue frequently litigated. The Haze Rule provides that a state choosing to meet the emissions reduction requirements of CAIR by participating in an EPA-administered trading program for $\mathrm{SO}_{2}$ and $\mathrm{NO}_{\mathrm{x}}$ need not require BART-eligible EGUs to install, operate, and maintain BART. ${ }^{134}$

On September 6, 2005, the Center for Energy and Economic Development ("CEED") filed suit against EPA in the D.C. Circuit claiming the BART requirements were not stringent enough and because the rule excludes utilities in the Eastern half of the nation that are subject to the CAIR rule. CEED represented a major coal transporter (CSX Corp.) and Peabody Energy, the world's largest coal company. The Utility Air Regulatory Group ("UARG") also challenged the rule because it regulates utilities that do not have haze impacts. The cases were consolidated as $U A R G v . E P A .{ }^{135}$ On October 13, 2006, EPA made changes to 40 C.F.R. Part 51 as a response to some of the issues raised by UARG. ${ }^{136} \mathrm{On}$ December 12, 2006 the D.C. Circuit decided UARG v. EPA.

The $U A R G$ case involved challenges by both industry and environmental petitioners concerning the need to comply with the BART requirement under the Haze Rule. Industry said the requirements were too onerous; environmentalist claimed they were too weak. However, the D.C. Circuit rejected the petitions and affirmed the Haze Rule. ${ }^{137}$ The case also involved the CAIR provisions that impose specified emissions reduction

\footnotetext{
${ }^{130}$ Nushin Huq, Luminant Coal Plant to Close Despite EPA Easing Haze Rule, Bloomberg ENVIRONMENT \& ENERGY REP. (Oct. 9, 2017), https://bnanews.bna.com/environment-and-energy/luminantcoal-plant-to-close-despite-epa-easing-haze-rule. 
requirements on each affected state, and enables states to meet the requirements by means of cap-and-trade programs. ${ }^{138}$ But, the CAIR-for-BART comparison was to be evaluated under the standards imposed to protect visibility enumerated in 40 C.F.R. $\S 51.308(\mathrm{e})$.

EPA demonstrated that CAIR would achieve greater overall emission reductions than BART, and would result in a greater aggregate visibility improvement than BART averaged over all Class I areas without reducing visibility at any individual area. ${ }^{139}$ However, the "determination that CAIR makes greater reasonable progress than BART for EGUs" did not mean that CAIR satisfied all reasonable progress requirements imposed by the Haze Rule. ${ }^{140}$ Despite the rule changes reflecting CAIR, states must establish reasonable progress goals that provide for an improvement in visibility for the most impaired days and ensure there is no degradation in visibility for the least impaired days. ${ }^{141}$ The court rejected the claim that the CAA requires that any BART Alternative improve visibility at least as much as BART at every Class I area and in all categories of days. ${ }^{142}$

The D. C. Circuit upheld the Haze Rule stating that "nothing in $\S 169$ A(b)'s 'reasonable progress' language requires at least as much improvement at each and every individual area as BART itself would achieve...." 143 The regulation at 40 C.F.R. $\S$ 51.308(d)(1), in the court's view, is a reasonable interpretation of the reasonable progress requirement. Although the court upheld the rule, the complexity and vagueness of the rule made it difficult for states to meet the December 17, 2007 deadline for submitting SIP revisions. The control of visibility impacts was also affected by the $\mathrm{PM}_{2.5}$ national ambient air quality standard ("NAAQS") promulgated on July 18, 1997. ${ }^{144}$

CAIR was replaced with the Cross-State Air Pollution Rule ("CSAPR") on August 8, 2011. ${ }^{145}$ The D.C. Circuit vacated CSAPR in 2012, in EME Homer City Generation, L.P. v. EPA, ${ }^{146}$ but the U.S. Supreme Court reversed and remanded the case in $2014 .{ }^{147}$ The case returned to the D.C. Circuit and on July 28, 2015, the petitions for review were granted in part and denied in part. ${ }^{148}$ The court invalidated EPA's $2014 \mathrm{SO}_{2}$ emissions budgets for Texas, Alabama, Georgia, and South Carolina. It also invalidated EPA's 2014 ozone season $\mathrm{NO}_{\mathrm{x}}$ emissions budgets for the 1997 eight-hour ozone NAAQS for upwind States (including Texas) that required each of those states to reduce emissions. It held

\footnotetext{
${ }^{138}$ Id. at 1337 (citing Regional Haze Regulations and Guidelines for Best Available Retrofit Technology (BART) Determinations, 70 Fed. Reg. 39,104, 39,106, 39,138 (July 6, 2005) (codified at 40 C.F.R. pt. 51)).

${ }^{139}$ Id.

${ }_{140} \mathrm{Id}$.

${ }^{141} I d$. (citing 40 C.F.R. $\S 51.308(\mathrm{~d})(1)(2017)$ ).

${ }^{142}$ Id. at 1338 .

${ }^{143} I d$.

${ }^{144}$ National Ambient Air Quality Standards for Particulate Matter, 62 Fed. Reg. 38,652, 38,711 (July 18, 1997) (codified at 40 C.F.R. pt. 50).

${ }^{145}$ Cross-State Air Pollution Rule, 76 Fed. Reg. 48,208 (Aug. 8, 2011) (to be codified at 40 C.F.R. pt. 51, $52,72,78,97)$ [hereinafter CSAPR].

${ }^{146}$ EME Homer City Generation, L.P. v. EPA, 696 F.3d 7, 12 (D.C. Cir. 2012).

${ }^{147}$ EPA v. EME Homer City Generation, L.P., 134 S. Ct. 1584, 1593 (2014).

${ }^{148}$ EME Homer City Generation, L.P. v. EPA, 795 F.3d 118, 124 (D.C. Cir. 2015).
} 
uniform cost thresholds were not required, and EPA had the authority to promulgate a Transport FIP. The court rejected all the challenges to the Transport Rule. ${ }^{149}$

On March 14, 2016, the Eighth Circuit in National Parks Conservation Assn. v. McCarthy, upheld EPA's approval of Minnesota's regional haze SIP that used an alternative emissions trading program under the Transport Rule in place of BART for five EGUs. ${ }^{150}$ The conservation organizations challenged EPA's approval of the Minnesota Plan, claiming the Transport Rule allowances in the Plan are not "better than BART." A state subject to the Transport Rule is not required to impose BART, ${ }^{151}$ and it may exercise its discretion to not require BART. EPA decided that Minnesota properly exercised its discretion in using the Transport Rule to regulate the five EGUs because it would provide for greater reasonable progress toward improving visibility than source-specific BART controls for EGUs. ${ }^{152}$

The Forest Service was concerned that using CSAPR would likely mean that the air pollution control equipment proposed for Minnesota power plants under BART would not be installed. The Forest Service argued it is clear that the source-specific BART limits provide the greatest visibility improvement. ${ }^{153}$ However, the court found that EPA's explanation that the Transport Rule is better than source-specific BART was rational. EPA's model projected slightly better emissions reductions from the use of the Transport Rule and, compared to BART, an overall improvement in visibility in the Minnesota Class I areas. Compared to BART, the Transport Rule would achieve a greater visibility improvement for the $20 \%$ worst-visibility days and equivalent improvement for the $20 \%$ best-visibility days in the affected Class I areas. ${ }^{154}$ Conservation organizations disagreed with EPA's numbers, but EPA rejected their position based on its own analysis in the Transport Rule. ${ }^{155}$

The court held that EPA acted within its sphere of expertise, and it had a rational basis to conclude that the Transport Rule is better than BART. ${ }^{156}$ It also held that the Transport Rule "seeks to achieve greater, overall reasonable progress towards improving visibility than source-specific BART." The D.C. Circuit has rejected the claim "that the Clean Air Act requires EPA to ensure that any BART-alternative improves visibility at least as much as BART at every Class I area and in all categories of days." 157 Here, EPA determined the Transport Rule would achieve greater overall reasonable progress than source-specific BART. In this case, the court's arbitrary and capricious standard of review did not ask who is right; it asked whether the EPA followed a defensible process in assessing who is right. ${ }^{158}$ "EPA did not rely on factors that Congress did not intend it to

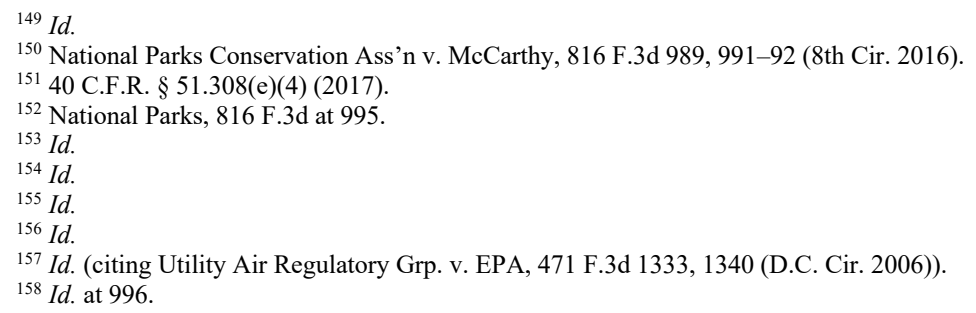


consider, did not entirely fail to consider an important aspect of the problem, and did not offer an explanation that runs counter to the evidence before the agency." "159 Therefore, EPA's approval of the use of the Transport Rule was not arbitrary, capricious, an abuse of discretion, or otherwise not in accordance with law. ${ }^{160}$ This case is also discussed at infra $\S 3(b)(2)$.

The issue of whether and how interstate controls can be used to satisfy visibility requirements remains unsettled. Industry wants emissions trading to qualify as a substitute for source specific BART requirements; environmental groups argue that trading cannot be used to replace BART analysis and controls. ${ }^{161}$ Environmental groups often oppose using emissions trading because sources can buy credits to comply rather than actually reducing emissions. SIPs that allow trading as a substitute for BART continue to be litigated with no clear rules concerning when a SIP or FIP is too weak or too stringent.

On October 26, 2016, EPA promulgated an update to CSAPR to address the 2008 change in the ozone NAAQS. ${ }^{162}$ It imposes requirements to reduce $\mathrm{NO}_{\mathrm{x}}$ emissions from 886 electric power plants in twenty-two eastern states. ${ }^{163}$ On November 10, 2016, EPA proposed to withdraw the FIP provisions requiring Texas EGUs to participate in CSAPR trading programs. ${ }^{164}$ The visibility issues in 2017 continue to be litigated in the D.C. Circuit in Utility Air Regulatory Group (UARG) v. EPA with EPA supporting the use of CSAPR as a BART Alternative. ${ }^{165}$ Industry continued to oppose CSAPR, while states in the Northeast oppose industry's efforts to update the rule. ${ }^{166}$ On May 19, 2017, EPA proposed to largely approve Louisiana's participation in CSAPR as the equivalent of BART for meeting the state's $\mathrm{NO}_{\mathrm{x}}$ control requirements, ${ }^{167}$ but subject to its final approval of a November 10, 2016 proposed rule that CSAPR is better than BART. ${ }^{168}$ On September 21, 2017, EPA announced revisions to the methodologies for projecting interstate air pollution

\footnotetext{
${ }^{159} \mathrm{Id}$.

${ }^{160}$ National Parks, 816 F.3d at 996.

${ }^{161}$ Stuart Parker, States, Utilities Defend Use of Air Trading to Satisfy Regional Haze Rule, INSIDE EPA: DAILY NEWs (Feb. 28, 2017), https://insideepa.com/daily-news/states-utilities-defend-use-air-tradingsatisfy-regional-haze-rule.

${ }^{162}$ Cross-State Air Pollution Rule Update for the 2008 Ozone NAAQS, 81 Fed. Reg. 74,504 (Oct. 26, 2016) (codified at 40 C.F.R. pts. 52, 78, 97).

${ }^{163}$ Id. at 74,504; see also Patrick Ambrosio, More Power Sector Emissions Cuts Required Under CrossState Update Rule, 47 ENV’T REP. (Sept. 9, 2016), www.bloomberglaw.com.

${ }^{164}$ Interstate Transport of Fine Particulate Matter: Revision of Federal Implementation Plan Requirements for Texas, 81 Fed. Reg. 78,954 (Nov. 10, 2016) (codified at 40 C.F.R. pt. 52).

${ }^{165}$ Stuart Parker, EPA Hears Competing Arguments Over Revisions To Texas Haze Air Plans, Inside EPA DAILY NEWS (May 11, 2017), https://insideepa.com/daily-news/epa-hears-competing-arguments-overrevisions-texas-haze-air-plan.

${ }^{166}$ East Coast States Oppose EPA's Proposal for Delay in CSAPR Litigation, INSIDE EPA: CLEAN AIR REP. (Aug. 24, 2017), https://insideepa.com/clean-air-report/east-coast-states-oppose-epas-proposal-delay-csaprlitigation.

${ }^{167}$ Approval and Promulgation of Implementation Plans; Louisiana; Regional Haze State Implementation Plan, 82 Fed. Reg. 22,936 (May 19, 2017) (codified at 40 C.F.R. pt. 52).

${ }^{168}$ Interstate Transport of Fine Particulate Matter: Revision of Federal Implementation Plan Requirements for Texas, 81 Fed. Reg. 78,954 (Nov. 10, 2016) (codified at 40 C.F.R. pt. 52).
} 
from power plants and the oil and gas sector under CSAPR. ${ }^{169}$

On March 20, 2018, the D.C. Circuit decided Utility Air Regulatory Group v. $E P A .{ }^{170}$ Conservation groups, power companies, industry group, and states had filed petitions for review of EPA's final rule amending its regional haze rule, disapproving portions of certain SIPs designed to achieve reasonable progress under regional haze rule, and promulgating federal implementation plans to address haze levels in disapproved states. In 2012, EPA “amended the Regional Haze Rule to specify that CSAPR's requirements were stringent and effective enough for it to serve as a better-than-BART alternative for states participating in CSAPR, thus excusing states from compliance with BART." $" 171$ EPA also disapproved portions of certain SIPs designed to achieve reasonable progress under the Regional Haze Rule because those plans relied on the soon-to-bedefunct CAIR Rule. EPA promulgated FIPs to address haze levels in the disapproved states until those states could submit approvable SIPs that relied on CSAPR or otherwise demonstrated a local alternative better than BART. ${ }^{172}$ The National Parks Conservation Association and the Sierra Club challenged the Final Rule allowing states to treat CSAPR compliance as a better-than-BART alternative." Multiple power companies and the Utility Air Regulatory Group, as well as the State of Texas and the Louisiana Department of Environmental Quality challenged the disapproval of SIPs that relied on CAIR as a betterthan-BART alternative." ${ }^{173}$ However, the court affirmed EPA's actions and denied the petitions. ${ }^{174}$ CAIR is dead and cannot be used to meet haze requirements. In states subject to CSAPR, it may be used as a BART alternative if the regulatory requirements are met. ${ }^{175}$

\section{§ 3 EPA's Regional Haze Program}

As previously discussed, Congress intended to have visibility problems that are created by a single or a small group of sources to be subject to controls based on CAA $\S$ 169A. ${ }^{176}$ The 1990 amendments to the CAA expanded the CAA's focus to include a regional haze program to address "visibility impairment that is caused by the emission of air pollutants from numerous anthropologic sources located over a wide geographic area." 177 Emissions of fine particles and their precursors were to be reduced in order to make reasonable progress and to achieve natural visibility by $2064 .{ }^{178}$ Regional haze SIPs

\footnotetext{
${ }^{169}$ Stuart Parker, EPA Plans 'Key Revisions' to CSAPR Methods as States Criticize Program, Inside EPA: DAILY News (Sept. 21, 2017), https://insideepa.com/daily-news/epa-plans-key-revisions-csapr-methodsstates-criticize-program.

${ }^{170}$ Utility Air Regulatory Grp. v. EPA, 885 F.3d 714 (D.C. Cir. 2018).

${ }^{171} I d$. at 717.

${ }^{172} \mathrm{Id}$.

${ }^{173} \mathrm{Id}$.

${ }^{174} I d$. at 718,724 .

${ }^{175}$ Id. at $721,723$.

17642 U.S.C. \& 7491 (2012).

17740 C.F.R. $\$ 51.301$ (2017).

${ }^{178}$ Id. § 51.308(d).
} 
must also identify the BART to reduce emissions from certain major emission sources. ${ }^{179}$ A source subject to BART must install and operate the appropriate technology "as expeditiously as practicable but in no event later than five years" after approval of a SIP or issuance of a FIP. ${ }^{180}$ This BART requirement can be avoided if a state adopts a "better than BART" alternative. ${ }^{181}$ The CAA's five-year deadline for installing BART does not apply to a "better than BART" Alternative. ${ }^{182}$

For a state to adopt a BART Alternative, its SIP must require all necessary emission reductions to take place during the period of the first long-term strategy for regional haze (2008-2018). ${ }^{183}$ A state can demonstrate "better-than-BART" through "greater reasonable progress: (1) "[i]f the distribution of emissions is not substantially different than under BART, and the alternative measure results in greater emission reductions"; (2) "[i]f the distribution of emissions is significantly different," a state must conduct "dispersion modeling," which focuses on visibility rather than emissions; or (3) the catch-all "otherwise based on the clear weight of the evidence." 184

The problem of regional haze was addressed on June 10, 1996, by the Grand Canyon Visibility Transport Commission ("GCVTC") ${ }^{185}$ in a report to EPA that included nine general recommendations to reduce air pollution in the region. ${ }^{186}$ For stationary sources, sulfur levels were to be reduced and a reduction in the range of $20-30 \%$ needed to be achieved by the year 2000. ${ }^{187}$ Automobile emissions were to be reduced and heavy-duty vehicle pollution was to be reduced by $50 \% .{ }^{188}$ Low emission vehicle standards were to be adopted. ${ }^{189}$ Other recommendations for air pollution prevention included road dust control, control of emissions from Mexico, and the use of prescribed fire. ${ }^{190}$ It also favored the use of emissions trading to reduce emissions. ${ }^{191}$ The GCVTC report triggered CAA $\S 169 \mathrm{~B}(\mathrm{e})$ that requires the Administrator, within eighteen months of the receipt of the report, to carry out the responsibility imposed by CAA $\S 169 \mathrm{~B}(\mathrm{e})$, including the need for "criteria for measuring 'reasonable progress' toward the national goal."192

\footnotetext{
17942 U.S.C. § 7491(b)(2) (2012). BART is "an emission limitation based on the degree of reduction achievable through the application of the best system of continuous emission reduction for each pollutant which is emitted by an existing stationary facility.” 40 C.F.R. $\$ 51.301$ (2017).

18042 U.S.C. $\S \S 7491(\mathrm{~b})(2)(\mathrm{A}),(\mathrm{g})(4)(2012)$.

18140 C.F.R. $\S 51.308(\mathrm{e})(2)(2017)$.

182 Yazzie v. EPA, 851 F.3d 960, 969 (9th Cir. 2017).

18340 C.F.R. $\S 51.308(\mathrm{e})(2)(\mathrm{iii})(2017)$.

${ }^{184} I d . \S 51.308(\mathrm{e})(2)(\mathrm{i})(\mathrm{E}),(\mathrm{e})(3)$

${ }^{185}$ See 42 U.S.C. $\$ 7492$ (f) (2012).

${ }^{186}$ See generally Recommendations for Improving Western Vistas, GRAND CANYON VISIBILITY TRANSP. COMM'N 26-65 (June 10,1996), https://www.wrapair.org/WRAP/reports/GCVTCFinal.PDF (describing the nine recommendations).

${ }^{187} I d$. at 33 .

${ }^{188} \mathrm{Id}$. at 38,40

${ }^{189}$ Id. at 39 .

${ }^{190}$ Id. at Executive Summary II.

${ }^{191} I d$. at 42. For further discussion see Dennis Arfmann, The Grand Canyon Visibility Transport

Commission: Reasonable Progress toward the National Visibility Goal, 2 ENVTL. L. 725 (1996); Marilyn

S. Kite et al., Visibility: A Critique of the National Program; A Review of the Impacts in Southwest Wyoming, 33 LAND \& WATER L. REV. 3, 8 (1998).

19242 U.S.C. § $7492(\mathrm{e})(2012)$.
} 
By 1997, the focus on visibility issues had shifted to regional haze issues, and the GCVTC was replaced by the Western Regional Air Partnership ("WRAP") as the planning group in the western United States. WRAP has a broader geographical reach, with a membership that includes the governors of thirteen western states (including Alaska); eleven western tribes; and representatives of the Department of the Interior (National Park Service and Fish and Wildlife Service), the Department of Agriculture (Forest Service), and EPA. ${ }^{193}$ WRAP is administered jointly by the Western Governors' Association ("WGA") and the National Tribal Environmental Council with funding by EPA. ${ }^{194}$ WRAP developed a plan for dealing with visibility issues. ${ }^{195}$

On July 31, 1997, EPA issued a notice of proposed rulemaking ("NPRM") concerning regional haze regulations "to address regional haze visibility impairment in the nation's most treasured national parks and wilderness areas." 196 The NPRM utilized the information in the GCVTC's report and EPA's approach to "reasonable progress." ${ }^{197}$ The regional haze program compliments the Prevention of Significant Deterioration ("PSD") program ${ }^{198}$ through its focus on long-term emission decreases from all emission sources includes major and minor stationary sources, area sources, and mobile sources. ${ }^{199}$ The CAA calls for regulations to assure reasonable progress to meet the national goal of remedying visibility impairment. ${ }^{200}$ The aim of the 1997 NPRM was to develop a longterm strategy, to be adopted by affected states throughout the country, in order to reduce regional haze impairment in mandatory Class I areas. ${ }^{201}$

The major elements of the proposed visibility protection program were:

1. expanded applicability of the regional haze program to all states, the District of Columbia, and certain territories;

2. establishment of presumptive reasonable progress targets;

3. requirements for periodic SIP revisions, including periodic demonstrations by states on whether reasonable progress targets are being achieved for each mandatory Class I Federal area;

4. analysis of sources contributing to regional haze impairment, including sources potentially subject to BART;

\footnotetext{
${ }^{193}$ Facts about the WRAP, WESTERN REGIONAL AIR PARTNERSHIP, https://www.wrapair.org/forums/cc/projects/handouts/031109WRAP Facts.pdf (last visited May 30, 2017). ${ }^{194} I d$.

${ }^{195}$ See Western Regional Air Partnership 2008-12 Strategic Plan, WeStern REgIONAL AIR PARTNERSHIP (Mar. 2008), https://www.wrapair.org/WRAP/documents/WRAP_2008-12_Strategic_Plan3_08final.pdf. See also Western Regional Air Partnership Strategic Plan, WeSTERn REgIONAL AIR PARTNERSHIP (Mar. 9, 2015), https://www.wrapair2.org/pdf/WRAP\%20Strategic\%20Plan\%20final\%20March 2015.pdf.

${ }^{196}$ Regional Haze Regulations, 62 Fed. Reg. 41,138 (proposed July 31, 1997) (to be codified at 40 C.F.R. pt. 51).

${ }^{197}$ Recommendations for Improving Western Vistas, supra note 186.

${ }^{198}$ See generally 42 U.S.C. $\$ \$ 7470-7479$ (2012) (PSD program).

199 American Corn Growers Ass'n v. EPA, 291 F.3d 1, 11 (D.C. Cir. 2002).

20042 U.S.C. § 7491(b)(2) (2012)

${ }^{201} I d . \S 7492$.
} 
5. expansion of the current monitoring network, as necessary to be representative of all mandatory Class I Federal areas; and 6. development of strategies to reduce emissions of visibility impairing pollutants in conjunction with strategies to meet the new and revised NAAQS for $\mathrm{PM}_{2.5}$ and ozone. ${ }^{202}$

The existing visibility program based on CAA $\S 169$ A remains in place, including, for example, requirements for BART and a long-term strategy to address "reasonably attributable" visibility impairment, state consultation with FLMs on SIP revisions, consideration of integral vistas, and visibility monitoring. ${ }^{203}$ The visibility program also requires a review of new source impacts on visibility in mandatory Class I Federal areas in order to prevent future visibility impairment. ${ }^{204}$ The proposed rule expanded the existing program, which applied to thirty-six states ${ }^{205}$ the District of Columbia, and the Virgin Islands, ${ }^{206}$ and aimed to restore visibility in the 156 areas classified as Class I. ${ }^{207}$ The proposed regulations also established the "deciview" standard of measurement. ${ }^{208}$

After publication of the haze rule's NPRM, EPA responded to the opposition of the WGA by agreeing to take a closer look at the recommendations of the WGA and the GCVTC. On September 3, 1998, EPA reopened the comment period for the regional haze rule, but limited comments to two specific issues. ${ }^{209}$ The first issue was to revisit the WGA's recommendations. The second issue was to seek responses concerning the effect of the Transportation Equity Act for the Twenty-first Century ("TEA-21") enacted on June 9, 1998. ${ }^{210}$ Section 4102(c)(2) of that Act established a new deadline for SIP submissions. On July 1, 1999, EPA published the final Regional Haze Rule ("the Rule"), which provides specific methodologies that are compatible with the recommendations of the GCVTC. ${ }^{211}$ It made changes to the proposed regional haze rule published in $1997 . .^{212}$ Regional haze program regulations were modified again in 2005, 2006, 2012, and 2017 and are codified at 40 C.F.R. $\S 51.308 .{ }^{213}$ The 2017 Amendments are discussed infra at $\S 3(\mathrm{C})$.

The Haze Rule requires each state subject to the Haze Rule to submit a regional haze implementation plan no later than December 17, 2007, that meets the Rule's requirements. ${ }^{214}$ The Rule allows the nine western states and the eligible Indian Tribes

\footnotetext{
${ }^{202}$ Regional Haze Regulations, 62 Fed. Reg. 41,138, 41,143 (proposed July 31, 1997) (codified at 40

C.F.R. pt. 51).

${ }^{203}$ Id. at 41,144 .

${ }^{204}$ Id. at 41,143 .

${ }^{205} \mathrm{Id}$. at 41,145 .

${ }^{206} \mathrm{Id}$. at 41,144 .

${ }^{207}$ See 42 U.S.C. $\S 7472(a)$ (2012) (defining Class I areas in CAA $\S 162(a)$ ).

20840 C.F.R. $\S 51.301$ (2017).

${ }^{209}$ Notice of Availability of Additional Information Related to Proposed Regional Haze Regulations;

Solicitation of Comments, 63 Fed. Reg. 46,952 (Sept. 3, 1998) (codified at 40 C.F.R. pt. 51).

${ }^{210}$ Transp. Equity Act for the $21^{\text {st }}$ Century, Pub. L. No. 105-178, 112 Stat. 107 (1998).

${ }^{211}$ Regional Haze Regulations, 64 Fed. Reg. 35,714 (July 1,1999) (codified at 40 C.F.R. pt. 51)

${ }^{212}$ Regional Haze Regulations, 62 Fed. Reg. 41,138 (proposed July 31, 1997) (to be codified at 40 C.F.R.

pt. 51).

21340 C.F.R. $\S 51.308$ (2017).

${ }^{214}$ Id. $\S 51.308(\mathrm{~b})$.
} 
within the region that participated in the GCVTC to implement measures recommended by the Commission as an alternative to the BART requirements with respect to sixteen Class I areas. ${ }^{215}$ This provision became controversial, and is discussed infra. In addition, the Rule contains detailed provisions regarding the tracking of visibility conditions and emissions reductions, establishment of visibility baselines, monitoring, and implementation of the regional haze program in Indian country. ${ }^{216}$

For each mandatory Class I Federal area located within the state, the State must determine the following visibility conditions (expressed in deciviews). Baseline visibility is based on the most impaired and least impaired days in the five years from 2000-2004. The baseline visibility is the average of these annual values. If there is no onsite monitoring data for 2000-2004, the State must establish baseline values using the most representative available monitoring data for $2000-2004 .{ }^{217}$ Natural visibility conditions are estimations of visibility impairment existing under natural conditions for the most impaired and least impaired days, based on available monitoring information and appropriate data analysis techniques. $^{218}$

Each state subject to the Haze Rule must submit a long-term strategy that addresses regional haze visibility impairment for each mandatory Class I area within the state and for each mandatory Class I area outside the state that may be affected by emissions from within the State. The long-term strategy must include the measures needed to achieve the reasonable progress goals, which are set out in the regulations. ${ }^{219}$ This includes the need for the State to document the technical basis, including modeling, monitoring and emissions information, on which the State is relying to determine its apportionment of emission reduction obligations necessary for achieving reasonable progress in each mandatory Class I Federal area. ${ }^{220}$ The State must also identify all anthropogenic sources of visibility impairment considered by the State in developing its long-term strategy including major and minor stationary sources, mobile sources, and area sources. ${ }^{221}$ The states are to identify sources that may contribute to regional haze in a Class I area in another state and determine whether and to what extent emission controls are needed to protect visibility in downwind Class I areas. ${ }^{222}$

Each state subject to the Haze Rule is required to develop an updated regional implementation plan and submit it to EPA by July 31, 2018, and every 10 years thereafter. ${ }^{223}$ The haze SIP must address regional haze in each mandatory Class I Federal area within the State and in each mandatory Class I Federal area located outside the State that may be affected by emissions from the State. ${ }^{224}$ As part of the implementation plan,

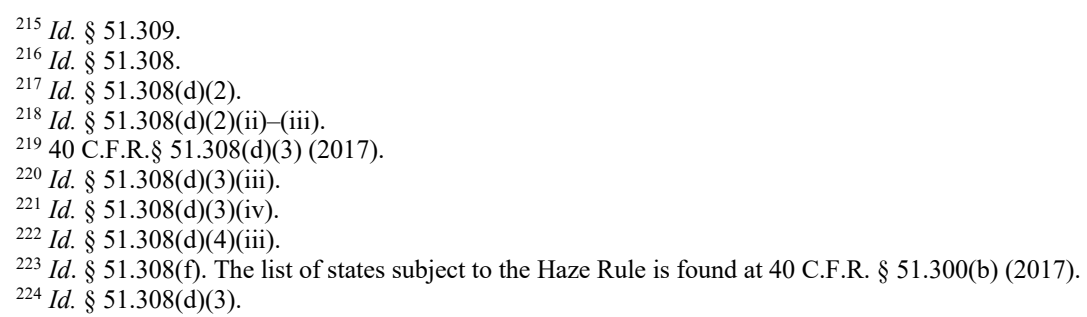


the State must submit a monitoring strategy for measuring, characterizing, and reporting of regional haze visibility impairment. ${ }^{225}$ Each State must also submit a long-term strategy that must include enforceable emissions limitations, compliance schedules, and other measures that are needed to make reasonable progress. ${ }^{226}$

Each state subject to the Haze Rule is required to submit progress reports to EPA in order to determine the adequacy of the state's implementation plan. ${ }^{227}$ The state must also take one of the following actions. If the state determines that no revision is needed it must provide to the Administrator a declaration that revision of the existing implementation plan is not needed. ${ }^{228}$ If a state determines that the implementation plan is or may be inadequate due to emissions from sources in another state(s) that participated in a regional planning process, it must provide notification to the Administrator and to the other state(s) and collaborate with the regional planning process to develop strategies to address the plan's deficiencies. ${ }^{229}$ If a state determines its implementation plan is or may be inadequate due to emissions from another country, the state must notify the Administrator. ${ }^{230}$ If a state determines that the implementation plan is or may be inadequate due to emissions from sources within the state, it must revise its implementation plan to address the deficiencies within one year. ${ }^{231}$

The FLM must be given the opportunity for consultation early enough in the state's policy analyses of its long-term strategy emission reduction obligation so that any information and recommendations provided by the FLM can meaningfully inform the state's decisions. ${ }^{232}$ The state must provide procedures for continuing consultation between the state and FLM on the implementation of the visibility protection program. ${ }^{233}$ States are required to submit periodic plans demonstrating how they have and will continue to make progress towards achieving their visibility improvement goals. The first state plans were due on December 17, 2007. ${ }^{234}$

On May 24, 2002, the D.C. Circuit in American Corn Growers Association v. EPA vacated the 1999 Haze Rule ${ }^{235}$ in part and sustained it in part. ${ }^{236}$ On June 5, 2003, EPA revised the Regional Haze Rule at 40 C.F.R. $\S 51.309$ to address regional haze in the 16 Class I areas in the nine western states covered by the GCVTC report. ${ }^{237}$ The 2003 Haze Rule provides a framework to be used by Western States and Tribes in developing regional

\footnotetext{
22540 C.F.R. $\S 51.308(\mathrm{~g})(6)(2017)$.

${ }^{226} \mathrm{Id} . \S 51.308(\mathrm{~g})(2)$.

${ }^{227}$ Id. $\S 51.308(\mathrm{~g})$.

${ }^{228} \mathrm{Id} . \S 51.308(\mathrm{~h})(1)$

${ }^{229}$ Id. $\S 51.308(\mathrm{~h})(2)$

${ }^{230} \mathrm{Id} . \S 51.308(\mathrm{~h})(3)$

${ }^{231} 40$ C.F.R. $\S 51.308(\mathrm{~h})(4)(2017)$

${ }^{232} I d$. $\S 51.308(\mathrm{i})(2)$

${ }^{233} \mathrm{Id}$. $51.308(\mathrm{i})(4)$

${ }^{234}$ Id. $\$ 51.308(\mathrm{~b})$.

${ }^{235}$ Regional Haze Regulations, 64 Fed. Reg. 35,714 (July 1,1999) (to be codified at 40 C.F.R. pt. 51).

${ }^{236}$ American Corn Growers Ass'n v. EPA, 291 F.3d 1 (D.C. Cir. 2002).

${ }^{237}$ The sixteen areas are found at 40 C.F.R. $\S 51.309$ (b)(1) (2017).
} 
haze implementation plans and it has been modified several times. ${ }^{238}$ It incorporated $\mathrm{SO}_{2}$ milestones for the years 2003 to 2018 to limit $\mathrm{SO}_{2}$ emissions from stationary sources. ${ }^{239}$ It called for reductions in $\mathrm{SO}_{2}$ emissions of fifty to $70 \%$ from 1990 levels by $2040 .{ }^{240} \mathrm{It}$ requires implementation plans to have quantitative emissions milestones for each year through 2018. ${ }^{241}$ The failure to meet the milestones triggers the use of a backstop emissions trading program. ${ }^{242}$ On February 18, 2005, the D.C. Circuit in Center for Energy and Economic Development v. EPA granted a petition challenging provisions in the Regional Haze Rule concerning an optional emissions trading program involving the Western Regional Air Partnership (“WRAP”) Annex Rule. ${ }^{243}$ On October 13, 2006, EPA responded by promulgating Regional Haze Regulations dealing with alternatives to source-specific BART requirements, which are discussed below. ${ }^{244}$

\section{$\S 3(a)$. BART Requirements}

States that are subject to visibility requirements must develop a haze SIP that contains BART-based emission limitations and schedules for compliance with BART for each BART-eligible source. ${ }^{245}$ The BART process consists of two steps. First, in the "Attribution Step," states must review each "BART-eligible source" within the state to determine whether they emit any air pollutants that may cause or contribute to any impairment of visibility in any mandatory Class I Federal area. If they do, they must comply with BART requirements. ${ }^{246}$ The second step is the "Determination Step," which requires states to determine the technology that a source subject to BART must install. ${ }^{247}$ EPA provides guidance concerning this process at 40 C.F.R. Part 51, Appendix Y, including presumptive $\mathrm{NO}_{\mathrm{x}}$ limits at Table 1 for BART-eligible large coal-fired electric generating units. However, the Haze Rule also permits states to implement an emissions trading program or other alternative measure rather than requiring BART if it will achieve greater reasonable progress than the installation of BART. ${ }^{248}$ This "better than BART" approach was approved in CEED v. EPA, although the court in that case objected to the

\footnotetext{
${ }^{238}$ Revisions to the Regional Haze Rule to Correct Mobile Source Provisions in Optional Program, 68 Fed. Reg. 39,842, 39,846 (July 3, 2003) (to be codified at 40 C.F.R. pt. 51); Revisions to the Regional Haze Rule to Correct Mobile Source Provisions in Optional Program, 68 Fed. Reg. 61,367, 61,369 (Oct. 28, 2003) (to be codified at 40 C.F.R. pt. 51); Revisions to the Regional Haze Rule to Correct Mobile Source Provisions in Optional Program, 68 Fed. Reg. 71,009, 71,014 (Dec. 22, 2003) (codified at 40 C.F.R. pt. 51).

${ }^{239}$ Revisions to Regional Haze Rule to Incorporate Sulfur Dioxide Milestones and Backstop Emissions Trading Program for Nine Western States and Eligible Indian Tribes Within That Geographic Area, 68 Fed. Reg. 33,763 (June 5, 2003) (codified at 40 C.F.R. pt. 51)

${ }^{240} 40$ C.F.R. $\S 51.309(d)(4)(2017)$.

${ }^{241} I d . \$ 51.309(\mathrm{~d})(4)(\mathrm{i})$.

${ }^{242} I d . \S \S 51.309(\mathrm{~d})(4)(\mathrm{iv}),(\mathrm{v})$.

${ }^{243}$ Center for Energy and Econ. Dev. v. EPA, 398 F.3d 653 (D.C. Cir. 2005).

${ }^{244}$ Regional Haze Regulations; Revisions to Provisions Governing Alternative to Source-Specific Best Available Retrofit Technology (BART) Determinations, 71 Fed. Reg. 60,612 (Oct. 13, 2006) (codified at 40 C.F.R. pt. 51).

24540 C.F.R. $\$ 51.308(\mathrm{e})(2)(2017)$.

${ }^{246}$ Utility Air Regulatory Grp. v. EPA, 471 F.3d 1333, 1333 (D.C. Cir. 2006). See also 40 C.F.R. $\S$

51.308(e)(1)(ii) (2017).

${ }^{247} I d$. at 1336 .

${ }^{248}$ Id.
} 
program under review. ${ }^{249}$ EPA subsequently modified 40 C.F.R. $\S 51.308(e)(3)$ to meet the court's objections. EPA has promulgated regulations that specify the requirements for determining whether a BART Alternative achieves "greater reasonable progress" than BART, which is discussed below. ${ }^{250}$

The requirement to install BART may lead to legal challenges to a decision to require a specific technology. For example, in St. Marys Cement, Inc. v. EPA, the Sixth Circuit upheld a decision of EPA that selective non-catalytic reduction ("SNCR") technology to control $\mathrm{NO}_{\mathrm{x}}$ emissions from a cement plant was BART. ${ }^{251}$ As previously stated, if a SIP or SIP revision is rejected by EPA, the Agency is to promulgate a Federal Implementation Plan ("FIP"). ${ }^{252}$ EPA's use of this power was challenged in the Tenth Circuit in Oklahoma v. EPA. ${ }^{253}$ The State of Oklahoma, led by its Attorney General E. Scott Pruitt, the Administrator of EPA, as well as Oklahoma Industrial Consumers, and Oklahoma Gas \& Electric Co. (OG \& E) challenged EPA's rejection of the state's regional haze SIP and EPA's replacing it with a more stringent FIP to control $\mathrm{SO}_{2}$ from two OG \& E generating stations. ${ }^{254}$ The Tenth Circuit ruled "that the EPA has authority to review the state's plan and that it lawfully exercised that authority in rejecting it and promulgating its own." $" 255$

The 2005 Regional Haze Rule requires states to submit SIP revisions by December 17, 2007. ${ }^{256}$ But, on January 15, 2009, EPA found that Oklahoma and 31 other states, the District of Columbia, and the U.S. Virgin Islands had failed to submit Regional Haze SIPs, which triggered EPA's duty to promulgate a FIP within two years. ${ }^{257}$ Before EPA promulgated a FIP, Oklahoma submitted its SIP dealing with two units at OG \& E's Muskogee Generating Station and two units at its Sooner Generating Station. The Oklahoma SIP set $\mathrm{SO}_{2}$ emissions limits for each of these four units based on the continued use of low-sulfur coal, but it rejected, an emissions limit that would require the installation of scrubbers.

On March 22, 2011, EPA proposed to partially approve Oklahoma's SIP, but it proposed to disapprove the $\mathrm{SO}_{2}$ emission limitations for OG \& E's four units because Oklahoma "did not properly 'take into consideration the costs of compliance' when it relied on cost estimates that greatly overestimated the costs of dry and wet scrubbing in order to conclude these controls were not cost effective." ${ }^{258}$ EPA said that Oklahoma failed to follow the Agency's regulations in determining BART. ${ }^{259}$ After notice and comment, EPA

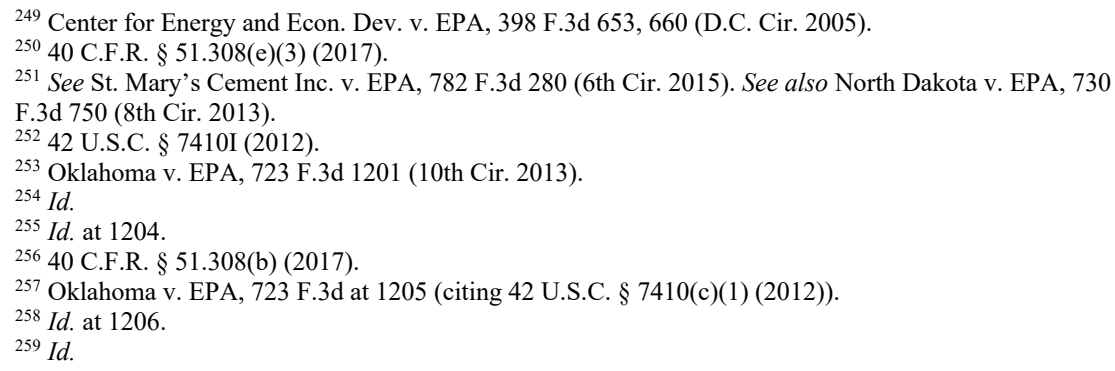


published a FIP. ${ }^{260}$ In the lawsuit that followed, the petitioners argued that EPA usurped the state's authority in an effort to force OG \& E to spend more than \$1_billion in five years to install unnecessary technology. ${ }^{261}$ However, the Tenth Circuit recognized that a BART determination for fossil-fuel fired power plants having a total generating capacity greater than 750 megawatts must be based on the guidelines appendix Y. EPA rejected Oklahoma's SIP because the BART determinations failed to comply with these guidelines. ${ }^{262}$

The court referred to American Corn Growers Ass'n v. EPA ${ }^{263}$ as support for BART-eligible sources being subject to BART "even absent empirical evidence of that source's individual contribution to visibility impairment in a Class I area so long as the source is located within a region that may contribute to visibility impairment." The state needed to "analyze the degree of visibility improvement that would be achieved .... as a result of the emission reductions achievable from all sources subject to BART located within the region that contributes to visibility impairment."264 "Under EPA's take on the statute, it is therefore entirely possible that a source may be forced to spend millions of dollars for new technology that will have no appreciable effect on the haze in any Class I area." $" 265$

The court recognized that the CAA delegates the power to require BART to the states, but EPA may reject BART determinations from states that do not comply with its guidelines. ${ }^{266}$ The court went on to determine that EPA lawfully exercised its authority when it rejected Oklahoma's SIP because OG \& E did not comply with the guidelines. ${ }^{267}$ Furthermore, many of OG \& E's cost assumptions were unjustified and they were not analyzed in compliance with EPA's Control Cost Manual. ${ }^{268}$ Moreover, OG \& E estimated the cost effectiveness of scrubbers based on emissions from plants using low-sulfur coal, but this was not a binding requirement and EPA assumed OG \& E would use high sulfur coal if they installed scrubbers, which would dramatically change the cost per ton of $\mathrm{SO}_{2}$ removal. ${ }^{269}$ After reviewing many other claims of error raised by the petitioners, the court denied the petition for review holding that EPA had the authority to review Oklahoma's BART determinations and it exercised that authority properly. ${ }^{270}$

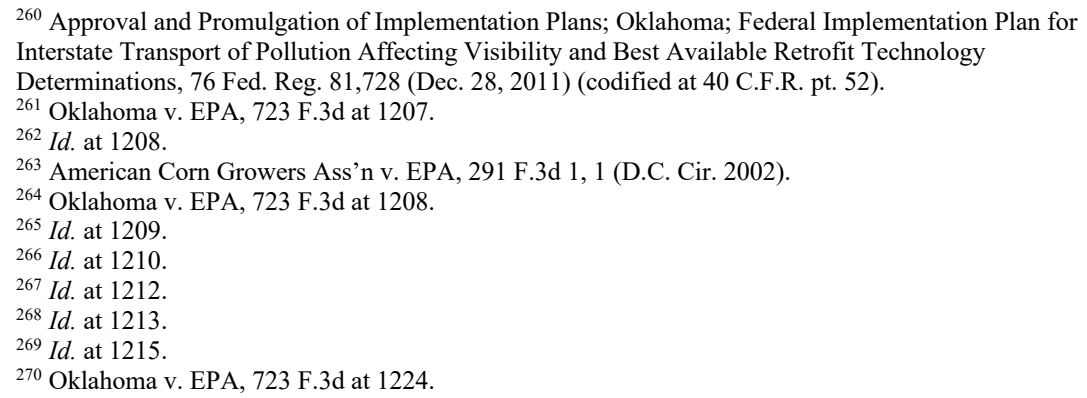


On May 14, 2013, the Eighth Circuit decided North Dakota v. EPA. ${ }^{271}$ This case involves challenges to the application of regional haze rules concerning reasonable progress goals that are discussed at supra § 2(a)(1) and BART requirements that are discussed here. North Dakota and Great River Energy, the owner of the Coal Creek Station, “challenged EPA's disapproval of the State's SIP determination that SOFA + LNB with an emission limit of $0.17 \mathrm{lb} / \mathrm{MMBtu}$ on a thirty-day rolling average basis was BART for the Coal Creek Station." 272 EPA's FIP determination that SNCR + SOFA + LNB with an emission limit of $0.13 \mathrm{lb} / \mathrm{MMBtu}$ on a thirty-day rolling average is BART for the Coal Creek Station was also challenged. ${ }^{273}$

During its BART analysis for the Coal Creek Station, the State concluded that using SNCR to control additional emissions at the plant would result in producing fly ash that is unsuitable for Coal Creek to sell for use in concrete production. Thus, SNCR would cause Great River Energy to lose $\$ 36$ a ton in revenue from the fly ash sales as well as resulting in additional costs to dispose of the fly ash in landfills. The State estimated the cost would be $\$ 8,551$ per-ton per ton of $\mathrm{NO}_{\mathrm{x}}$ removed using SNCR, which includes the cost of lost fly ash revenue and the additional cost for disposing of the unusable fly ash. ${ }^{274}$ The State calculated the cost effectiveness of SOFA + LNB as $\$ 411$ per-ton-of- $\mathrm{NO}_{\mathrm{x}}$ removed. The incremental cost of SNCR, in addition to SOFA + LNB was excessive, but if fly ash sales were not lost while using SNCR the cost would not have been considered excessive. The State also found that the incremental improvement in visibility of SNCR + SOFA + LNB was only 0.105 deciviews. The State concluded that "[b]ecause of the potential for lost sales of fly ash, the negative environmental effects of having to dispose of the fly ash instead of recycling it into concrete, and the very small amount of visibility improvement from the use of SNCR, this option is rejected as BART." 275 Instead, the State proposed that BART was SOFA + LNB. ${ }^{276}$

Great River Energy made a mistake in its disclosure to the State by stating that it received $\$ 36$ per ton of fly ash in revenue, when its actual revenue from fly ash was only $\$ 5$ per ton. Therefore, EPA disapproved the State's BART determination for the Coal Creek Station. EPA concluded that the State's SIP failed to properly consider the cost of compliance because the cost of compliance analysis was "based upon fundamentally flawed and greatly inflated cost estimates regarding lost fly ash revenue." 277 EPA then proposed to promulgate a FIP that included a BART determination for the Coal Creek Station. Great River Energy objected because EPA failed to consider existing control technology in use at the Coal Creek Station that included a prototype pollution control technology. EPA concluded that it was not required to consider a voluntarily installed control technology that was installed after the baseline period. EPA's Final Rule concluded that BART was SNCR + SOFA + LNB, but determined that the emission limit should be

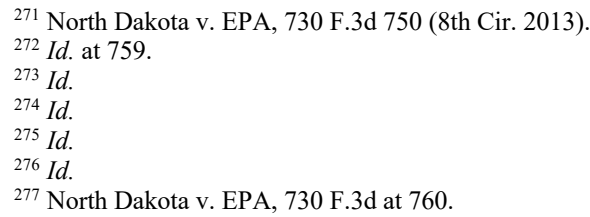




\section{$0.13 \mathrm{lb} / \mathrm{MMBtu}$ on a thirty-day rolling average. ${ }^{278}$}

The Eighth Circuit cited the Tenth Circuit's decision in Oklahoma v. EPA ${ }^{279}$ that supported EPA's rejecting a BART determination on the basis that the state relied on cost estimates that greatly overestimated the costs of dry and wet scrubbing to conclude these controls were not cost effective. ${ }^{280}$ The Tenth Circuit held that because the state's cost of compliance estimate was based upon fundamental methodological flaws, EPA had a reasonable basis for rejecting the state's BART determination for failure to comply with the requisite BART guidelines. ${ }^{281}$ The Eighth Circuit concluded "that EPA's disapproval of the State's BART determination for failing to consider the cost of compliance as required under the statute and the BART guidelines was neither arbitrary, capricious, nor an abuse of discretion." ${ }^{282}$ EPA is required to take action on a SIP submission within twelve months of the date that the submission is deemed complete, which was April 30, 2011. In this case, EPA took final action on the State's BART determination on April 6, 2012, but Great River Energy did not submit its final revised calculations until June 2012. The State has identified no provision of the CAA that obligated EPA to wait for its supplemental BART determination before disapproving a BART determination. Thus, the State failed to demonstrate that EPA's disapproval of the BART determination was arbitrary, capricious, or an abuse of discretion. ${ }^{283}$

After EPA disapproved the State's BART determination it was required to promulgate a FIP within two years of the disapproval "unless the State correct[ed] the deficiency, and the Administrator approve[d] the plan or plan revision, before the Administrator promulgate[d] such Federal implementation plan." ${ }^{284}$ Great River Energy challenged EPA's determination that SNCR in addition to SOFA and LNB is BART. It claimed EPA violated the CAA by refusing to consider existing pollution control technology at the station during its BART analysis. EPA refused to consider the pollution control technology in use at the Coal Creek Station, because it was not installed until after the baseline period and was installed voluntarily, not to meet any regulatory requirement. ${ }^{285}$ The Eighth Circuit ruled that EPA's interpretation that it was not required to consider the existing pollution control technologies in use at the Coal Creek Station was entitled to no deference. "EPA's refusal to consider the existing pollution control technology in use at the Coal Creek Station because it had been voluntarily installed was arbitrary and capricious, and its FIP promulgating SNCR as BART for the Coal Creek Station is therefore vacated." 286

\footnotetext{
${ }^{278} I d$.

${ }^{279}$ Oklahoma v. EPA, 723 F.3d 1201, 1208-10, (10th Cir. 2013).

${ }^{280}$ North Dakota v. EPA, 730 F.3d at 760.

${ }^{281}$ Oklahoma v. EPA, 723 F.3d at 1211-1212.

${ }^{282}$ North Dakota v. EPA, 730 F.3d at 761.

${ }^{283} \mathrm{Id}$. at 762 .

${ }^{284}$ Id. (citing 42 U.S.C. $\left.\$ 7410(\mathrm{c})(1)(\mathrm{B})(2012)\right)$.

${ }^{285} \mathrm{Id}$.

${ }^{286} \mathrm{Id}$. at 764 .
} 


\section{§ 3(a)(2). National Parks Conservation Ass'n v. EPA.}

On June 9, 2015, the Ninth Circuit decided the National Parks Conservation Ass'n v. EPA. ${ }^{287}$ This case involved a challenge to EPA's regional haze regulations promulgated for the State of Montana that was brought by the operator of Montana power plants ("PPL") and environmental groups. The former arguing the regulations were too stringent and the latter arguing the regulations were too lax. The petition was granted in part and denied in part; the rule was vacated and remanded. ${ }^{288}$ The court held that the rule requiring the operator to implement SNCR and SOFA at power plants was arbitrary and capricious; the rule requiring installation of a fourth scrubber at one power plant was arbitrary and capricious; the rule requiring operator to implement BART at one power plant was inconsistent with its BART analysis at a second plant; and EPA did not provide a meaningful response to the operator's objection to EPA's use of a model to estimate emission source's impact on visibility. ${ }^{289}$

The Ninth Circuit had to review Montana's compliance with the five steps required for compliance with the Regional Haze Rule ("Guidelines") in order to determine BART. ${ }^{290}$ They are: (1)_identify all available retrofit control technologies;_(2) eliminate technically infeasible options; (3)_evaluate the control effectiveness of remaining control technologies; (4) evaluate impacts and document the results; and_(5) evaluate visibility impacts in deciviews. ${ }^{291}$ Montana proposed a rule requiring PPL to reduce emissions of $\mathrm{NO}_{\mathrm{x}}$ and $\mathrm{SO}_{2}$ at its Colstrip and Corette power plants. PPL Montana was required to reduce $\mathrm{NO}_{\mathrm{x}}$ emissions to a 30-day rolling average of $0.15 \mathrm{lb} / \mathrm{mmBtu}$ by installing SOFA and SNCR at Colstrip Units 1 and 2. To reduce $\mathrm{SO}_{2}$ emissions to a 30-day rolling average of $0.08 \mathrm{lb} / \mathrm{mmBtu}$, PPL was to install lime injection and a fourth scrubber at Colstrip Units 1 and 2. No new technologies had to be implemented at Colstrip Units 3 and $4 .{ }^{292}$ Montana imposed 30-day average rolling emission limits of $0.40 \mathrm{lb} / \mathrm{mmBtu}$ for $\mathrm{NO}_{\mathrm{x}}$ and 0.70 $\mathrm{lb} / \mathrm{mmBtu}$ for $\mathrm{SO}_{2}$ for the Corette station, but it did not require the installation of new technology. ${ }^{293}$ EPA issued a FIP for Montana on September 18, 2012, which was nearly identical to Montana's proposed rule. ${ }^{294}$

The petitioners on both sides of the controversy claim that EPA's cost-effectiveness analysis failed to consider the costs of compliance and degree of visibility impairment, as required by the CAA. ${ }^{295}$ The environmentalists contended that EPA offered insufficient justification for its rejection of the more effective Selective Catalytic Reduction ("SCR") technology as BART in favor of SOFA and SNCR together, and PPL should be required to install SCR and SOFA at all four Colstrip units and more stringently regulate Corette. PPL contended that EPA offered insufficient justification for requiring SOFA and SNCR

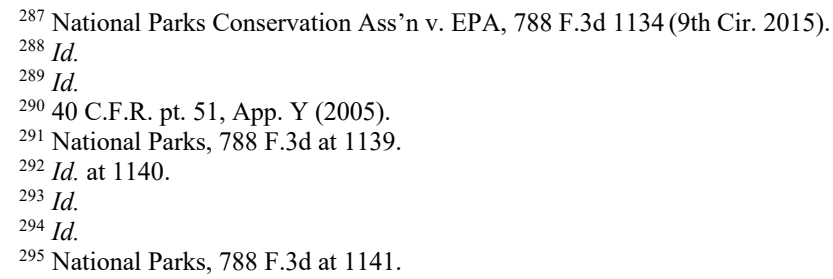


as BART instead of just SOFA. Both parties claim EPA's cost-effectiveness analysis failed to properly consider the costs of compliance and degree of visibility impairment, as required by the CAA. ${ }^{296} \mathrm{EPA}$ responded that its BART determination was discretionary and that it considered all relevant factors. ${ }^{297}$ The CAA requires that EPA explain the basis for its decisions, including underlying factual bases, methods of analysis, and legal and policy considerations. ${ }^{298}$ "The Agency must also respond to the comments, criticism, and new data submitted during the comment period."299

The Ninth Circuit ruled that the FIP offers essentially no reasoning behind EPA's selection of SOFA and SNCR together, as opposed either to SOFA alone or SOFA and SCR together, as BART for Colstrip Units 1 and 2. Without any explanation at all of how EPA determines cost-effectiveness, the court ruled it is impossible to determine why EPA ruled SOFA and SNCR in and ruled SCR out. ${ }^{300 ~ " E P A ~ s i m p l y ~ a s s e r t e d ~ t h a t ~ t h e ~ c o s t ~ o f ~}$ SOFA and SCR together (\$3,195/ton at Colstrip Unit 1) was "not justified by the visibility improvement of .404 deciviews," but that "[t] he lower cost of SOFA + SNCR ( $\$ 1,564 /$ ton) is justified when the visibility improvement [of .264 deciviews] is considered." ${ }^{301}$ Therefore, the court concluded that EPA's BART determination for $\mathrm{NO}_{\mathrm{x}}$ emissions at Colstrip Units 1 and 2 was arbitrary and capricious. ${ }^{302}$

The cost-effectiveness analysis for $\mathrm{SO}_{2}$ emissions at Colstrip Units 1 and 2 had similar defects as the analysis of $\mathrm{NO}_{\mathrm{x}}$ emissions. EPA failed to explain what makes a cost reasonable in light of potential visibility benefits. ${ }^{303} \mathrm{EPA}^{\prime} \mathrm{S} \mathrm{SO}_{2}$ emission limits for Colstrip Units 1 and 2 would impose on PPL an additional \$25 million in capital costs and an additional $\$ 2,210,000$ annually to achieve a visibility improvement of 0.055 deciviews. But EPA provided no reasons justifying its determination. ${ }^{304}$ By contrast, EPA thoroughly explained why it decided not to require complete replacement of the existing emissions control systems for $\mathrm{SO}_{2}$ at Colstrip Units 1 and 2. BART Guidelines recommend constructing a new system when a current control system achieves less than $50 \%$ removal efficiencies. The $\mathrm{SO}_{2}$ emissions control system at Colstrip Units 1 and 2 achieves these removal efficiencies. Therefore, EPA is not required to consider replacement technology. ${ }^{305}$ This kind of explanation was missing from EPA's conclusion that PPL must install a fourth scrubber at Colstrip Units 1 and 2, which made the requirement arbitrary and capricious. ${ }^{306}$

PPL also contended that EPA's BART determinations at Colstrip Units 1 and 2 were arbitrary and capricious because they were inconsistent with EPA's Corette analysis.

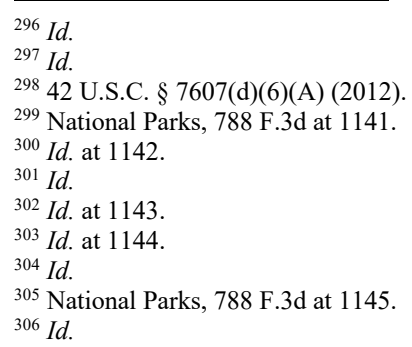


The court found that EPA concluded that a cost-per-ton rate of approximately $\$ 1,500$ for $\mathrm{NO}_{\mathrm{x}}$ emissions controls was justified at Colstrip, but at Corette, EPA concluded that a costper-ton rate of $\$ 1,487$ did not justify the potential emissions reductions. Corette, moreover, is closer to Class I areas than Colstrip. There was no explanation, and that made this an arbitrary and capricious action. ${ }^{307}$

PPL objected to EPA's use of the CALPUFF visibility model in determining BART at Colstrip Units 1 and 2. ${ }^{308}$ It claimed that the maximum potential incremental visibility benefit of SNCR was below the range of perceptibility and falls within the model's margin of error. Moreover, PPL claimed that because of the distance of the source from Class I areas, the CALPUFF model is inaccurate. ${ }^{309}$ The court found that EPA's response that low levels of visibility impairment must be addressed even if they are not perceptible to the human eye, or that measures have been taken to minimize the margin of error was inadequate. ${ }^{310}$ It was arbitrary and capricious for EPA to require an emissions source to spend millions of dollars for new technology that will have no appreciable effect on the haze in any Class I area. The court did find that EPA offered a reasoned response to PPL's challenge to the use of CALPUFF at the distances in question. ${ }^{311}$

\section{§ 3(a)(3). State of Nebraska v. EPA.}

On February 3, 2016, the Eighth Circuit decided State of Nebraska v. EPA. ${ }^{312}$ In 2012, EPA rejected Nebraska's BART determination for the Gerald Gentleman power plant that was part of the State's Haze Implementation Plan and substituted a FIP. Nebraska petitioned for review and environmental organizations opposed the petition and sought a court review of the FIP. However, the petition for review was denied. ${ }^{313}$

A state haze SIP must require specific major stationary sources that may reasonably be anticipated to cause or contribute to any impairment of visibility to "procure, install, and operate, as expeditiously as practicable" BART. ${ }^{314}$ A state may use an alternative to BART if there will be an overall improvement in visibility. ${ }^{315}$ In 2012, EPA determined that the Transport Rule ("CSAPR"), achieved greater reasonable progress in those states covered by the Transport Rule, which includes Nebraska. The Gerald Gentleman Station, the largest source of $\mathrm{SO}_{2}$ pollution in Nebraska, affects six Class I areas. ${ }^{316}$

Nebraska's SIP evaluated wet and dry FGD Flue Gas Desulfurization ("FGD") and Dry Sorbent Injection ("DSI") for $\mathrm{SO}_{2}$ control. Nebraska concluded that the costs for FGD

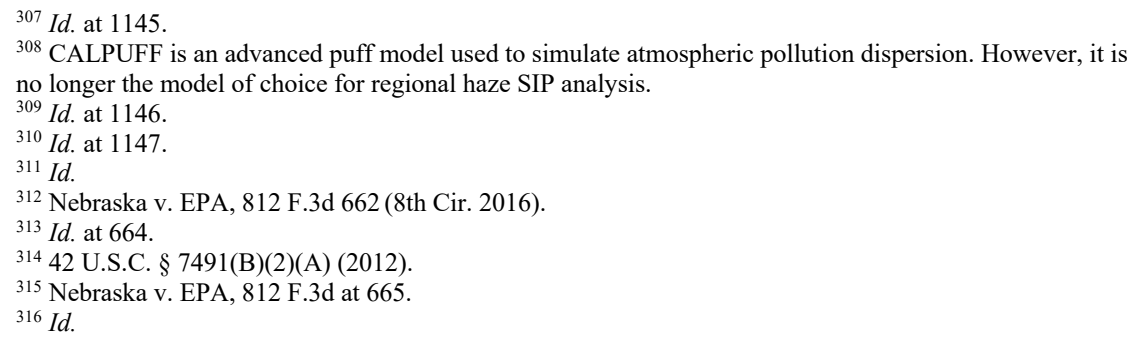


controls were unreasonable on a cost per deciview of improvement, based on the impact on one Class I area. Nebraska concluded that BART for the Station required no $\mathrm{SO}_{2}$ controls. ${ }^{317}$ EPA disagreed and disapproved Nebraska's determination citing "errors in Nebraska's cost analysis for FGD controls, the reasonableness of the costs of controls, the significant visibility improvement achieved as a result of installing FGD or DSI, and improper rejection of DSI." EPA then promulgated a FIP that relied on the Transport Rule as an alternative to source-specific BART for $\mathrm{SO}_{2}$ emissions control. Nebraska and the conservation organizations then petitioned for review. ${ }^{318}$

In valuating $\mathrm{SO}_{2}$ controls at Gerald Gentleman, Nebraska focused on dry and wet FGD. It concluded the costs for dry and wet FGD were " $\$ 2,726$ per ton and $\$ 2,724$ per ton, respectively." " 319 It determined that the cost-effectiveness for both types of FGD was "reasonable on a cost per ton basis." As part of the reasonable cost-effectiveness, the visibility improvement was deemed "significant." However, Nebraska concluded the cost of water to operate wet FGD would add approximately $8.6 \%$ to the cost of controls, which resulted in the State's determination that BART for the facility was no $\mathrm{SO}_{2}$ controls. ${ }^{320}$ EPA determined that Nebraska erred in its "cost analysis for FGD controls, the reasonableness of the costs of controls, the potential for significant visibility improvement as a result of installing FGD or DSI, and improper rejection of DSI." ${ }^{21}$ EPA considered DSI to be cost effective at " $\$ 2,058$ per ton, and the visibility improvements to be significant at the closest Class I area." 322 It disapproved Nebraska's BART determination based on Nebraska's flawed analysis and unreasonable conclusion. ${ }^{323}$

EPA determined that FGD controls are capable of controlling emissions to a greater degree than Nebraska had assumed, and that Nebraska overestimated the Station's emissions baseline, skewing its analysis of the proposed controls' cost-effectiveness. These errors resulted in an over estimation of the costs of FGD controls. EPA also concluded there was no adequate explanation for rejecting DSI, which does not require as much water as FGD. Given Nebraska's errors and EPA's determination that Nebraska's action was not well reasoned, the court denied Nebraska's petition for review. ${ }^{324}$

The conservation organizations objected to the FIP including the reliance on the Transport Rule because EPA did not consider or respond to evidence that FGD and DSI controls would improve visibility more than the Transport Rule. ${ }^{325}$ EPA did not detail why the Transport Rule was better than BART. EPA may use an alternative to BART if there will be an overall improvement in visibility. ${ }^{326}$ Although the Transport Rule may not reduce the Station's emissions as much as BART, EPA determined that the Transport Rule,

\footnotetext{
${ }^{317} I d$. at 666

${ }^{318} \mathrm{Id}$.

${ }^{319} \mathrm{Id}$. at 667.

${ }^{320} \mathrm{Id}$.

${ }^{321} I d$.

${ }^{322} I d$. at 668

${ }^{323} \mathrm{Id}$.

${ }^{324} \mathrm{Id}$.

${ }^{325} \mathrm{Id}$. at 669 .

${ }^{326} \mathrm{Id}$.
} 
compared to source-specific BART, would result in greater improvement in the affected Class I areas. EPA determined that the emission reductions from a single EGU subject to BART would not improve visibility across all affected Class I areas as effectively as implementing the Transport Rule. ${ }^{327}$ The court then deferred to EPA because the analysis of the relevant information requires a high level of technical expertise. ${ }^{328}$

Nebraska's plan concluded that no $\mathrm{SO}_{2}$ controls were needed for the power plant and rejected scrubbers as source-specific BART. ${ }^{329} \mathrm{EPA}$ was tasked with evaluating that action. It concluded Nebraska's decision was unreasoned because scrubbers were a costeffective option. The Transport Rule, at that point, was not an option. However, when promulgating its plan, EPA did have the option of choosing between source-specific BART or the Transport Rule. EPA chose to rely on the Transport Rule, finding that the Transport Rule met the minimum requirements for haze reduction, which the court held was not an abuse EPA's discretion. ${ }^{330}$

\section{§ 3(a)(4). Arizona, ex rel. Darwin v. EPA.}

On February 24, 2016, the Ninth Circuit decided Arizona, ex rel. Darwin v. EPA. ${ }^{331}$ The case involved a challenge by Arizona and a power district to an EPA rule that partially disapproved Arizona's regional haze SIP submission and the FIP that was promulgated to replace it. Petitioners challenged EPA's disapproval of the State's BART determinations, and the FIP's replacement determinations, concerning $\mathrm{NO}_{\mathrm{x}}$ emission limits at the Coronado Generating Station (Coronado), a two-unit, 733-megawatt coal-fueled power plant located in Eastern Arizona. The court denied the consolidated petitions for review, holding that EPA did not act arbitrarily and capriciously when it disapproved, in part, the SIP's BART determinations for Coronado and issued a FIP to replace the disapproved portions. ${ }^{332}$

Arizona opted to develop its haze SIP based on the BART Alternative provision. ${ }^{333}$ EPA found that Arizona had failed to submit plan elements in January 2009 that were required by the section 309 regulations, which started the two-year clock for the Agency to promulgate a FIP. ${ }^{334}$ EPA did not respond as required by the CAA until a consent decree required it to either approve the State's SIP with respect to its BART determinations or to propose a FIP by November 15, 2012. ${ }^{335}$ To avoid a FIP, Arizona developed a section 308 haze SIP and submitted it to EPA on February 28, 2011. The SIP included BART determinations for emission units at three fossil fuel power plants subject to BART: Apache Generating Station Units 1-3, Cholla Power Plant Units 2-4, and Coronado Generating

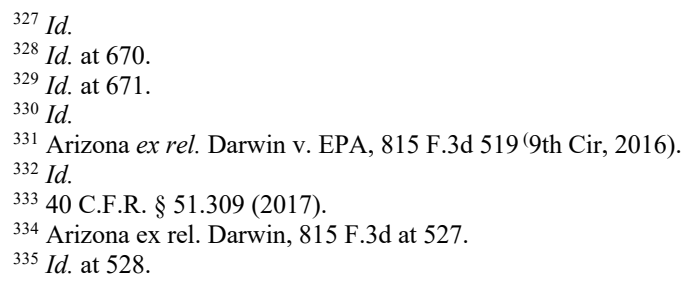


Station Units 1-2, but only the Coronado's requirements are at issue in this case. ${ }^{336}$ Arizona determined that the proper control technology was low-NOx burners with overfire air, which resulted in an enforceable $\mathrm{NO}_{\mathrm{x}}$ emissions limit of $0.32 \mathrm{lb} / \mathrm{mmBtu}$ for both units of the Coronado facility. ${ }^{337}$

The final rule that was the subject of this challenge was promulgated December 2012. ${ }^{338}$ The Rule disapproved the State's emissions limits for NOx at the seven coal-fired generating units at Apache, Cholla, and Coronado. EPA found that Arizona's analysis was flawed with respect to costs and visibility improvement, which led to $\mathrm{NO}_{\mathrm{x}}$ control determinations that were inconsistent with the Haze Regulations. Arizona's analyses concerning $\mathrm{SO}_{2}$ and particulate matter suffered from similar "deficiencies," but EPA approved the determinations for these pollutants because the flaws did not affect the State's selection of controls. ${ }^{339}$ EPA did its own analysis focusing on the cost controls and visibility impacts associated with the different BART options. "It concluded that SCR with low-NO $\mathrm{NO}_{\mathrm{x}}$ burners and overfire air - the most stringent available retrofit control optionwas the proper BART control for Coronado." ${ }^{440}$ The $\mathrm{NO}_{\mathrm{X}}$ emission limit was much lower than the limit in Arizona's haze SIP for Coronado Unit 2 and it included recordkeeping and reporting requirements needed to enforce the FIP's BART determinations. ${ }^{341}$ In the Final Rule, the proposed $\mathrm{NO}_{\mathrm{x}}$ emission limits for Coronado Unit 1 and Unit 2 were made less stringent and the compliance deadlines for installation and operation of the controls at the facilities were extended. ${ }^{342}$

Arizona cited the American Corn Growers case that involved the court disapproval of EPA's haze rule in part because its requirements were inconsistent with the CAA's provisions giving the states broad authority over BART determinations. ${ }^{343}$ However, the Eighth Circuit's holding in that case did not suggest that after a state determines BART in a proposed SIP, the court lacks authority to substantively review the SIP for consistency with the Act. ${ }^{344}$ The court held that Congress intended that EPA is authorized to disapprove state analysis that is neither reasoned nor in compliance with the CAA. Once the federal agency acts, the reviewing court, with appropriate deference to the federal agency, must decide whether the agency's action was arbitrary, capricious, an abuse of discretion, or otherwise not in accordance with law. ${ }^{345}$

The court recognized that EPA is authorized to approve or disapprove a SIP submittal or a part of a submittal. ${ }^{346}$ The SIPs must contain reasonable progress goals as

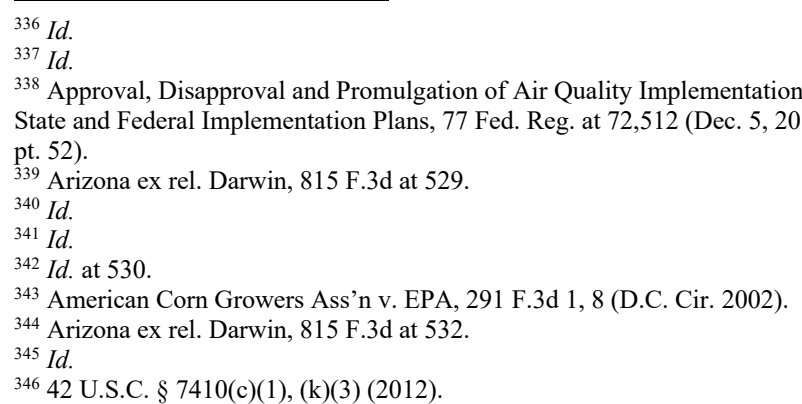


well as BART determinations that are not dependent on achieving the visibility goals. ${ }^{347}$ EPA concluded the State's BART determinations were deficient because: (1) the cost calculations were not performed in accordance with the Guidelines and were otherwise unreasonable; (2) the visibility improvements for all the Class I areas were not properly evaluated; and (3) the State inadequately explained its consideration of the BART factors. 348

Cost calculations are critical to determining whether a BART control is cost effective based on the annualized control cost for a ton of pollutant emissions removed. States are to develop estimates of capital and annual costs. Cost estimates should be documented either with data supplied by an equipment vendor or by a referenced source such as the Office of Air Quality Planning and Standards Control Cost Manual. The Cost Manual provides information concerning control technologies that is sufficient for a BART analysis, States are allowed to include additional information if they document any elements of the calculation that differs from the Cost Manual. The cost analysis should consider any site-specific design or other conditions that affect costs. ${ }^{349}$

Arizona did not provide cost information at a level of detail that included line item costs for the Coronado facility. This omission caused EPA to believe the BART analysis was inadequate because it did not properly consider the cost. Thus, the court held that EPA's disapproval was not arbitrary, capricious, or an abuse of discretion. States are required by statute to consider the costs of compliance when making BART determinations, and if they are not presented with enough data to do so, EPA may reasonably conclude that their analysis is inadequate. ${ }^{350}$

EPA also found Arizona's interpretation of the visibility modeling for all three plants "problematic," which resulted in an understating of the visibility benefits associated with installing SCR technology at Coronado. The court ruled that the State's visibility analysis was based on the evaluation of appropriate factors rationally, but it deferred to the Agency's conclusions. Arizona averaged the visibility benefits at the closest nine Class I areas, but it did not evaluate the benefits separately at the most impacted Class I area. States may assess visibility improvements due to BART controls by one or more methods. The indexing approach, therefore, "could be acceptable in itself as part of assessing multiple area impacts and improvements." But here, the averaging process that was used caused large benefits at some individual areas to be diluted or lost. EPA claimed Arizona's visibility analysis was unreasonable because it used two assessment approaches. It used a visibility index average to analyze visibility benefits at Coronado, but its analysis for other plants considered visibility improvements only at the Class I area with the greatest modeled impact from a facility, rather than at all impacted Class I areas. This leads to the appearance that the State selected a methodology for each plant to minimize the visibility improvement achieved by the more stringent emission controls. ${ }^{351}$ Arizona made no attempt to explain

\footnotetext{
${ }^{347}$ Arizona ex rel. Darwin, 815 F.3d at 532.

${ }^{348}$ Id.

${ }^{349} \mathrm{Id}$. at 534

${ }^{350} \mathrm{Id}$. at $534-535$.

${ }^{351} \mathrm{Id}$. at 535 .
} 
why it used differing approaches to the visibility analysis for different facilities. Using inconsistent approaches without providing an explanation for that decision frustrates the review of the BART determination. ${ }^{352}$

Arizona also claimed the visibility improvements resulting from installing SCR, would have been "imperceptible" to the human eye. However, the Haze Rule of 2005 requires visibility improvement from an individual source that may not be perceptible, but still should be considered in setting BART because the contribution to haze may be significant relative to other source contributions in the Class I area ${ }^{353}$ Failing to consider less-than-perceptible contributions to visibility impairment violates the CAA's intent to have BART requirements apply to sources that contribute to, as well as cause, such impairment. 354

To support their BART determinations states must provide documentation for all required analyses, which includes complying with the BART five-factor analysis. ${ }^{355}$ States are to explain the reasons for adopting the technology they select and the reason alternative technologies were not selected unless the source has, or was committed to installing, the most stringent controls available. Although Arizona presented information relevant to each of the BART factors, it did not provide an explanation regarding how this information was used to develop its BART determinations or that it actually took into consideration the BART factors in making its determinations. ${ }^{356}$ It did not discuss how the results of the visibility index were weighed against the other BART factors for Coronado While Arizona's SIP included cost data, it provided no explanation regarding how cost information was used in arriving at its NOx BART determinations. ${ }^{357}$

The court found that Arizona provided no reasoning or rationale to justify its ultimate BART selection. ${ }^{358}$ It then concluded that Arizona did not adequately explain its $\mathrm{NO}_{X}$ BART determinations, which supports EPA's partial disapproval of the haze SIP. ${ }^{359}$ Although the CAA affords the states substantial authority to determine BART controls, the combination of these defects provided reasonable grounds for EPA to disapprove Arizona's BART determination as to $\mathrm{NO}_{\mathrm{X}}$ emissions limits at Coronado. Its partial disapproval of the SIP in this respect was not arbitrary or capricious. ${ }^{360}$

EPA's partial disapproval of Arizona's haze SIP led to the promulgation of a FIP that required SCR with low-NOX burners and overfire air as the most stringent available control option for $\mathrm{NO}_{\mathrm{X}}$ emissions for the Coronado. It thus proposed $\mathrm{NO}_{\mathrm{X}}$ emission limits of $0.05 \mathrm{lb} / \mathrm{mmBtu}$, based on a rolling 30-boiler-operating day average, but in the Final

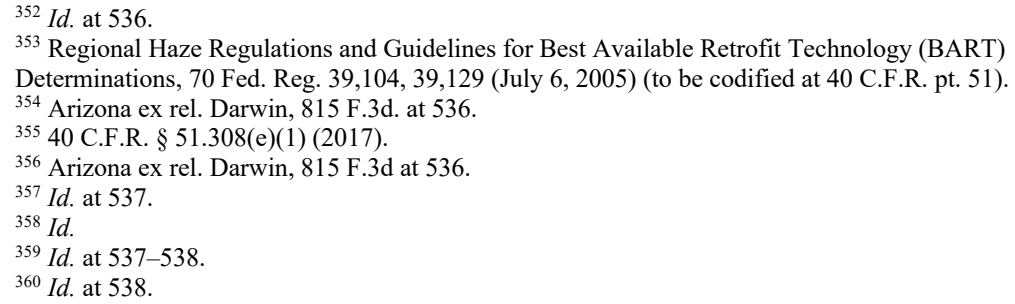


Rule EPA revised $\mathrm{NO}_{\mathrm{X}}$ emission limits to $0.065 \mathrm{lb} / \mathrm{mmBtu}$, which was significantly more stringent than Arizona's $0.32 \mathrm{lb} / \mathrm{mmBtu}_{\mathrm{NO}}$ limit. $^{361}$

EPA must perform the same BART analysis as a state when promulgating a regional haze FIP. ${ }^{362}$ Challenges to the FIP are reviewed under the arbitrary and capricious standard as well. The Salt River Project Agricultural Improvement and Power District ("SRP") petitioner claimed EPA's cost and visibility analyses was arbitrary and capricious, and the FIP's $\mathrm{NO}_{\mathrm{X}}$ emission limits were neither achievable nor reasonable. The court rejected these claims except for the challenge to EPA's use of a cumulative approach in its visibility analysis. ${ }^{363} \mathrm{EPA}$ aggregated the improvements that would occur at each of the Class I areas potentially impacted by Coronado's emissions. ${ }^{364}$ SRP contended this analysis resulted in "a large deciview number" that does not represent the actual perception of visibility conditions at any particular Class I area. ${ }^{365}$

EPA's modeling showed that SCR control technology would result in visibility benefits at each of eleven Class I areas. The court held that the record did not support SRP's claim that EPA relied on the cumulative methodology, and SRP's claim that "human perception" was the determinative "cornerstone" for the BART determinations for each individual source was overstated. The court held that the Final Rule provided a fully adequate explanation of its application of the deciview concept in the FIP. The Guidelines suggest that states use a minimum threshold of 0.5 deciviews to determine whether a source is subject to BART controls. EPA explained that smaller improvements should be considered in BART determinations, and the court held this was consistent with the statute and the regulatory requirements, and was supported by the record..$^{366}$

SRP also challenged the cost analysis because it did not follow the Guidelines, it was inadequate to support the BART determination, and was flawed because of rigid adherence to the Cost Manual irrespective of site-specific costs. EPA used a component of the Integrated Planning Model ("IPM") to develop its cost estimates. SRP claims that EPA ignored the Coronado facility's "site-specific characteristics," and so understated the actual costs of compliance for installing controls at Coronado. ${ }^{367}$ EPA, however, explained it used databases of actual SCR projects from 2004, 2006, and 2009 and it conducted supplemental cost analyses that relied upon "cost estimates provided by SRP." The court ruled that EPA's analysis was reasonable. ${ }^{368}$ Using a costing methodology that focuses on achieving consistency and facilitating comparisons allows the Agency to promulgate national regulations concerning BART determinations. Thus, the court rejected SRP's argument that the FIP's underlying cost analysis was arbitrary and capricious.

In addition to its substantive challenges to the FIP, Arizona contended that EPA

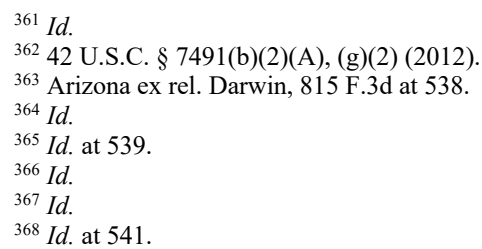


erred in promulgating the FIP in the same rule as its partial disapproval of the SIP, but the court disagreed. The FIP may be promulgated at the same time as the partial disapproval of the SIP. ${ }^{369}$ Further, as stated in the Final Rule, the State remains free to, at any time, to submit a revised SIP to replace the FIP. ${ }^{370}$

\section{§ 3(a)(5). State of Arizona v. EPA.}

On April 3. 2017, the Ninth Circuit decided the State of Arizona v. EPA. ${ }^{371}$ Plaintiffs in this case are the State of Arizona, a cement kiln owner, and a copper smelter owner that are subject to BART controls. They sought review of EPA's FIP that was promulgated for Arizona. ${ }^{372}$ The Ninth Circuit held that imposing SNCR control on a cement kiln and limiting $\mathrm{NO}_{\mathrm{x}}, \mathrm{PM}$, and $\mathrm{SO}_{2}$ emissions from copper smelters was not arbitrary or capricious but was valid rulemaking. ${ }^{373}$ This controversy began when Arizona, which has twelve wilderness areas subject to CAA section 169A's haze requirements, submitted a SIP that was rejected by EPA and a FIP was issued. ${ }^{374}$ The portions of Arizona's SIP that EPA rejected involved the BART control analyses and determinations as well as the long-term strategies for making reasonable progress. ${ }^{375}$ The reasonable progress issue was previously discussed. ${ }^{376}$

EPA rejected Arizona's BART analysis. Arizona had identified CalPortland's cement kiln as a source that might contribute to visibility impairment, but it failed to conduct the requisite CAA $\S 169 \mathrm{~A}(\mathrm{~g})(2)$ analysis in its SIP. ${ }^{377}$ EPA engaged in its own balancing of the factors listed in section 169A and proposed that CalPortland install SNCR having a 50\% control-efficiency, although it sought comments concerning whether a different SNCR control efficiency was appropriate. ${ }^{378}$ In the final rule, it reduced the control efficiency requirement to $35 \% .{ }^{379}$ It also proposed and finalized an annual limit of 40 tons per year of $\mathrm{NO}_{\mathrm{x}}$ from Asarco's copper smelter and a second non-party smelter, which is consistent with the current emissions from the smelters, to ensure that the smelters would not drastically increase their emissions. ${ }^{380}$

The Asarco smelter was also subject to proposed limits on particulate and $\mathrm{SO}_{2}$ emissions. But the Agency determined that the estimated level of visibility improvement

\footnotetext{
${ }^{369}$ Arizona ex rel. Darwin, 815 F.3d at 543.

${ }^{370}$ Id. ; see also Approval, Disapproval and Promulgation of Air Quality Implementation Plans; Arizona; Regional Haze State and Federal Implementation Plans, 77 Fed. Reg. at 72,512, 72,571 (Dec. 5, 2012) (codified at 40 C.F.R. pt. 52).

${ }^{371}$ Arizona ex rel. Darwin v. EPA, 852 F.3d 1148 (9th Cir. 2017).

${ }^{372}$ Id.

${ }^{373} \mathrm{Id}$.

${ }^{374} \mathrm{Id}$. at 1151 .

${ }^{375} \mathrm{Id}$. at 1154 .

${ }^{376}$ See discussion, supra $\S 2$ (a).

${ }^{377}$ Arizona ex rel. Darwin, 852 F.3d at 1154

${ }^{378} \mathrm{Id}$.

${ }^{379} \mathrm{Id}$. at 1155 .

${ }^{380} \mathrm{Id}$. at $1154,1156$.
} 
from additional BART $\mathrm{NO}_{\mathrm{x}}$ controls was not worth the cost. ${ }^{381}$ EPA proposed and then incorporated emission limitations from the National Emission Standard for Hazardous Air Pollutants for Primary Copper Smelting at $40 .{ }^{382}$ EPA addressed $\mathrm{SO}_{2}$ emissions from Asarco's smelter by approving the technology the company was already using in order to require a control efficiency of about $99.8 \%$ on a 30-day rolling average, which Asarco said its technology could meet. ${ }^{383}$

Several issues in this case were rejected because they were not raised during the notice-and-comment period. The remaining issues resulted in a finding that the EPA's control measures were not arbitrary or capricious and thus constituted valid agency rulemaking. ${ }^{384}$ The technical challenges to the emission controls were given due deference. ${ }^{385}$

\section{$\S 3(b)$. Alternatives to BART}

The 1999 regulations provide an option for some states to avoid imposing BART requirements. It is known as the WRAP Annex, for the nine western states and Indian tribes within the region based on the final report issued by the GCVTC in 1996 aimed at improving visibility in the sixteen Class I areas located on the Colorado Plateau. ${ }^{386}$ It specifies emissions control strategies including stationary, area and mobile sources. ${ }^{387}$ The provisions for adoption of strategies based on the GCVTC recommendations does not preclude the States and tribes from adopting additional control strategies for achieving reasonable progress in other Class I areas. ${ }^{388}$ EPA established specific SIP requirements for the time period 2003 through 2018 based on demonstrations by the GCVTC, which satisfies the requirements for review of the statutory factors as provided for under subsection 51.308(d). ${ }^{389}$ EPA's position was that a SIP that meets section 51.309's requirements would satisfy the requirement for reasonable progress and minimize the analyses required of States, compared to States making an independent submittal under section 51.308. After the end of 2018, the section 51.309 option ends and an implementation plan is required based on the requirements of section $51.308(f) .{ }^{390}$

\footnotetext{
${ }^{381} \mathrm{Id}$. at 1155 .

${ }^{382}$ Id. at 1155,1156 . See 40 C.F.R. pt. 63 , subpt. QQQ.

${ }^{383}$ Arizona ex rel. Darwin, 852 F.3d. at 1156.

${ }^{384} \mathrm{Id}$. at 1152.

${ }^{385} \mathrm{Id}$. at 1161 .

38640 C.F.R. § 51.308 (1999).

${ }^{387}$ Regional Haze Regulations, 64 Fed. Reg. 35,714, 35,765 (July 1,1999) (codified at 40 C.F.R. pt. 51).

${ }^{388} \mathrm{Id}$.

${ }^{389} \mathrm{Id}$.

39040 C.F.R. $\S 51.309$ (d)(1) (1999).
} 
EPA revised the Regional Haze Rule on October 13, 2006. ${ }^{391}$ The Rule provides that a State may implement an emissions trading program or another alternative measure as an alternative to requiring BART if it achieves a greater reasonable progress than would be achieved through BART. ${ }^{392}$ This requires an analysis by the state of the projected emissions reductions achievable through the trading program or other alternative measure. ${ }^{393}$ To utilize this option, a State must "provide a detailed description of the emissions trading program or other alternative measure, including schedules for implementation, the emission reductions required by the program, all necessary administrative and technical procedures for implementing the program, rules for accounting and monitoring emissions, and procedures for enforcement." ${ }^{394}$ The state must show by the clear weight of the evidence that the alternative measure achieves greater reasonable progress than would be achieved through BART. ${ }^{395}$ This can entail consideration of many factors. ${ }^{396}$ The emission reductions must be surplus to those achieved by measures adopted to meet requirements of the CAA as of the baseline date of the SIP. ${ }^{397}$

The 2006 Haze Rule amended the generally applicable provisions found at 40 C.F.R. $§ 51.308(\mathrm{e})(2)$, which describes the analysis needed to determine the emissions reductions that can be achieved using BART compared to an alternative program. The 2006 Rule also established minimum elements for a cap and trade program and provides BART guidelines for electric generating units ("EGUs"). The Rule amended 40 C.F.R. § 51.309 to enable GCVTC States and Tribes to continue to utilize the optional strategies contained in the GCVTC report. ${ }^{398}$ States with the authority to implement an emissions trading program or other alternative measures in lieu of imposing BART have the flexibility to design programs to reduce emissions from stationary sources in more cost-effective manners so long as they can demonstrate that the alternative approach will achieve greater reasonable progress than would be achieved from implementing BART requirements. ${ }^{399}$

The 2006 Haze Rule makes it clear that emissions reductions that could be achieved by the implementation of the BART provisions found in section 51.308(e)(1) are to be used as the benchmark against which an alternative program can be compared. Where a trading program or other similar alternative program has been designed primarily to meet a Federal or State requirement other than BART, the State can use a simplified method to demonstrate the alternative program will result in greater reasonable progress than BART. This approach could entail separate visibility analyses to: (1) determine the sources subject

${ }^{391}$ Regional Haze Regulations; Revisions to Provisions Governing Alternative to Source-Specific-Best Available Retrofit Technology (BART) Determinations, 71 Fed. Reg. 60,612 (Oct. 13, 2006) (codified at 40 C.F.R. pt. 51).

39240 C.F.R. $\S 51.308(\mathrm{e})(2)(2017)$

${ }^{393}$ Id. $\S 51.308(\mathrm{e})(2)(\mathrm{D})$.

${ }^{394}$ Id. $\$ 51.308(\mathrm{e})(2)(\mathrm{D})(\mathrm{iii})$.

${ }^{395} I d$. $\$ 51.308(\mathrm{e})(2)(\mathrm{i})(\mathrm{E})$.

${ }^{396}$ See Regional Haze Regulations; Revisions to Provisions Governing Alternative to Source-Specific-Best Available Retrofit Technology (BART) Determinations, 71 Fed. Reg. 60,612, 60,612 (Oct. 13, 2006) (codified at 40 C.F.R. pt. 51).

39740 C.F.R. $\S 51.308(e)(2)(D)(i v)$ (2006).

${ }^{398}$ Regional Haze Regulations, 71 Fed. Reg. at 60,614.

${ }^{399}$ Id. 
to BART; (2) determine what BART is for the sources; and (3) determine the visibility improvement anticipated from all sources subject to BART. ${ }^{400}$ States have the discretion to employ a cumulative visibility analysis for purposes of estimating the potential visibility impacts of BART. EPA interprets the American Corn Growers and CEED cases, as not allowing the Agency to require states to use a cumulative visibility approach to estimate the improvement achievable from BART, but states may use such an approach if they so choose. $^{401}$

Fossil fuel-fired power plants with a total generating capacity of greater than $750 \mathrm{MW}$, are required to have BART determinations as specified in EPA's guidelines. ${ }^{402}$ The guidelines require the use of CALPUFF or another appropriate dispersion model to determine the visibility improvement expected from the BART control technology being evaluated. ${ }^{403}$ EPA considers CALPUFF is the best model for predicting visibility impacts from single sources. ${ }^{404}$ EPA assumed States would adopt trading programs, or other substantially similar programs as alternatives to source-by-source BART. ${ }^{405}$

The 2006 Haze Rule generally requires states to undertake source specific BART analyses for each source subject to BART in order to estimate the emissions reductions achievable under the source-by-source BART requirements. This BART benchmark enables a State to design an alternative "better than BART" program and may be based on a simplified BART analysis if trading programs are used and are able to meet CAA requirements other than BART. ${ }^{406}$ If a trading program or other alternative measures are used, EPA will allow this to be used as a substitute for BART for some source categories, while still requiring source-by-source BART analysis for BART-eligible sources in any source categories not covered by the alternative program. ${ }^{407}$ Any BART-eligible sources not included in an alternative program would remain subject to the general requirements governing BART sources. ${ }^{408}$

The alternative program of 40 C.F.R. $\$ 51.309$ will have limited applicability in the future. Its provisions only apply to 16 Class I areas covered by the GCVTC report, but only three states rely on this provision and only for their SIPs covering the first regional implementation period through $2018 .{ }^{409}$

\section{§ 3(b)(1). WildEarth Guardians v. EPA}

\footnotetext{
${ }^{400} \mathrm{Id}$. at 60,615 .

${ }^{401} \mathrm{Id}$. at 60,616 .

40240 C.F.R. $\S 51.308(\mathrm{e})(1)(\mathrm{ii})(\mathrm{B})$ (2006).

${ }^{403}$ Regional Haze Regulations, 71 Fed. Reg. at 60,616.

${ }^{404}$ Id.

${ }^{405} \mathrm{Id}$. at 60,617 .

${ }^{406} \mathrm{Id}$. at 60,618 .

${ }^{407} I d$. at 60,619 .

${ }^{408} \mathrm{Id}$. at 60,620 .

${ }^{409}$ Protection of Visibility: Amendments to Requirements for State Plans, 82 Fed. Reg. 3,078, 3,120 (Jan.

10, 2017) (codified at 40 C.F.R. pt. 51, 52).
} 
On October 21, 2014, the Tenth Circuit decided WildEarth Guardians v. EPA, a case involving environmental organizations petition for review of EPA's approval of a regional cap-and-trade program to regulate $\mathrm{SO}_{2}$ emissions from sources in the Colorado Plateau. ${ }^{410}$ Three states (New Mexico, Utah, and Wyoming), one city (City of Albuquerque), and one county (Bernalillo County) adopted a regional cap-and-trade program to reduce $\mathrm{SO}_{2}$ emissions. Sources of these emissions were allowed a limited number of tons of $\mathrm{SO}_{2}$ that could be emitted. With these allocations, polluters had a choice. ${ }^{411}$ They could use the allocations or cut emissions and trade the unused portions of their allocation. This program was available because states affecting visibility over the Colorado Plateau are allowed to use an alternative program in lieu of BART if EPA approved it as being better than BART for improving air visibility.

EPA approved the program because: it covered polluters that would not have been subject to BART, and it covered new sources not subject to BART. Furthermore, it encouraged polluters to expedite equipment upgrades and to operate below full capacity. ${ }^{412}$ The five environmental petitioners argued that the EPA should not have approved the trading program. The Tenth Circuit using an arbitrary and capricious test had to determine whether to support EPA's approval and determine whether the trading program was better than BART. The court concluded that the EPA's decision was neither arbitrary nor capricious and denied the petitions for review. ${ }^{413}$

EPA had previously established the GCVTC, which recommended a regional capand-trade program for $\mathrm{SO}_{2}$ to become effective when participating states exceed an emissions target. ${ }^{414}$ When WRAP replaced the GCVTC it continued to recommend a cap_and-trade program for $\mathrm{SO}_{2}$ that would act as a "backstop" if emissions exceeded milestone targets. ${ }^{415}$ In 1999, the EPA adopted the Transport Commission's recommendations in its Regional Haze Rule that allows a cap-and-trade program if participants expected better results than they would have had under BART regulations. ${ }^{416}$ This involved adopting measures to reduce $\mathrm{SO}_{2}$ through milestones providing "steady and continuing emissions reductions through 2018" after which they remain constant until a revised Haze SIP is approved. ${ }^{417}$ The milestones must provide for a $\mathrm{SO}_{2}$ reduction of 50 to $70 \%$ from 1990 emissions by $2040 .{ }^{418}$ For sources that exceed their allowances, there is a financial penalty and a loss of allocated emissions. For sources that reduce emissions ahead of schedule, the program provides for additional allowances. ${ }^{419}$ If the state has sources not covered by the cap-and-trade program, they are subject to the long-term program under 40 C.F.R. $\S$ 51.309. ${ }^{420}$

\footnotetext{
${ }^{410}$ WildEarth Guardians v. EPA, 770 F.3d 919 (10th Cir. 2014).

${ }^{411} I d$. at 923 .

412 Id.

${ }^{413}$ Id.

${ }^{414} I d$. at 925 .

415 Id.

41640 C.F.R. $\$ 51.309$ (1999).

${ }^{417}$ Id. $\S 51.309(\mathrm{~d})(4)$.

${ }^{418}$ WildEarth Guardians v. EPA, 770 F.3d at 925.

${ }^{419}$ Id. at $925-926$.

${ }^{420} \mathrm{Id}$. at 926 .
} 
The western participants in the "309 program" submitted revisions to EPA, but before the Agency could act, the D.C. Circuit invalidated part of the haze rule methodology. ${ }^{421}$ The D.C. Circuit held that an alternative program could satisfy the reasonable progress goals. ${ }^{422}$ Subsequently, in 2006, EPA revised the Regional Haze Rule's, which forced the participating states to resubmit haze plans. ${ }^{423}$ New Mexico, Utah, Wyoming, the City of Albuquerque, and Bernalillo County resubmitted plans, but Arizona and Oregon then dropped out of the 309 program. ${ }^{424}$ The 309 program submissions were projected to outperform BART by: encouraging early cuts in emissions; by covering 63 more emission sources; capping growth in new sources; addressing mobile sources, fire, and clean air corridors that are not covered by BART; and establishing an absolute limit on allowable emissions. ${ }^{425}$ In late 2012, EPA approved the 309 program plans, which led to this lawsuit to determine whether EPA acted in a manner that was "arbitrary, capricious, an abuse of discretion, or otherwise not in accordance with law." 426 The environmental petitioners argued that the approved 309 programs did not achieve greater reasonable progress than the implementation of BART. They claimed the programs would not achieve reasonable progress because only three of the nine eligible states participated, and New Mexico's program was deficient because of the failure to analyze emissions from the Escalante coal plant. The court rejected these arguments. ${ }^{427}$

To determine whether an alternative program is better than BART, the regulations require a comparison of an established BART benchmark that provided predictable emission reductions from BART with a prediction of the emission reductions from an alternative program. ${ }^{428}$ The states used the presumptive benchmark in the regulations as the basis for the BART-based emissions estimate, but the petitioners wanted sourcespecific data. However, the court recognized an exception that exists when the alternative program is designed to achieve a requirement other than BART, such as the reasonable progress goals. In this situation, a state can determine the BART benchmark "based on both source-specific and category-wide information, as appropriate." 429 The states assumed that all utilities subject to BART operated at the presumptive rate for $\mathrm{SO}_{2}$ established in 40 C.F.R. Part 51, Appendix Y, except for two power plants in Utah where a lower emission rate was used. ${ }^{430}$ The court held that the petitioners could not object to this approach because their remedy would have been to file for a petition for review of the Regional Haze Rule within 60 days of publication. ${ }^{431}$ EPA's "regulations expressly allowed participants to use the presumptive benchmark to predict emissions instead of assessing how much pollution would be emitted from each source under a BART

\footnotetext{
${ }^{421}$ American Corn Growers Ass'n v. EPA, 291 F.3d 1, 8-9 (D.C. Cir. 2002).

${ }^{422}$ Center for Energy \& Econ. Dev. V. EPA, 398 F.3d 653 (D.C. Cir. 2005).

${ }^{423}$ WildEarth Guardians v. EPA, 770 F.3d at 926.

${ }^{424} \mathrm{Id}$.

${ }^{425} \mathrm{Id}$. at 927.

${ }^{426}$ See Id.. See also 5 U.S.C. § 706(2)(A) (2012).

${ }^{427}$ WildEarth Guardians v. EPA, 770 F.3d at 928.

42840 C.F.R. $\S 51.308(\mathrm{e})(2)(2017)$.

${ }^{429}$ WildEarth Guardians v. EPA, 770 F.3d at 929.

${ }^{430} \mathrm{Id}$.

${ }^{431} \mathrm{Id}$. at 930 .
} 
regime." ${ }^{432}$ Some of the other objections raised by petitioners were rejected based on timeliness. In the end, the court held that EPA did not act arbitrarily or capriciously when it approved the participants' implementation plans. ${ }^{433}$

\section{$\S 3(b)(2)$. National Parks Conservation Association v. McCarthy}

The Eighth Circuit on March 14, 2016, decided National Parks and Conservation Ass' $n$ v. McCarthy case. ${ }^{434}$ The case involved Minnesota's use of the Transport Rule rather than BART to determine the technology required to control emissions from EGUs. The Transport Rule aspects of the case were discussed previously at $\S 2$ (B). However, the case is one of the few U.S. Court of Appeals decisions to deal with alternatives to BART.

Minnesota has two Class I federal areas: Boundary Waters Canoe Area Wilderness and Voyageurs National Park. It has five EGUs subject to BART. For these EGUs, Minnesota adopted the Transport Rule as an alternative to source-specific BART, which was approved by EPA. ${ }^{435}$ Conservation organizations then challenged EPA's approval claiming the Transport Rule allowances in the Plan are not better than BART. ${ }^{436}$ The court held that because EPA acted rationally and within its sphere of expertise, the conservation organizations' petition for review of the Minnesota Haze Plan's reasonable-progress goals was denied. ${ }^{437}$

\section{§3(c). The 2017 Revisions to the Haze Rule}

On January 10, 2017, EPA finalized revisions to the Haze Rule. ${ }^{438}$ The revisions clarify the relationship between the states' long-term obligations and the reasonable progress goals found in their SIPs. The Haze Rule modifications change the requirements that states and some tribes need to meet for the second and subsequent implementation periods. The final rule supports continued environmental progress by retaining much of the 1999 Regional Haze Rule. ${ }^{439}$ It clarifies the relationship between reasonable progress goals in state plans and the long-term strategy obligations of all states to meet the national goal. ${ }^{440}$ The four statutory factors (costs of compliance, time necessary for compliance, energy and non-air quality environmental impacts, and remaining useful life $)^{441}$ must be evaluated in each implementation period to determine the rate of progress towards natural visibility

\footnotetext{
${ }^{432}$ Id.

${ }^{433} \mathrm{Id}$. at 944.

${ }^{434}$ National Parks Conservation Ass'n v. McCarthy, 816 F.3d 989 (8th Cir. 2016).

$435 \mathrm{Id}$. at 992 .

${ }^{436} \mathrm{Id}$. at 994

${ }^{437}$ Id. at 997.

${ }^{438}$ Protection of Visibility: Amendments to Requirements for State Plans, 82 Fed. Reg. 3,078, 3,078 (Jan.

10, 2017) (codified at 40 C.F.R. pt. 51, 52).

${ }^{439} \mathrm{Id}$. at 3080 .

${ }^{440}$ Clean Air Act $\S 169 A(b)(2)(B), 42$ U.S.C. $\S 7491(b)(2)(B)(2012)$

44142 U.S.C. $\S 7492(\mathrm{~g})(2)(2012)$.
} 
conditions. ${ }^{442}$ The States must determine whether additional progress would be reasonable based on applying the four factors. ${ }^{443}$ Even if the rate of progress in some Class I areas meet or exceed the uniform rate of progress needed to achieve natural visibility conditions by 2064 , the states must conduct the required analysis and determine whether additional progress would be reasonable based on the four factors. ${ }^{444}$

These clarifications reflect long-standing interpretation of the Regional Haze Rule by EPA. ${ }^{445}$ The revisions related to how days are selected for visibility progress tracking will provide more meaningful information on how emission reduction measures contribute to reasonable progress in reducing visibility impairment. ${ }^{446}$ FLMs consultation requirements aim to ensure FLMs can more meaningfully contribute to the state's deliberations. ${ }^{447}$

The July 31, 2018 deadline for states to submit SIP revisions for the second implementation period was extended to July $31,2021 .{ }^{448}$ The 2028 date for the end of the second implementation period remains unchanged. No other changes were made concerning the due dates for future periodic comprehensive SIP revisions. ${ }^{449}$ EPA finalized its proposal to replace its process for assessment of reasonably attributable visibility impairment with an as-needed approach. ${ }^{450}$ The as-needed approach only applies to the determination of reasonably attributable visibility impairment. If a source or a small number of sources in a state without any Class I area causes reasonably attributable visibility impairment at a Class I area in another state, the state is subject to the Haze Rule. ${ }^{451}$

Alaska, the Utility Air Regulatory Group and several electric utilities have filed petitions with EPA to reconsider the Haze Rule. ${ }^{452}$ The rule is also being challenged as part of the consolidated litigation in the D.C. Circuit in State of Texas v. EPA. Numerous states, industries, and environmental organizations are litigating, and several environmental organizations have intervened to support EPA. ${ }^{453}$ Industry and some states are expected to sue to prevent EPA from requiring states to develop a long-term haze control program before developing reasonable progress objectives. Environmentalists object to EPA's method of calculating baseline visibility conditions and they object to defining wildfires as

\footnotetext{
442 Protection of Visibility: Amendments to Requirements for State Plans, 82 Fed. Reg. 3,078, 3,080 (Jan. 10, 2017) (to be codified at 40 C.F.R. pt. 51, 52).

${ }^{443} I d$.

${ }^{444}$ Id.

${ }^{445} \mathrm{Id}$.

${ }^{446} I d$.

${ }^{447}$ Id.

${ }^{448} I d$.

${ }^{449} \mathrm{Id}$.

${ }^{450} \mathrm{Id}$. at 3,081 .

${ }^{451} \mathrm{Id}$.

${ }^{452}$ Stuart Parker, Trump EPA Urged to Reconsider Obama Revisions to Regional Haze Rule, INSIDE EPA: DAILY NEWS (Apr. 17, 2017), https://insideepa.com/daily-news/trump-epa-urged-reconsider-obamarevisions-regional-haze-rule.

${ }^{453}$ Id.
} 
natural events even if they are caused by deliberate or accidental human action. ${ }^{454}$ This litigation will complicate the efforts to develop SIP revisions for the second ten-year implementation period that begins in 2018 where the focus will be on long-term strategy and reasonable progress goals, rather than the BART requirements that were the focus of the SIP revisions during the first phase of the program, which ran from 2008-2018. ${ }^{455}$ In January 2018, the Trump Administration's EPA announced it would revisit aspects of the 2017 regulation including its Reasonably Attributable Visibility Impairment provision. ${ }^{456}$

\section{§ 4. Visibility in Grand Canyon National Park}

The 1990 CAA Amendments added CAA $\S 169 \mathrm{~B}$ that required studies and provides the authority to establish visibility transport regions and visibility transport commissions to deal with interstate transport of pollutants that contribute to visibility impairment. ${ }^{457}$ Section 169B(f) required that the GCVTC be established. ${ }^{458}$ The views that make Grand Canyon National Park one of the world's most spectacular sights are impaired by air pollution, primarily due to fine suspended sulfate (" $\mathrm{SO}_{4}$ ") particles whose primary source is $\mathrm{SO}_{2}$ emissions from anthropogenic sources. The haze is especially serious in the winter. One of the important strategies of the new regional haze program is to establish regional milestones for $\mathrm{SO}_{2}$ reduction. ${ }^{459}$

On November 13, 1991, EPA established the GCVTC under the authority granted by CAA $\S 169 \mathrm{~B}(\mathrm{f}){ }^{460}$ The Commission was to focus on the Class I areas on the Colorado Plateau near the Grand Canyon in the "Golden Circle" that includes most of the national parks and wilderness areas in the region. ${ }^{461}$ The voting members were Arizona, California, Colorado, Nevada, New Mexico, Oregon, Utah, Wyoming, the Acoma Pueblo, the Hopi Tribe, the Hualapai Tribe, the Navajo Nation, and the Columbia River Intertribal Fish Commission. There were six non-voting members, including EPA. ${ }^{462}$

During the 1980s, EPA began to study the visibility impairment of the Grand Canyon. In 1987, the National Park Service carried out the Winter Haze Intensive Tracer Experiment. This data led to the conclusion that the Navajo Generating Station ("NGS")

\footnotetext{
${ }^{454}$ Stuart Parker, States, Industries Attack EPA Policy Shift in Revised Regional Haze Rule, InSIDE EPA: DAILY NEWS (Apr. 17, 2017), https://insideepa.com/daily-news/states-industries-attack-epa-policy-shiftrevised-regional-.

${ }^{455}$ Parker, supra note 454.

${ }^{456}$ Jennifer Lu, EPA to Reopen Obama-Era Visibility Improvement Rule, BLOOMBERG ENVIRONMENT \& ENERGY REPORT (Jan. 19, 2018), https://bnanews.bna.com/environment-and-energy/epa-to-reopen-obamaera-visibility-improvement-rule.

45742 U.S.C. $\$ 7492$ (1990).

45842 U.S.C. $\$ 7492(\mathrm{f})(1990)$.

45940 C.F.R. $\$ 51.308(d)(4)(1990)$.

${ }^{460}$ Grand Canyon Visibility Transport Commission; Meeting, 56 Fed. Reg. 57,522, 57,523 (Nov. 12, 1991).

${ }^{461}$ Regional Haze Regulations, 64 Fed. Reg. 35,714, 35,749 (July 1,1999) (codified at 40 C.F.R. pt. 51).

${ }^{462}$ See EPA's Fact Sheet: Proposed Regional Haze Regulations for Protection of Visibility in National Parks and Wilderness Areas (July 18, 1997); see also Vickie Patton \& Bruce Polkowsky, EPA's Regional Haze Proposed: Protecting Visibility in National Parks and Wilderness Areas, 11 Tulane ENVTL. L.J. 299,311 (1998).
} 
was responsible for approximately $70 \%$ of the sulfate particulates and $40 \%$ of the lightextinguishing aerosols during the winter. ${ }^{463}$ The NGS is a 2250 megawatt coal-fired electric power plant located on the Navajo Nation near Page, Arizona. ${ }^{464}$ It is 15.5 miles from the park border and about fifty-eight miles from Grand Canyon Village. ${ }^{465}$ It is the largest coal-fired plant in the western United States, and emits large quantities of several pollutants that affect visibility at Class I national parks and wilderness areas, including the Grand Canyon National Park. The NGS is owned by four utilities (the Salt River Project, Arizona Public Service Co., NV Energy, and Tucson Electric Power) and the Department of Interior (through the U.S. Bureau of Reclamation), ${ }^{466}$ which powers a water distribution system that meets over $20 \%$ of Arizona's water demands. ${ }^{467}$ The utilities operate the NGS under a lease that bars the Navajo Nation from controlling or regulating the operation of the facility. ${ }^{468}$

EPA proposed a $70 \%$ reduction in $\mathrm{SO}_{2}$ emissions from the $\mathrm{NGS}$, calculated on a thirty-day average basis. ${ }^{469}$ EPA's air office staff claimed $90 \%$ control, based on a thirtyday rolling average basis, was cost effective; EPA wanted to avoid visibility rulemaking and the inevitable fight with the Office of Management and Budget and Vice President Quayle's Council on Competitiveness that championed industry's position. ${ }^{470}$ Environmentalists led by the Environmental Defense Fund, pressured EPA to control the NGS. ${ }^{471}$ In August 1991, EPA announced an agreement to reduce $\mathrm{SO}_{2}$ emissions from the facility by 1993 and to achieve a $90 \%$ reduction by 1999 based on an annual average basis. ${ }^{472}$ Because the NGS is located on the Navajo Nation, it is subject to the jurisdiction of EPA and the Navajo Nation. ${ }^{473}$ A FIP for Arizona was imposed, which required BART to be installed on the NGS. ${ }^{474}$

\footnotetext{
${ }^{463}$ U.S. Nat'l Research Council, Haze in the Grand Canyon: An Evaluation of the Winter HAZE INTENSIVE TRACER EXPERIMENT 1 (1990).

${ }^{464}$ Navajo Generating Station, SRP, https://www.srpnet.com/about/stations/ngs/default.aspx (last visited Oct. 3, 2018).

${ }^{465}$ HAZE IN THE GRAND CANYON, supra note 463.

${ }^{466}$ Approval of Air Quality Implementation Plans; Navajo Nation; Regional Haze Requirements for Navajo Generating Station, 79 Fed. Reg. 46,514 (Aug. 8, 2014) (to be codified at 40 C.F.R. pt. 49).

467 Approval of Air Quality Implementation Plans; Navajo Nation; Regional Haze Requirements for Navajo Generating Station, 78 Fed. Reg. 8,274, 8,275, 8,283 (proposed Feb. 5, 2013) (to be codified at 40 C.F.R. pt. 49).

${ }^{468}$ See Salt River Project Agr. Imp. and Power Dist. v. Lee, 672 F.3d 1176, 1178 (9th Cir. 2012).

${ }^{469}$ Approval and Promulgation of Implementation Plans: Revision of the Visibility FIP for Arizona, 56 Fed. Reg. 5173 (proposed Feb. 8, 1991) (to be codified at 40 C.F.R. pt. 52).

${ }^{470}$ Grand Canyon -- Industry, Environmentalists Strike Deal over Plant Emissions, VIII ENVTL. POL'Y ALERT (Inside EPA) 17:7 (Aug. 21, 1991).

${ }^{471} I d$.

${ }^{472}$ Central Arizona Water Cons. Dist. v. EPA, 990 F.2d 1531 (9th Cir. 1993), cert. denied, 510 U.S. 828 (1993); see also Robert L. Glicksman, Pollution on the Federal Lands I: Air Pollution Law, 12 UCLA J. ENVTL. L. \& POL'Y 1, 49 (1993).

${ }^{473}$ See generally Arnold W. Reitze, Jr., The Control of Air Pollution on Indian Reservations, 46 EnVTL. L. 893 (2016)

${ }^{474}$ Approval and Promulgation of Implementation Plans: Revision of the Visibility FIP for Arizona, 56 Fed. Reg. 50,172 (Oct. 3, 1991) (to be codified at 40 C.F.R. pt. 52)
} 
The Grand Canyon visibility rulemaking is an example of negotiated rulemaking being used successfully in an environmental controversy. To meet a thirty-day average achieving a $70 \%$ reduction would have required the installation of back-up scrubbers at high cost. However, it was determined that $90 \%$ control on an annual basis could be achieved at a much lower cost. EPA would not allow annual averaging for health protection regulations, but was willing to accept this compromise in a regulation designed to protect aesthetic values. ${ }^{475}$ The key to this settlement was the active participation of the concerned parties and their ability to convince industry and EPA to accept the use of an annual average. ${ }^{476}$

Subsequent challenges to the control of emissions from the NGS were litigated. In 1993, the Ninth Circuit decided Central Arizona Water Conservation District v. EPA. ${ }^{477}$ Petitioners argued that in promulgating the visibility rule, ${ }^{478}$ EPA acted in excess of its statutory jurisdiction. The court concluded the Final Rule was legitimately promulgated and directed at "reasonably attributable" visibility impairment. ${ }^{479}$ Petitioners relied on Vermont $v$. Thomas, where the court held that EPA did not have the authority to regulate regional haze. ${ }^{480}$ In Thomas, the state of Vermont submitted to EPA a SIP which "proposed a federally enforceable 'long-term strategy' to combat the effects of regional haze" at the Lye Brook National Wilderness Area. The court held that without EPA rulemaking addressing regional haze, the state's regional haze measures were "outside the scope" of EPA's statutory and regulatory authority. ${ }^{481}$ Thomas involved a direct and explicit attempt to regulate "regional haze."

EPA acknowledged that the NGS was not the only source of visibility impairment at the Grand Canyon but argued it had the statutory authority to address that portion of the visibility impairment problem "reasonably attributable" to the Navajo plant even if the Final Rule addressed only a small fraction of the visibility impairment at the Grand Canyon. Congress mandated an extremely low threshold in section $169 \mathrm{~A}(\mathrm{~b})(2)(\mathrm{A})$, requiring the installment of stringent emission controls when an individual source emits any air pollutant that "may reasonably be anticipated to cause or contribute to any impairment of visibility" in a Class I area. ${ }^{482}$ Therefore, when EPA promulgates a FIP, it is given substantial discretion to determine whether visibility impairment is "reasonably attributable" to a given source. The court concluded that the technical scientific record more than adequately supported EPA's conclusion that visibility impairment in the Grand Canyon was "reasonably attributable" to the NGS. ${ }^{483}$

\footnotetext{
${ }^{475}$ D. Michael Rappoport \& John F. Cooney, Visibility at the Grand Canyon: Regulatory Negotiations Under the Clean Air Act, 24 ARIz. ST. L.J. 627 (1992). 
Generally, the CAA and its regulations require the application of BART once it has been determined that visibility impairment is "reasonably attributable" to an existing source. On February 5, 2013, EPA issued a proposed rule that BART for the NGS would include retrofitting all three NGS units with SCR by 2018. EPA also included two alternatives in its proposal. ${ }^{484}$ First, EPA chose not to adopt the emission control limits indicated by the NGS BART analysis. Instead it adopted an emission limitations standard that would produce greater visibility improvement at a lower cost. Second, EPA proposed an amended lease of the land from the Navajo Nation to the owner-operators of the NGS. ${ }^{485}$ The Ninth Circuit, in Central Arizona Water Conservation District, applied the U.S. Supreme Court's deferential Chevron standard and held that the Agency's reliance on the "reasonable progress" provisions is a "permissible construction of the statute," since "reasonable progress" is the overarching requirement that implementation plan revisions under section 169A must address. ${ }^{486}$ The case involved a proposed amended lease of the land from the Navajo Nation to the owner-operators of the NGS. ${ }^{487}$

EPA's s original focus on the NGS was regarded as unlikely to protect the Grand Canyon National Park from visibility impairment. Many sources account for a significant fraction of the Grand Canyon's haze, and many of these sources are either grandfathered or are minor sources that are not required to comply with the visibility program. This led to the regional haze program. Nevertheless, the amount of emissions generated by the NGS has continued to keep this facility the focus of government and environmentalists' pollution control efforts. Complicating the efforts to control emissions from the NGS is the dependence of the Navajo Nation and the Hopi Tribe on the $\$ 35$ million per year paid to the Nation, which is $30 \%$ of the Nation's yearly revenue and the $\$ 13$ million per year paid to the Hopi Tribe, which is $85 \%$ of their yearly revenue. ${ }^{488}$

\section{$\S 4(a)$. Yazzie v. EPA}

On March 20, 2017, the Ninth Circuit issued two concurrent opinions that involved the Navajo Nation FIP, which called for reductions in emissions from the NGS. ${ }^{489}$ In Yazzie v. EPA, the court ruled that because of the discretion that EPA enjoys, it could not conclude that the Agency acted arbitrarily and capriciously and thus the court denied the petitions. ${ }^{490}$ Petitioners Yazzie, several tribal conservation organizations, and non-profit environmental

\footnotetext{
${ }^{484}$ Summary of Navajo Generating Station Agreement, ENVTL. DEFENSE Fund, https://www.edf.org/sites/default/files/Fact\%20Sheet\%20July\%2025\%20-\%202013.pdf (last visited July 26, 2018).

${ }^{485}$ Yazzie v. EPA, 851 F.3d 960, 965 (9th Cir. 2017).

${ }^{486}$ Central Arizona Water Cons. Dist., 990 F.2d at 1543.

${ }^{487}$ Yazzie v. EPA, 851 F.3d at 965.

${ }^{488}$ Ian Frisch, The End of Coal Will Haunt Navajo Power Station, BloomBerg (Oct. 13, 2017, 5:00 AM), https://www.bloomberg.com/news/features/2017-10-13/the-end-of-coal-will-haunt-the-navajo.

${ }^{489}$ Yazzie, 851 F.3d at 960; Hopi Tribe v. EPA, 851 F.3d 957 (9th Cir. 2017).

${ }^{490}$ See Yazzie, 851 F.3d at 975; see also Arizona Pub. Serv. Co. v. EPA, 562 F.3d 1116 (10th Cir. 2009).
} 
organizations sought a review of EPA's FIP for the NGS. ${ }^{491}$ The CAA authorizes EPA to treat Indian tribes as States if the tribe meets specified requirements. ${ }^{492}$ The requirements are found in EPA's Tribal Authority Rule ("TAR"). ${ }^{493}$ The petitioners claimed that EPA could not issue the FIP under TAR because the Navajo Nation had agreed by contract not to regulate the NGS and, therefore, it could not issue a tribal implementation plan ("TIP"). ${ }^{494}$ However, the court held that 40 C.F.R. § 49.11(a) is not limited to "eligible" tribes that can be treated as a state. Rather, it applies so long as "a tribe" does not submit an approved TIP. ${ }^{495}$ Therefore, TAR authorizes EPA to promulgate a FIP. ${ }^{496}$ The Navajo Nation did not issue a TIP for the NGS, so in February 2013, EPA issued a proposed FIP as authorized by TAR. ${ }^{497}$

The FIP proposed a BART determination and a BART alternative. The BART determination called for a reduction in $\mathrm{NO}_{\mathrm{x}}$ emissions of nearly $80 \%$ within five years after the effective date of a final FIP, based on the use of SCR and LNB with SOFA technologies. Under the BART Alternative the FIP extended the time for achieving $\mathrm{NO}_{\mathrm{x}}$ emission reductions to 2023. ${ }^{498}$ In October 2013, EPA issued a supplemental proposal calling for the NGS to end conventional coal-fired power generation by the end of 2044. The revised plan also imposed a "lifetime cap" on $\mathrm{NO}_{\mathrm{x}}$ emissions from 2009 to $2044 .{ }^{499} \mathrm{In}$ August 2014, EPA issued a final rule that essentially adopted the supplemental proposal. ${ }^{500}$

The petitioners claimed EPA failed to comply with the statutory requirement requiring the Agency to implement BART within five years of the promulgation of a FIP. ${ }^{501}$ However, the court held the five-year deadline applied to BART, but did not apply to a BART Alternative. ${ }^{502}$ Petitioners challenged EPA's determination that the FIP was "better than BART," because it "will achieve greater reasonable progress than would have resulted from the installation and operation of BART." 503 The Regional Haze Regulations, provided three methods to show that an alternative will result in greater reasonable progress: "(1) "[i]f the distribution of emissions was not substantially different than under BART, and the alternative measure results in greater emission reductions;" "504 (2) if the distribution of emissions is significantly different, "dispersion modeling" must be conducted, which

\footnotetext{
${ }^{491}$ Yazzie, 851 F.3d at 965

49242 U.S.C. $§$ 7601(d)(1)(A) (2012); see generally Reitze, Jr., supra note 473.

${ }^{493}$ Indian Tribes: Air Quality Planning and Management, 63 Fed. Reg. 7,254 (Feb. 12, 1998) (to be codified at 40 C.F.R. pts. 9, 35, 49, 50, 81).

${ }^{494}$ Yazzie, 851 F.3d at 969.

${ }^{495} I d$. at 970 .

${ }^{496} \mathrm{Id}$. at 966 .

${ }^{497}$ Indian Tribes: Air Quality Planning and Management, 63 Fed. Reg. 7,254, 7,254 (Feb. 12, 1998) (to be codified at 40 C.F.R. pts. 9, 35, 49, 50, 81).

${ }^{498}$ Hopi Tribe v. EPA, 851 F.3d 957, 967 (9th Cir. 2017).

${ }^{499}$ Approval of Air Quality Implementation Plans; Navajo Nation; Regional Haze Requirements for Navajo Generating Station; Supplemental Proposal, 78 Fed. Reg. 62,509 (proposed Oct. 22, 2013) (to be codified at 40 C.F.R. pt. 49).

${ }^{500}$ Approval of Air Quality Implementation Plans; Navajo Nation; Regional Haze Requirements for Navajo Generating Station, 79 Fed. Reg. 46,514 (Aug. 8, 2014) (to be codified at 40 C.F.R. pt. 49).

50142 U.S.C. $\S 7491(\mathrm{~b})(2)(\mathrm{A}),(\mathrm{g})(4)$ (2012).

${ }^{502}$ Hopi Tribe, 851 F.3d at 969.

50340 C.F.R. $\S 51.308(\mathrm{e})(2)(\mathrm{i})(2017)$

${ }^{504}$ Id. $\S 51.308(\mathrm{e})(3)$.
} 
focuses on visibility rather than emissions; ${ }^{505}$ or (3) "otherwise based on the clear weight of the evidence." 506 EPA utilized the first method, therefore, it was only required to show that (1) the "distribution of emissions" is not substantially different under BART; and (2) the alternative "results in greater emission reductions." ${ }^{507}$ EPA has consistently interpreted distribution to refer only to geographic distribution, and the court deferred to the Agency's interpretation. ${ }^{508}$

Petitioners also argued "the FIP's BART Alternative does not actually result in greater emission reductions than BART and therefore does not meet the second prong of the first method for demonstrating greater reasonable progress." 509 The BART Alternative incorporated an emission credit for the NGS's voluntary installation of LNB with OFA technology, and without this credit, the BART alternative would not achieve greater $\mathrm{NO}_{\mathrm{x}}$ reductions than BART. ${ }^{510}$ EPA only used the emission credit for evaluating alternatives to BART, and the TAR grants EPA wide latitude to determine FIP provisions. The court held it was reasonable for EPA to give the NGS an emission credit when evaluating whether the BART Alternative results in greater emission reductions, and it deferred to EPA's determination. ${ }^{511}$

Petitioners' final claim was that EPA failed to conduct a BART analysis or include any BART emission limits for PM for the NGS because they were already well controlled, which the court opined was a reasonable exercise of the discretion that EPA has under the TAR. The court concluded that based on the discretion that EPA may exercise, it could not find that EPA acted arbitrarily and capricious and it denied the petitions.

\section{§4(b). Hopi Tribe v. EPA}

The Hopi Tribe also petitioned for review of EPA's FIP. ${ }^{512}$ The NGS is operated by a consortium of utilities led by the Salt River Project on land leased from the Navajo Nation, which expires in 2019. The coal used by the NGS is mined from Hopi tribal lands for which the Tribe which receives royalties. ${ }^{513}$ The 44,000 acre open pit Peabody Kayenta Mine is about 100 miles from the NGS and straddles the Navajo Nation and the Hopi Reservations. ${ }^{514}$ The Hopi Tribe claimed it was not adequately consulted about its interests before the plan was promulgated and objected to a proposed closure of the NGS. The court

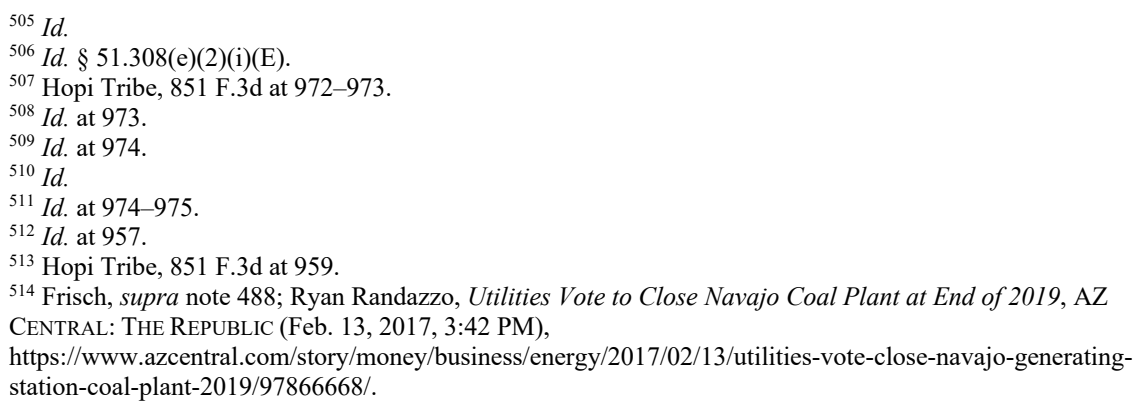


denied the Hopi Tribe's petition based on its determination that the facts demonstrated that EPA acted appropriately. ${ }^{515}$

EPA issued the final rule for the NGS in August 2014 after a process that took over five years, beginning with an Advance Notice of Proposed Rulemaking ("ANPRM") in $2009 .{ }^{516}$ The Hopi Tribe was notified and participated in the process of developing a proposed rule that was promulgated on February 5, 2013. ${ }^{517}$ Subsequently, EPA issued a Supplemental Proposed Rule and Notice of Public Hearings. ${ }^{518}$ The proposed Rule set an emissions cap for the future operation of the NGS and required it be shut down in 2044 or when the cap was reached, whichever occurred first. The final rule, issued in 2014, was materially the same as the Supplemental Proposed Rule. ${ }^{519}$ The Hopi Tribe's interests are adverse to the goals of the CAA because the NGS is responsible for about 3,000 Navajo Nation and Hopi Reservation jobs, with more than a third of the jobs being full-time. ${ }^{520}$ The Kayenta Mine employs about 325 tribal members, and the $\$ 12.5$ million paid to Tribe is an important portion of the tribes' revenues. ${ }^{521}$

The principal issue before the Ninth Circuit was EPA failed to consult with the Tribe. However, EPA did consult with the Hopi Tribe throughout the rulemaking process. The Hopi Tribe also claimed that EPA failed to analyze each of the five BART factors. However, BART Alternatives are governed separately by a regulation that requires them to achieve "greater reasonable progress" than BART. ${ }^{522}$ These regulations do not require that the BART factors be evaluated when analyzing a BART Alternative. Because the proposal was an alternative to BART, there was no error by EPA in not analyzing the BART factors under the BART Alternative. Therefore, the Hopi Tribe's Petition for Review was denied. ${ }^{523}$

\section{§ 4(c). Developments Since 2017}

The Salt River Project owns $42.9 \%$ of the NGS, which includes the $21.2 \%$ it recently purchased from the Los Angeles Department of Water and Power. It operates the plant for the other owners that include the U.S. Bureau of Reclamation (24.3\%), Arizona

\footnotetext{
${ }^{515}$ Hopi Tribe, 851 F.3d at 959.

${ }^{516}$ Assessment of Anticipated Visibility Improvements at Surrounding Class I Areas and Cost Effectiveness of Best Available Retrofit Technology for Four Corners Power Plant and Navajo Generating Station, 74 Fed. Reg. 44,313 (proposed Aug. 28, 2009) (to be codified at 40 C.F.R. pt. 49).

${ }^{517}$ Approval of Air Quality Implementation Plans; Navajo Nation; Regional Haze Requirements for Navajo Generating Station, 78 Fed. Reg. 8,274, 8,274 (proposed Feb. 5, 2013) (to be codified at 40 C.F.R. pt. 49).

${ }^{518}$ Approval of Air Quality Implementation Plans; Navajo Nation; Regional Haze Requirements for Navajo Generating Station; Supplemental Proposal, 78 Fed. Reg. 62,509, 62,509 (proposed Oct. 22, 2013) (to be codified at 40 C.F.R. pt. 49).

${ }^{519}$ Approval of Air Quality Implementation Plans; Navajo Nation; Regional Haze Requirements for Navajo Generating Station, 79 Fed. Reg. 46,514, 46,514 (Aug. 8, 2014) (to be codified at 40 C.F.R. pt. 49).

${ }^{520}$ Frisch, supra note 488.

${ }^{521}$ Randazzo, supra note 514; Lamar B. Keevama, Candidate for Vice Chairman, 25 Hopi Tutuveni 20:3 (Oct. 17, 2017).

52240 C.F.R. $\S 51.308(\mathrm{e})(2)(2017)$.

${ }^{523}$ Hopi Tribe v. EPA, 851 F.3d 957, 960 (9th Cir. 2017).
} 
Public Service Co. (14\%), Tucson Electric Power Co. (11.3\%), and NV Energy (7.5\%). In 2014, EPA reached an agreement with NGS to reduce $\mathrm{NO}_{\mathrm{x}}$ emissions by $80 \%$ over sixteen years and shut down the plant in 2044. But, in February 2017 the owners announced the plant would close when their lease with the Navajo Nation expires at the end of 2019 because low prices for natural gas have made this coal-fired plant noncompetitive. ${ }^{524}$ However, the Bureau of Reclamation seeks to keep the NGS operating. To operate until the end of the lease the owners need to contract with the Navajo Nation to allow decommissioning to take place after the lease ends. ${ }^{525}$ On June 26, 2017, the Navajo Nation Council agreed to allow operations until the end of 2019. The agreement still requires the Bureau of Reclamation to complete an environmental assessment and sign the agreement. The former owner, Los Angeles Department of Water \& Power must also agree because it is responsible for part of the costs of retiring the facility. ${ }^{526}$ During the fall of 2017, the owners of the NGS continued to search for a buyer for the plant. ${ }^{527}$

The Kayenta coal mine will probably shut down at the end of 2019 because it only serves the NGS, and there is no rail link that would deliver the coal to other buyers. ${ }^{528}$ The Navajo Nation is considering building a coal-to-gas generating station to use the coal, but the economics of that project make it unlikely it will be constructed. ${ }^{529}$ The Navajo Nation has begun producing electricity from its Kayenta Solar Facility, which could be the direction the Nation goes. ${ }^{530}$

In the first half of 2018 the uncertainty concerning the fate of the NGS and the Kayenta coal mine was not resolved. Reports of potential buyers for the NGS continued to circulate, but nothing concrete developed. ${ }^{531}$ In April 2018, Rep. Paul Gosar (R-Ariz) the chairman of the House Energy and Mineral Resources Subcommittee, was claiming the Central Arizona Project ("CAP")was legally required to buy its power from the NGS. CAP denied this. Neither the NGS or the Kayenta mine is in Rep. Gosar's district, but Peabody coal contributed to his re-election campaign. ${ }^{532}$

On May 1, 2018, Peabody Energy Corp, the Hopi Tribe, and the United Mine Workers sued CAP in the U.S. District Court for the District of Arizona. Their claim is that the 1968 Colorado River Basin Project Act and the Hoover Power Plant Act requires CAP to buy the electricity. The CAP denies they are so bound and resists paying the

\footnotetext{
${ }^{524}$ Frisch, supra note 488.

${ }^{525}$ Randazzo, supra note 514.

${ }^{526}$ Navajo Generating Station-News \& Statements, SRP, https://www.ngspower.com/about/newsroom.aspx (last visited Sept. 22, 2017).

${ }^{527}$ Catherine Traywick, Navajo Coal Plant Slated for Closing Identifies Potential Buyers, BLoOMBERG ENERGY AND Climate ReP. (Oct. 2, 2017), www.bloomberglaw.com.

${ }^{528}$ Stephen Lee, Peabody Mine Survival May Rest on Navajo Coal Gasification Plan, BloOMBERG DAILY ENV'T REP. (Aug. 4, 2017), https://www.bna.com/peabody-mine-survival-n73014462822/.

${ }^{529} \mathrm{Id}$.

${ }^{530}$ Associated Press, Navajo Solar Plant Breaks New Ground, SALt LAKE TrIB., Aug. 31, 2017, at B7.

${ }^{531}$ Steven Lee, Navajo Generating Station Owner Sets May Deadline for Sale, BloOMBERG DAILY ENV'T REP. (Apr. 27, 2018).

532 Stephan Lee, Coal Power Plant Puts Congressman, Arizona Water Authority at Odds, BLOOMBERG ENV'T (Apr. 18, 2018, 2:02 PM), https://news.bloombergenvironment.com/environment-and-energy/coalpower-plant-puts-congressman-arizona-water-authority-at-odds.
} 
much higher rates for power required by the NGS. ${ }^{533}$ In June the Trump Administration was attempting to come to the aid of the NGS and Peabody Coal. ${ }^{534}$ With no firm buyer in sight ${ }^{535}$ the CAP board voted on June 7, 2018, not to renew its contract with the

NGS. ${ }^{536}$ In September 2018 the only two potential investors ended their bid to purchase the NGS, and as of November no new investors have come forward. ${ }^{537}$

\section{§ 5. Utah's Haze SIP}

Utah's Regional Haze SIP began with the GCVTC's work in $1991 .{ }^{538}$ In September 2000 the WRAP submitted an Annex to the GCVTC recommendations that included regional milestone requirements and a trading program applicable to stationary sources with $\mathrm{SO}_{2}$ emissions whenever milestones are not achieved. EPA approved the Annex on June 5, 2003 and incorporated the stationary source provisions into the Regional Haze Rule. ${ }^{539}$ In December 2003, based on the GCVTC recommendations and the WRAP Annex, Utah's Air Quality Board adopted section XX of its SIP to address regional haze. Section $\mathrm{XX}$ focused on controlling $\mathrm{SO}_{2}$ because it is considered the pollutant with the greatest impact on visibility on the Colorado Plateau. It reacts to form ammonium sulfate $\left(\left(\mathrm{NH}_{4}\right)_{2} \mathrm{SO}_{4}\right)$, which affects visibility throughout the year. $\mathrm{NO}_{\mathrm{x}}$ reacts to form ammonium nitrate $\left(\left(\mathrm{NH}_{4}\right) \mathrm{NO}_{3}\right)$, which is primarily a winter problem for which the chemistry is not well understood. ${ }^{540}$

There has been a large increase in $\mathrm{NO}_{\mathrm{x}}$ in the Uinta Basin due to oil and gas operations, but the Basin is north of the Class I areas and has little impact on them. ${ }^{51}$ The 2003 Haze SIP included $\mathrm{SO}_{2}$ emission milestones and a backup emissions trading program. ${ }^{542}$ After EPA approved the Annex it was challenged, and on February 18, 2005, the D.C. Circuit vacated EPA's 2003 rules in Center for Energy and Economic Development (CEED) v. EPA. ${ }^{543}$ The court held that the Annex was based on a

\footnotetext{
${ }^{533}$ Steven Lee, Peabody Energy, Hopi Tribe, Union Sue to Keep Arizona Plant Open, BLoomBERG DAILY ENV'T REP. (May 2, 2018).

${ }^{534}$ Stephen Lee, Trump Administration Wades Into Fight Over Navajo Coal Plant, BLOOMBERG

ENV'T (June 4, 2018, 2:55 PM), https://news.bloombergenvironment.com/environment-and-energy/trumpadministration-wades-into-fight-over-navajo-coal-plant.

535 Stephen Lee, Potential Buyer of Navajo Plant Seeks 'Glidepath' to Alternatives, BLOOMBERG News (May 24, 2018), https://www.bna.com/potential-buyer-navajo-n57982092885/.

${ }^{536}$ Steven Lee, Navajo Generating Station About to Lose Its Biggest Customer, BLOOMBERG

ENV'T (June 7, 2018, 4:09 PM), https://news.bloombergenvironment.com/environment-and-energy/navajogenerating-station-about-to-lose-its-biggest-customer.

${ }^{537}$ Stephen Lee \& Amena H. Saiyid, No Interest, Not New Air Limits, Is Reason Navajo Plant Not Selling, Bloomberg LaW News (Nov. 8, 2018, 1:39PM).

${ }^{538}$ Utah Division Envtl. Quality, 2011 Regional Haze SIP 1.

${ }^{539} \mathrm{Id}$. at 2 .

${ }^{540}$ Utah Division of Air Quality, Staff Review 2008 PM BART Determination and Recommended

Alternative to BART for $N O_{x} 16$ (Feb. 13, 2015).

${ }^{541} \mathrm{Id}$. at 18 .

${ }^{542} \mathrm{Id}$. at 2.

${ }^{543}$ Center for Energy \& Econ. Dev. V. EPA, 398 F.3d 653 (D.C. Cir 2005).
} 
methodology for determining BART that was inconsistent with the CAA and had been rejected in 2002 in the American Corn Growers Ass. v. EPA. ${ }^{544}$ Subsequently, EPA revised the Regional Haze Rule on October 13, 2006 to provide directions concerning the methodology that would allow states to develop an alternative to BART. ${ }^{545}$

The State also developed The Utah Smoke Management Plan on July 20, 1999 that was revised on January 16, 2006 and on January 24, 2014 to regulate prescribed fire, wildfire, and wildland fire on federal, state and private wildlands in Utah. It was codified in Utah's Air Quality Rule R307-204 and in section XX.G.3 of Utah's Regional Haze SIP. ${ }^{546}$ EPA approved the Plan on January 18, 2013.

In Utah, between 2002 and 2008, anthropogenic $\mathrm{SO}_{2}$ emissions decreased by $39 \%$. Natural fire was the major natural source of $\mathrm{SO}_{2}$ emissions, and fire emissions decreased by $96 \%{ }^{547}$ Anthropogenic $\mathrm{NO}_{\mathrm{x}}$ emissions decreased $11 \%$; ammonia emissions increased $40 \%$; VOCs increased $37 \%$; fine soil emissions increased by more than $100 \%$; primary organic aerosol emissions increased 98\%; elemental carbon emissions increased $16 \%$; and course mass emissions increased more than $100 \%{ }^{548}$ Particulate organic mass emissions are important, but most are released from wildfires, which are highly variable from year to year. ${ }^{549}$ Not all increases impact Class I areas. During these years, Utah showed improvement on the most impaired days and no degradation on the least impaired days. ${ }^{550}$

On September 3, 2008, Utah's Air Quality Board adopted revisions to the stationary source provisions in its SIP to comply with EPA's revised haze rule. ${ }^{551}$ The haze rule required an updated SIP in order to comply with the BART requirement for $\mathrm{NO}_{\mathrm{x}}$ and $\mathrm{PM}$ and to meet requirements for an analysis of the impact of Utah sources on Class 1 areas outside of the Colorado Plateau. ${ }^{552}$ BART was to be imposed on Pacific Corp's units 1 and 2 of the Hunter and units 1 and 2 of the Huntington coal-fired power plants. These are the only BART eligible sources in Utah. BART included installing pulse jet fabric filter baghouses, and improved low $\mathrm{NO}_{\mathrm{x}}$ burners with separated overfire air at the four units. The Huntington units had to also install improved $\mathrm{SO}_{2}$ controls. These requirements were more stringent than the presumptive BART requirements found in EPA's regulations. ${ }^{553}$

In 2011, the $\mathrm{SO}_{2}$ milestones were updated because Arizona dropped out of the

\footnotetext{
${ }^{544}$ American Corn Growers Ass'n v. EPA, 291 F.3d 1 (D.C. Cir. 2002).

${ }^{545}$ Regional Haze Regulations; Revisions to Provisions Governing Alternative to Source-Specific Best Available Retrofit Technology (BART) Determinations, 71 Fed. Reg. 60,612, 60,612 (Oct. 13, 2006) (to be codified at 40 C.F.R. pt. 51).

${ }^{546}$ Utah Division of Air Quality, Progress Report for Utah's State Implementation Plan for Regional Haze 8 (May 18, 2015)

${ }^{547} \mathrm{Id}$. at 43 .

${ }^{548} I d$. at $44-50$.

${ }^{549} \mathrm{Id}$. at 52.

${ }^{550} \mathrm{Id}$. at 55 .

5512011 Regional Haze SIP, UTAH Division OF AIR QUALITY,

https://eq.utah.gov/legacy/pollutants/r/regional-haze/state-implementation-plan/index.htm.

${ }^{552} I d$.

${ }^{553}$ Utah Division of Air Quality, supra note 546, at 4 (EPA's presumptive BART is found at 40 C.F.R. pt. 51, App. Y).
} 
program in order to develop a SIP based on 40 C.F.R. $\S 51.308$. The growth estimates for the coal-fired electric power plants and the estimates of the emission reduction attributable to BART were also revised. ${ }^{554}$ In 2010 WildEarth Guardians sued EPA to force the Agency to take action on Utah's regional haze submission. ${ }^{555}$ A proposed consent decree was published October 31, 2010. ${ }^{556}$ By 2011, Utah's emissions were significantly below the 2018 milestone found in the 2008 Haze SIP. Therefore, the backstop emissions trading program was not triggered. ${ }^{557}$ On December 14, 2012, EPA approved most of Utah's 2008 Haze SIP but disapproved the BART determination for $\mathrm{NO}_{\mathbf{x}}$ and PM for the two PacificCorp plants because the five-factor analysis required by the haze rule was considered inadequate. ${ }^{558}$ PacifiCorp then prepared an updated five-factor analysis that it submitted to Utah's DAQ on August 5, 2014. ${ }^{559}$ Environmentalists continued to argue for SCR to be mandated as BART. 560

On June 3, 2015, the Utah Air Quality Board adopted a revised Regional Haze SIP that provided an alternative to BART that included alternative measures requiring low $\mathrm{NO}_{\mathrm{x}}$ burners with overfire air that were more stringent than EPA's presumptive BART. ${ }^{561}$ In addition, PacifiCorp's Carbon power plant's units 1 and 2, which were expected to be shut down by its management, were now required to close by August 15, 2015. ${ }^{562}$ This was challenged by environmentalists who claimed the benefits of closing the Carbon plant were overstated because if the plant remained operational it would have had to comply by April 16, 2015, with the stringent emission limits imposed by the Mercury and Air Toxics Standards for Power Plants. ${ }^{563}$ Nevertheless, Utah's DAQ believed that the weight of the evidence showed the alternative would provide greater visibility improvement than BART. ${ }^{564}$ The benefits of the alternative, according to DAQ, compared to the more stringent control of $\mathrm{NO}_{\mathrm{x}}$ were particularly significant for the Arches National Park Class I area. ${ }^{565}$

Utah's Regional Haze SIP is incorporated by reference and made part of Utah's Air Quality rules at R307-110, R307-110-17, and R307-110-28. ${ }^{566}$ The 2015 haze rule is discussed in more detail infra $\S 5$ (a). EPA's ability to approve the Alternative to BART

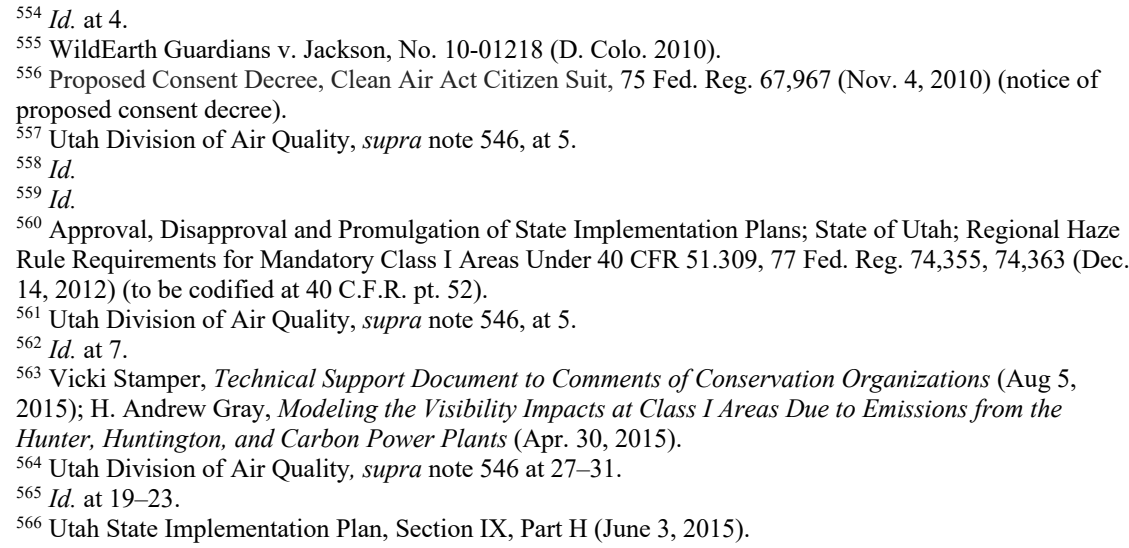


SIP was contingent on Utah submitting an enforceable commitment, which was approved by the Air Quality Board on September 15, 2015. The enforceable commitment certified that Utah would take credit for the $\mathrm{SO}_{2}$ emissions reduction due to the Carbon plant closure, but it would not take credit for the reductions in the annual Regional Haze $\mathrm{SO}_{2}$ Milestone Report in order to avoid double counting of the emissions reduction. ${ }^{567}$

\section{§ 5(a). EPA's Response to Utah's Haze SIP Revisions}

EPA partially rejected and partially approved Utah's haze SIP on December 14, 2012. It rejected the BART determination for PacificCorp's subsidiary Rocky Mountain Power's Hunter and Huntington power plants. ${ }^{568}$ On March 31, 2015, HEAL Utah, the National Parks Conservation Association, and the Sierra Club sued EPA alleging the Agency failed to perform a nondiscretionary duty to promulgate a FIP by January 14, $2015 .{ }^{569}$ The Utah Air Quality Board then approved the haze SIP revisions on May 21, 2015, and on June 3, 2015, they were submitted it to EPA. ${ }^{570}$ The Air Board and the DAQ staff supported the BART Alternative because of the high cost and marginal benefits of BART. ${ }^{571}$ Environmental organizations disputed this decision, and EPA subsequently agreed with the environmentalists.

EPA on January 14, 2016, promulgated a proposed regulation with two coproposals that indicated it was considering a partial approval and partial disapproval of Utah's submission. ${ }^{572}$ Utah's SIP revisions established an Alternative to BART to control nitrogen oxides $(\mathrm{NO})$ at the Hunter and Huntington power plants. The revisions also included BART determinations for particulate matter with an aerodynamic diameter of less than 10 micrometers $\left(\mathrm{PM}_{10}\right)$ at these power plants along with provisions for making the $\mathrm{NO}_{\mathrm{X}}$ and $\mathrm{PM}_{10}$ BART emission limits federally enforceable. Air emissions from the EGUs at the two plants affected by this haze SIP contribute to visibility impairment at nine Class I areas including Grand Canyon, Arches, Black Canyon, Bryce Canyon, Canyonlands, Capitol Reef, Mesa Verde and Zion National Parks and Flat Tops Wilderness Area. ${ }^{573}$

${ }^{567}$ Utah Air Quality Board, Utah State Implementation Plan Final Adoption: Section XX. Part N. Enforceable Commitments for the Utah Regional Haze SIP (Sept. 23, 2015).

${ }^{568}$ Tripp Baltz, Environmental Groups Sue EPA Over Failure to Develop Regional Haze Plan for Utah, 46 ENV'T REP. 992 (2015).

${ }^{569}$ HEAL Utah v. EPA, D. Colo., No. 15-CV-666 (Mar. 31, 2015).

${ }^{570}$ Final Adoption: Amend Utah State Implementation Plan Section XX.D.6. Regional Haze Long-Term Strategy for Stationary Sources. Best Available Retrofit Technology (BART) Assessment for NO and PM; Add New Utah State Implementation Plan Subsections IX.H.21 and 22. General Requirements: Control Measures for Area and Point Sources, Emission Limits and Operating Practices, Regional Haze

Requirements and Source Specific Emission Limitations: Regional Haze Requirements, Best Available Retrofit Technology (June 3, 2015).

${ }^{571}$ Bryce Bird, Utah is Committed to Finding Solutions to Haze, Salt LaKe TriB., Aug. 30, 2015, at O4

${ }^{572}$ Approval, Disapproval and Promulgation of Air Quality Implementation Plans; Partial Approval and

Partial Disapproval of Air Quality Implementation Plans and Federal Implementation Plan; Utah; Revisions to Regional Haze State Implementation Plan; Federal Implementation Plan for Regional Haze, 81 Fed. Reg. 2,004 (proposed Jan. 14, 2016) (to be codified at 40 C.F.R. pt. 52).

${ }^{573} I d$. 
The Utah haze revision is controversial. The State of Utah and PacifiCorp support the SIP revision that was submitted to EPA. The BART Alternative program, based on 40 C.F.R. $§ 51.308(\mathrm{e})$, includes requirements to reduce $\mathrm{NO}_{\mathrm{X}}$ emissions by installing upgraded combustion controls between 2006 and 2014 at the four BART units plus an additional EGU at PacifiCorp's Hunter plant and shutdown of the Carbon plant, a non-BART source. To meet its PM BART requirements, Utah's SIP submittal included stringent control technology at each of the four EGUs that are subject to BART. Conservation organizations including HEAL Utah, the National Parks Conservation Association, and Sierra Club as well as the National Parks Service (NPS) want BART NOx control to be imposed on the four EGUs.

The controversy over the SIP haze revision involves two primary issues. Is BART, rather than the BART Alternative, to be required? EPA considers BART to be selective catalytic reduction (SCR) technology + LNB) + SOFA Although Utah did not officially determined the cost of BART, it is clear that the BART Alternative would result in significant capital cost savings to PacifiCorp and its customers. ${ }^{574}$ Critics of EPA, claim the BART requirement would cost $\$ 700$ million more than Utah's alternative proposal and would result in marginal improvement. ${ }^{575}$ The haze provision in the CAA requires the cost of compliance and the degree of improvement in visibility to be considered. ${ }^{576}$ Utah does not believe the benefits of adding SCR to the four EGUs is worth the cost. Environmental groups believe it is. Much of this controversy involves disagreement among the participants concerning modeling inputs and results. The second issue is whether the BART Alternative meets the regulatory requirement of greater reasonable progress than BART by the clear weight of the evidence, which is discussed below.

On July 5, 2016, EPA partially approved and partially disapproved Utah's Regional Haze SIP submitted to EPA on June 4, 2015, pursuant to section 169A of the CAA. ${ }^{577}$ It also promulgated a FIP to address the deficiencies identified in the partial disapproval of Utah's regional haze SIP. EPA did not take any final action on a related October 20, 2015 SIP revision. Utah retains its authority to submit a revised state plan consistent with CAA and Regional Haze Rule requirements. An approvable SIP submission will result in the modification or withdrawal of the FIP. EPAs final rule became effective on August 4, 2016.578

Utah's SIP submittal addressed the BART requirements for $\mathrm{NO}_{\mathrm{x}}$ in part through reliance on a BART Alternative program, which Utah's DAQ found produced a significantly increased number of days of improved visibility compared to using the most

\footnotetext{
${ }^{574}$ Id.

${ }^{575}$ William Yeatman, EPA's Expensive Haze Solution Won't Produce Detectable Difference, SALT LAKE

TRIB., June 10, 2016, at A11.

57642 U.S.C. $\$ 7491(\mathrm{~g})(2)(2012)$.

${ }^{577}$ Approval, Disapproval and Promulgation of Air Quality Implementation Plans; Partial Approval and Partial Disapproval of Air Quality Implementation Plans and Federal Implementation Plan; Utah; Revisions to Regional Haze State Implementation Plan; Federal Implementation Plan for Regional Haze, 81 Fed. Reg. 43,894 (July 5, 2016) (to be codified at 40 C.F.R. pt. 52)

${ }^{578}$ Id.
} 
stringent $\mathrm{NO}_{\mathrm{x}}$ controls. ${ }^{579} \mathrm{EPA}$ determined Utah's SIP submittal was not consistent with the applicable statutory and regulatory requirements. ${ }^{580}$ EPA noted that several metrics in the State's analyses did not appear to support a conclusion that the BART alternative achieves greater reasonable progress toward natural visibility conditions in Class I areas than BART. ${ }^{581}$ Utah opted to develop its SIP under the clear weight-of-evidence standard, and provided its analysis in the "Greater Reasonable Progress than BART" section of the SIP submittal. ${ }^{582}$

EPA stated Utah must consider the "future projected emissions levels under the BART Alternative as compared to under the BART benchmark; future projected visibility conditions under the two scenarios; the geographic distribution of sources likely to reduce or increase emissions under the program as compared to BART sources; monitoring data and emissions inventories; and sensitivity analyses of any models used." ${ }^{583}$ This information is to be evaluated by the State, and the State is to identify the relative strengths and weaknesses of the metrics used. The State is to consider the weights assigned to the individual pieces of information and consider the total weight of all the information to determine whether the proposed BART Alternative clearly provides greater reasonable progress than BART at impacted Class I areas. EPA relies on the BART Guidelines in actions involving a BART Alternative because they provide a reasonable and consistent approach regarding visibility modeling, as well as other aspects of a BART Alternative conducted as part of a weight-of-evidence analysis. ${ }^{584}$ Nevertheless, the BART Guidelines are not mandatory for the evaluation of a BART Alternative, and the Guidelines do not directly address this subject. EPA's rules at 40 C.F.R. $\S 51.309$ and the preamble have provisions governing alternatives to source-specific BART determinations. ${ }^{585}$

Utah collected and evaluated information based on nine metrics and concluded the weight-of-evidence shows that its alternative program will provide greater reasonable progress than BART. EPA evaluated the information for each of the nine metrics in the State's SIP submittal. It found the State included two metrics, (1) energy and non-air quality impacts, (2) and cost, that are inconsistent with the greater reasonable progress analysis in the Regional Haze Rule because the metrics do not evaluate visibility benefits at the nine Class I areas impacted by the two Utah power plants. Therefore, EPA did not give this information any consideration. ${ }^{586}$ Utah included information on the aggregate annual emissions of all three visibility-impairing pollutants, but EPA found this

\footnotetext{
${ }^{579}$ Utah Division of Air Quality, supra note 546, at 21.

${ }^{580}$ Approval, Disapproval and Promulgation of Air Quality Implementation Plans; Partial Approval and Partial Disapproval of Air Quality Implementation Plans and Federal Implementation Plan; Utah; Revisions to Regional Haze State Implementation Plan; Federal Implementation Plan for Regional Haze, 81 Fed. Reg. 43,894, 43,895 (July 5, 2016) (to be codified at 40 C.F.R. pt. 52).

${ }^{581} \mathrm{Id}$.

582 Id. at 43,896 .

${ }^{583} \mathrm{Id}$. at 43,897 .

${ }^{584} \mathrm{Id}$.

${ }^{585} \mathrm{Id}$.

${ }^{586}$ Approval, Disapproval and Promulgation of Air Quality Implementation Plans; Partial Approval and Partial Disapproval of Air Quality Implementation Plans and Federal Implementation Plan; Utah; Revisions to Regional Haze State Implementation Plan; Federal Implementation Plan for Regional Haze, 81 Fed. Reg. 43,894, 43,897 (July 5, 2016) (to be codified at 40 C.F.R. pt. 52)
} 
information inconclusive because it did not provide information on the likely visibility impacts of the State's BART Alternative compared to BART. ${ }^{587}$

Utah determined that five of the metrics supported the BART Alternative and one metric, the 98th percentile CALPUFF modeling results, did not support the BART Alternative, but it did not explain the relative importance of each metric. EPA assessed the relative strengths and weakness of each of the metrics to determine whether it was reasonable for the State to categorize the metrics as either supporting or not supporting the BART Alternative. EPA weighted some metrics as more meaningful than others and concluded the BART Alternative does not achieve greater reasonable progress than BART. ${ }^{588}$ For example, Utah's BART Alternative provides greater emission reductions for $\mathrm{SO}_{2}$ and $\mathrm{PM}_{10}$, but $\mathrm{NO}_{\mathrm{x}}$ emissions would be greater under the BART Alternative. The Agency decided it was not appropriate to combine all three pollutants in the annual emissions comparison test to support the BART Alternative. Therefore, EPA found this metric was inconclusive and did not weigh either in favor of or against the BART Alternative. ${ }^{589}$ Utah's modeling results compared the number of days with significant visibility impairment relative to natural visibility under the BART Alternative scenario to the number of days of impairment under BART. EPA evaluated the State's modeling and determined the results did not show the BART Alternative was better or alternatively the BART Alternative was only marginally better, depending on the scenario used. ${ }^{590}$

Utah determined that the CALPUFF modeling results from the 90th percentile deciview impact show that the BART Alternative provides greater improvement. EPA noted that the 90th percentile metric excludes more than a month's worth of visibility data, which significantly dilutes the overall visibility results achieved from potential control options and is therefore less relevant than the 98th percentile. Furthermore, while the 98th percentile day reflects visibility benefits on the days on which the sources have the largest impacts, the State did not indicate that the 90th percentile day has any particular significance other than to provide an additional metric to consider. Therefore, EPA found this metric only marginally supported the BART Alternative. ${ }^{591}$ Moreover, Utah did not properly consider the 98th percentile CALPUFF modeling metric, which did not support its BART Alternative. ${ }^{592}$ Utah asserted that the timing of emission reductions supports its determination that the BART Alternative will provide greater reasonable progress than BART and EPA agreed. However, the reductions from the BART Alternative would occur before the BART Benchmark because the controls at the Hunter and Huntington facilities have been achieving significant $\mathrm{NO}_{\mathrm{X}}$ reductions since the time of their installation between 2006 and 2014. Even though this supports Utah's finding that the BART Alternative is

\footnotetext{
${ }^{587} \mathrm{Id}$.

${ }^{588}$ Id. at 43,898 .

${ }^{589} \mathrm{Id}$.

${ }^{590}$ Id. at 43,899 .

${ }^{591} \mathrm{Id}$.

${ }^{592}$ Approval, Disapproval and Promulgation of Air Quality Implementation Plans; Partial Approval and Partial Disapproval of Air Quality Implementation Plans and Federal Implementation Plan; Utah; Revisions to Regional Haze State Implementation Plan; Federal Implementation Plan for Regional Haze, 81 Fed. Reg. $43,894,43,902$ (July 5, 2016) (codified at 40 C.F.R. pt. 52).
} 
better than BART, EPA still imposed BART in its FIP. ${ }^{593}$

Utah's regional haze SIP submittal determined that the BART Alternative provides greater reductions of sulfates, and EPA agreed that visibility impairment on the Colorado Plateau is dominated by sulfates, and they are the largest contributor to visibility impairment at the affected Class I areas. EPA's analysis confirmed that sulfate is a large contributor to light extinction year-round, but nitrate impacts are significant, particularly on the $20 \%$ worst days, and nitrate contributions are highest in the winter season. Contrary to the State's position that visibility improvements during seasons of peak Class I area visitation should carry more weight, EPA evaluated the visibility impacts for an entire year and concluded the monitoring data analysis only marginally shows the BART Alternative is better than BART. ${ }^{594}$

Utah's SIP submittal indicated in its weight-of-evidence assessment that the BART Alternative would avoid the energy penalty associated with operating the SCR units under BART and would have non-air quality benefits. EPA's position was that only metrics that are indicative of improvements in visibility are relevant in a weight-of-evidence analysis, meaning energy and non-air quality impacts are not relevant. ${ }^{595}$ Moreover, the significant capital cost savings to PacifiCorp and its customers does not have a direct bearing on whether the BART Alternative achieves greater reasonable progress. Therefore, EPA did not assign this metric any weight. ${ }^{596}$

Utah's SIP submittal indicated that eight of the nine metrics it used supported adopting the BART Alternative; only the 98th percentile CALPUFF modeling metric did not. EPA, however, claimed four metrics have documented weaknesses and only marginally support the BART Alternative. It concluded the Alternative modeling did not show greater visibility benefits than would BART, and therefore it was not reasonable for the State to determine that the clear weight of the evidence favors the BART Alternative. 597

EPA concluded that the Alternative clearly would achieve greater visibility benefits than BART. Therefore, it disapproved the State's NOX BART Alternative contained in its June 4, 2015 SIP submittal, including the $\mathrm{NO}_{\mathrm{X}}$ emission limits for Hunter Units 1, 2, and 3; and the $\mathrm{NO}_{\mathrm{x}}$ emission limits for Huntington Units 1 and 2; and the requirements for permanent closure of Carbon Units 1 and 2.598 The baseline visibility impacts in deciviews at all nine Class I areas are significant. Consideration of these source-wide visibility benefits confirms that SCR + LNB/SOFA at Hunter and Huntington is justified in light of its reasonable costs. EPA's FIP required BART must be installed and operated as

\footnotetext{
${ }^{593} \mathrm{Id}$. at 43,900 .

${ }^{594} \mathrm{Id}$.

${ }^{595} \mathrm{Id}$. at 43,901 .

${ }^{596} \mathrm{Id}$.

${ }^{597} \mathrm{Id}$.

${ }^{598}$ Approval, Disapproval and Promulgation of Air Quality Implementation Plans; Partial Approval and Partial Disapproval of Air Quality Implementation Plans and Federal Implementation Plan; Utah; Revisions to Regional Haze State Implementation Plan; Federal Implementation Plan for Regional Haze, 81 Fed. Reg. $43,894,43,902$ (July 5, 2016) (codified at 40 C.F.R. pt. 52).
} 
expeditiously as practicable, but in no event later than five years after the date that the final FIP becomes effective. ${ }^{599}$ EPA then approved SIP section IX, Part H.21 subsections a through $\mathrm{d}$ and $\mathrm{f}$ and conditionally approved subsection e (emission limitations shall apply at all times). It also approved SIP section IX, Part H.22 subsections a.i and b.i. EPA approved the $\mathrm{PM}_{10}$ reporting provision based on Utah's commitment to submit specific measures to address the reporting requirement. ${ }^{600}$ In 2017 EPA extended the deadline for the next period of visibility SIP revisions to July $31,2021 .{ }^{601}$

\section{$\S 5(b)$. Developments in 2017.}

All six of Utah's congressional delegates opposed EPA's rejection of the State's haze plan, and resolutions were introduced in the House and Senate in opposition to the targeting of the Huntington and Hunter power plants. ${ }^{602}$ On July 14, 2017, EPA's Administrator Scott Pruitt sent letters to officials in Utah announcing the Agency would reconsider its haze FIP following pressure from the State's congressional delegation. ${ }^{603}$ Utah and industry groups already were suing EPA in the Tenth Circuit over the FIP, ${ }^{604}$ and EPA had asked the court to place the proceedings in abeyance pending the Agency's reconsideration. ${ }^{605}$ On September 11, 2017, the Tenth Circuit stayed EPA's FIP requiring Rocky Mountain Power to install pollution controls on the Hunter and Huntington coalfired power plants. The court also placed hearings in the case on hold after EPA officials announced it would reconsider its FIP. ${ }^{606}$

\section{§ 6. Obstacles to Visibility Improvement}

The technical problems concerning visibility protection and improvement are daunting. ${ }^{607}$ One of the most important obstacles to improving visibility is that the atmospheric concentration of fine particles required to adversely affect visibility is much lower than the concentration required to be considered a threat to health. In many of the Class I areas in the Southwest the visibility is very sensitive to increased emissions. An addition of one microgram of particulates per cubic meter in the viewing path in a clean atmosphere can reduce the visual range by $30 \%$. But if one microgram of particulates per

\footnotetext{
${ }^{599} I d$. at 43,907 .

${ }^{600} \mathrm{Id}$.

${ }^{601}$ U.S.Envtl. Protection Agency, Protection of Visibility: Amendments to Requirements for State Plans, 82 Fed. Reg. 3078 (Jan. 10, 2017).

${ }^{602}$ Utah Lawmakers Push CRA Resolution to Kill EPA's Haze Plan, Inside EPA (Mar. 21, 2017), www.insideepa.com/clean-air-report/utah-lawmakers-push-cra-resolution-kill-epas-haze-air-plan.

${ }^{603}$ Trump EPA Moves to Soften States' Regional Haze Plan Requirements, 28 CleAn AIR REP. 15 (July 27, 2017).

${ }^{604}$ Utah v. EPA, 765 F.3d 1257 (10th Cir. 2014).

${ }^{605}$ Trump EPA Moves to Soften States' Regional Haze Plan Requirements, supra note 609.

${ }^{606}$ Emma Penrod, Future of Pollution-control Plan Hazy, Salt LaKe Tribune, Sept. 12, 2017, at B6.

${ }^{607}$ See generally U.S. Envtl. Protection Agency, Protecting Visibility Report to Congress, EPA-450/5-79008 (Oct. 1979); NAT'L Research COUnCIL, Protecting Visibility in NATIONAL PARKS AND WILDERNESS AREAS (1993).
} 
cubic meter is added to an area having impaired visibility the impact is limited to a $3 \%$ additional visibility reduction. ${ }^{608}$ The good news, however, is that the health-based programs to reduce fine particulates and their precursors, including $\mathrm{SO}_{2}$ and $\mathrm{NO}_{\mathrm{x}}$, also results in visibility improvement.

While the technical problems involved in visibility improvement efforts are challenging, the social, economic and political concerns are more difficult to overcome. Perhaps the most important threat to visibility is population growth and the related use of energy by the growing population. In the eight Rocky Mountain States known for long distance vistas the population growth since the passage of the 1990 CAA Amendments is significant. By 2016, the growth in population was as follows:

\begin{tabular}{|c|c|}
\hline Arizona & $3,665,228(1990)-6,931,071(2016)[89.1 \%]$ \\
\hline Colorado & $3,294394(1990)-5,545,540(2016)[68.2 \%]$ \\
\hline Idaho & $1,006,749(1990)-1,683,140(2016)[67.2 \%]$ \\
\hline Montana & $799,065(1990) \quad--1,042,520(2016)[30.5 \%]$ \\
\hline Nevada & $1,201,833(1990)--2,940,058(2016)[144.6 \%] ;$ \\
\hline New Mexico & $1,515,069(1990)--2,081,015$ (2016) $[37.4 \%] ;$ \\
\hline Utah & $1,722,850(1990)--3,051,217(2016)[77.1 \%]$ \\
\hline Wyoming & $453,588(1990) \quad--585,501(2016)[29.1 \%]^{609}$ \\
\hline
\end{tabular}

As the population grows, its consumption of natural resources, especially fossil fuels, results in increased emissions into the atmosphere, and this affects visibility. Vehicle highway miles traveled in the U.S. increased from 2,144,362 million miles in 1990 to $3,130,509$ million miles in 2015, a $46 \%$ increase ${ }^{610}$ Fossil fuel energy used by the electric power sector increased from 20,859 trillion BTU in 1990 to 22,384 trillion BTU in $2017^{611}$ In recent years fossil fuel consumption has decreased modestly because of the use of renewable resources, which can be expected to have a positive effect on visibility. ${ }^{612}$ The population and consumption growth means that visibility improvement must deal with a moving target. One activity that specifically impacts Class I areas is tourism in the nation's national parks. In Utah, for example, the demand for outdoor recreational experiences has brought the problems of urban areas to rural America. Between 1990 and 2016, the growth in visitors per year to Utah's National Parks resulted in Zion National Park visitation going from 2,102,400 to 4,295,127; Canyonlands went from 276,831 to 776,218; Capital Reef went from 620,000 to $1,585,718$; Arches went from 620,719 to $1,585,718$; and Bryce

\footnotetext{
${ }^{608}$ U.S. Envtl. Protection Agency, Protecting Visibility an EPA Report to Congress 6 (Oct. 1979) [EPA450/5-79-008].

${ }^{609}$ The population in 1990 came from Infoplease, U.S. Population by State 1790 to 2015. The 2016 population came from the U.S. Census, Table 1, Annual Estimates of the Resident Population of the United States, Regions, States, and Puerto Rico: April 1, 2010 to July 1, 2016. The percent increase was calculated by the author.

${ }^{610}$ U.S. Dept. of Transportation. Bureau of Transportation Statistics, Table 1-35: U.S. Vehicle-Miles (Million).

${ }^{611}$ U.S. Energy Information Administration, Table 2.6, Electric Power Sector Energy Consumption (Trillion BTU) (fossil fuel).

612 Id.
} 
Canyon went from 862,659 to 2,365,110. ${ }^{613}$ At Arches, for example, traffic seeking entry to the park on busy weekends often backs up for miles, and after getting into the park the vehicles exceed the availability of parking. ${ }^{614}$ Protecting air quality and improving visibility while accommodating millions of visitors was not the challenge in 1990 that it is today.

Another issue that complicates the efforts to achieve visibility improvement is climate change. Concentrations of carbon dioxide reached 403.3 parts per million in the atmosphere in 2016, which is the highest level in 800,000 years. ${ }^{615}$ While a comprehensive discussion of climate change is beyond the scope of this article, there are two aspects of climate change that directly impact visibility. Wildfires and particulate emissions from a more arid climate in the Southwest are affecting visibility. Wildfire emissions of particulate matter include the hazardous pollutants benzene, methyl chloride and polycyclic organic matter, as well the greenhouse gases ("GHGs") methane and carbon dioxide. ${ }^{616}$ A long history of fire suppression by the federal government has led to a six-fold increase during the forty years leading up to 2011, and the number of acres burned in Western U.S. wildfires, and the annual acreage burned, is expected to increase due to climate change. ${ }^{617}$ Since 1990, the number of U.S. wildfires has been relatively constant with an average year having 60,000 to 70,000 fires, but varying from 47,559 in 2013 to 96,385 in $2016 .{ }^{618}$ However, the acres burned have increased significantly. In 1990, 4,621,621 acres burned; in 1991, 2,953,578 acres burned; in 1992, 2,069,929 acres burned. In the sixteen years beginning with the year 2000, only five years have had less than 5,000,000 acres burned, and in seven years more than $8,000,000$ acres burned. ${ }^{619}$ In 2015 , for the first time over 10,000,000 acres burned. ${ }^{620}$ By September 2017, 8,464,884 acres burned. ${ }^{621}$ The Forest Service spent $\$ 2.9$ billion battling forest fires in this fire season. ${ }^{62}$ During the summer of 2017, much of the West was experiencing reduced visibility from the smoke produced by wildfires. ${ }^{623}$ Preventing wildfires often involves prescribed burning that adds to air

\footnotetext{
${ }^{613}$ National Parks statistics can be found at Zion national Park, Canyonlands National Park, Capital Reef National Park, Arches National Park, Bryce Canyon National Park (1990-2016). Insert the name of the National Park to obtain the relevant data. Park Reports, NAT'L PARK SERV.: U.S. DeP'T OF THE INTERIOR, https://irma.nps.gov/Stats/Reports/Park.

${ }^{614}$ Brian Maffly, Arches? Take a Number, Salt LaKe TrIP., Nov. 2, 2017, at A1, A4.

${ }^{615}$ Jessica Shankleman, Carbon Pollution Touched 800,000-Year Record in 2016 WMO Says, BLOOMBERG DAILY ENV'T REP. (Oct. 31, 2017, 6:00 AM), https://www.bloomberg.com/news/articles/2017-1030/carbon-pollution-touched-800-000-year-record-in-2016-wmo-says.

${ }^{616}$ Robert Keiter, Wildfire Policy, Climate Change, and the Law, 1 TeX. WeSleyAn J. REAL Prop. L. 501 (2012); see generally Arnold W. Reitze, Jr., EPA's Fine Particulate Air Pollution Control Program, 44 ENVTL. L. REP. 1096 (Nov. 2014)

617 Keiter, supra note 616

${ }^{618}$ National Interagency Fire Center, Total Wildfires and Acres (1960-2015).

${ }^{619} I d$.

${ }^{620} \mathrm{Id}$.

${ }^{621}$ Wildfires - September 2017, NAT'L OCEANIC AND ATMOSPHERIC ADMIN.: NAT'L CTR. FOR ENVTL. INFO., https://www.ncdc.noaa.gov/sotc/fire/201709.

${ }^{622}$ Matthew Daly, House OKs bill Easing Way for Forest Thinning to Combat Wildfires, SALt LAKE TRIB., Nov. 2, 2017, at A5; Stuart Parker, House Energy Panel Eyes Forest Management to Curb Fires' Air Pollution, Inside EPA: DAILY NEws (Oct. 4, 2017), www.insideepa.com/daily-news/house-energy-paneleyes-forest-management-curb-fires-air-pollution.

${ }^{623}$ For those desiring footnotes, this is the observation of the author.
} 
pollution, but these preventive measures are discouraged by air quality regulations. ${ }^{624}$ However, in 2008, prescribed fires were responsible for emissions of 700,000 tons of $\mathrm{PM}_{2.5}{ }^{625}$ On January 10, 2017, EPA issued a final regulation amending requirements for state haze SIPS that includes an effort to address prescribed fires. ${ }^{626}$ Exempting natural events from CAA requirements remains a controversial issue and is being litigated in the D.C. Circuit Court of Appeals. ${ }^{627}$

The Intergovernmental Panel on Climate Change in 2013 reported that higher surface temperatures in polluted regions are projected to increase peak levels of ozone $\left(\mathrm{O}_{3}\right)$ and $\mathrm{PM}_{2.5}{ }^{628}$ The Southwest has heated up in recent decades and since 1950 has been hotter than any comparably long period in at least 600 years. The decade 2001 to 2010 was the warmest on record with temperatures almost two degrees Fahrenheit higher than historic averages. ${ }^{629}$ The Southwest and the southern portions of the Northern Great Plains are projected to become more arid as a result of climate change ${ }^{630}$ Particulate emissions due to a more arid climate in the Southwest are can be expected to affect visibility. While there is substantial research available dealing with the effect of climate change on the Western water supply, the information concerning air impacts is unfortunately far more limited.

An important variable in projecting future visibility improvement will be the federal efforts to control, or not control traditional air pollutants regulated to protect human health. The pollutants that are the targets of haze regulations are also criteria pollutants regulated by the CAA. Candidate Donald Trump pledged to tilt the federal government to a pro-fossil fuel energy policy. This helped get him elected. In Emery County, Utah, the home of the Rocky Mountain Power's plants that are the subject of the haze rule controversy in Utah, $79 \%$ of the voters supported Donald Trump. In Seiver County, the home of Utah's largest coal mine, $78 \%$ of the voters supported Trump. ${ }^{631}$

After Donald Trump became President the federal government's tilt toward expanded use of fossil fuels began. The President's choices for Secretaries of State, Energy

${ }^{624}$ Kirsten H. Engel, Perverse Incentives: The Case of Wildfire Smoke Regulation, 40 ECOLOGY L.Q. 101, 101 (2013).

${ }^{625}$ Keiter, supra note 616.

${ }^{626}$ Protection of Visibility: Amendments to Requirements for State Plans, 82 Fed. Reg. 3,078, 3,078 (Jan. 10, 2017) (codified at 40 C.F.R. pt. 51, 52).

${ }^{627}$ Stuart Parker, EPA Defends Definition Of 'Natural Events' Subject to Air Act Exemptions, Inside EPA (Sept. 6, 2017), https://insideepa.com/daily-news/epa-defends-definition-natural-events-subject-air-actexemptions. See also Stuart Parker, House, Senate Lawmakers Probe Air Quality Impacts of Increased Wildfires, 28 ClEAN AIR REP. (Inside EPA) 20:22 (Oct. 5, 2017).

${ }^{628}$ Ben Kirtman et al., Near-term Climate Change: Projections and Predictability, in IPCC FIFTH ASSESSMENT REPORT 957 (T.F. Stocker et al. eds., 2013).

${ }^{629}$ Implications of Climate Change, U.S. Envtl. Prot.: Climate Change Adaptation Resource CENTER (AR-X), https://www.epa.gov/arc-x/implications-climate-change\#climate (last visited July 26 , 2018).

${ }^{630}$ Robert W. Adler, Managing Water Supplies, in The LaW of Adaptation To Climate Change 53 (Michael B. Gerrard \& Katrina Fisher Kuh eds., 2012).

${ }^{631}$ Mike Gorrell, 'We have a chance': Utah coal country optimistic, SALT LAKE TRIB., Dec. 27, 2016, at A1. 
and Interior as well as the Administrator of EPA are men with strong ties to the fossil fuel industry and a record of antipathy toward environmental protection. They are leading their organizations in a direction that will make it more difficult to achieve improvements in air quality, including visibility. While a detailed analysis of the environmental program in the Trump Administration is beyond the scope of this article there are some important changes to federal regulations that will impact the program aimed at visibility improvement.

On October 16, 2017, EPA proposed to repeal the Clean Power Plan ("CPP"), which provided guidelines for carbon emissions from existing EGUs. ${ }^{632}$ The CPP applies to new, modified, and reconstructed sources from two types of fossil-fueled fired power plants-stationary combustion turbines, and steam generating units. ${ }^{633}$ The CPP was expected to incentivize the generation of electricity from natural gas facilities and discourage the use of coal, which would reduce air pollution. ${ }^{634}$

On June 3, 2016, EPA finalized amendments to the new source performance standards for the oil and gas source category to expand the coverage of oil and gas VOC emissions to include controls on methane emissions. ${ }^{635}$ The EPA regulation of methane emissions from oil and gas wells was challenged by North Dakota in the D.C. Circuit on July 15, 2016, with numerous additional parties and interveners. ${ }^{636}$ In April 2017, the EPA asked the D.C. Circuit to indefinitely pause the lawsuits challenging the oil and gas New Source Performance Standards ("NSPS") because President Trump's March 28, 2017 Executive Order on climate and energy policy that requires EPA immediately review agency actions that "potentially burden the safe, efficient development of domestic energy resources." In April 2017, EPA announced it was initiating its review of the methane rule and provided advanced notice of forthcoming rulemaking proceedings. ${ }^{637}$

On June 16, 2017, EPA promulgated a proposed rule that would stay the oil and gas NSPS for three months. ${ }^{638}$ On July 3, 2017, the D.C. Circuit held that EPA lacked authority

\footnotetext{
${ }^{632}$ Repeal of Carbon Pollution Emission Guidelines for Existing Stationary Sources: Electric Generating Units, 82 Fed. Reg. 48,035 (Oct. 16, 2017) (to be codified at 40 C.F.R. pt. 52).

${ }^{633}$ EPA Fact Sheet: Final Limits on Carbon Pollution from New, Modified and Reconstructed Power Plants, U.S. EnVtL. Protection AgenCy (last updated Sept. 14, 2015), https://archive.epa.gov/epa/sites/production/files/2015-11/documents/fs-cps-overview.pdf.

${ }^{634}$ Julie DeMeester \& Sarah Adair, EPA's Clean Power Plan: Understanding and Evaluating the Proposed Federal Plan and Model Rules, 45 EnVTL. L. ReP. 11155, 11161 (2015); Andrew Childers, EPA Overstepping Authority in Effort to Foster Clean Power Plan, Agency Foes Say, 47 ENV'T REP. 2997 (2016).

${ }^{635}$ Oil and Natural Gas Sector: Emission Standards for New and Modified Sources, 81 Fed. Reg. 35,824 (June 3, 2016) (to be codified at 40 C.F.R. pt. 60) (amending 40 C.F.R. part 60, subpt. OOOO and proposing new standards at subpart OOOOa).

${ }^{636}$ See Anthony Adragna, North Dakota First to Sue EPA Over Rule Targeting Oil, Gas Well Methane Emissions, 47 ENV'T REP. 2186 (2016); Anthony Adragna, EPA Methane Rule for New, Modified Sources Faces More Challenges From States, Industry, 47 ENV'T REP. 2311 (2016); Anthony Adragna, Nine States, Environmental Groups Back EPA in Legal Battle Over Methane Regulations, 47 ENV'T REP. 2446 (2016).

${ }^{637}$ Lee Logan, Following Trump Order, EPA Launches Review of Oil \& Gas Methane Rule, INSIDE EPA (Apr. 3, 2017), https://insideepa.com/daily-news/following-trump-order-epa-launches-review-oil-gasmethane-rule.

${ }^{638}$ Oil and Natural Gas Sector: Emission Standards for New, Reconstructed, and Modified Sources: Three Month Stay of Certain Requirements, 82 Fed. Reg. 27,641 (June 16, 2017) (codified at 40 C.F.R. pt. 60).
} 
under the CAA to stay the final methane rule because it had already established NSPS for fugitive emissions of methane and other pollutants by the oil and natural gas industries, ${ }^{639}$ and the court vacated the stay. ${ }^{640}$ On July 13, 2017, the D.C. Circuit granted EPA's motion to delay enforcement of the vacated 90-day stay and allowed the Agency to seek a rehearing or appeal to the Supreme Court. ${ }^{641}$ On August 10, 2017, the full D.C. Circuit declined to review the decision that forced EPA to enforce the oil and gas NSPS. ${ }^{642}$ However, the court's ruling concerning the 90-day stay does not prevent the repeal of the methane rule if EPA follows a proper rulemaking process, including a notice-and-comment process. ${ }^{643}$ In October 2017, the Office of Management \& Budget was reviewing EPA's draft final rules to delay the NSPS for up to two years. ${ }^{644}$ On November 1, 2017, EPA requested further comments on its proposed three-month and two-year delay suspending the methane rule for new oil and gas wells. ${ }^{645}$ To make it more difficult to regulate the oil and gas industry, EPA is altering its calculation of the social cost of methane emissions in order to change its cost analysis of the methane regulations. ${ }^{646}$

EPA requires oil and natural gas companies to collect and report GHG emissions data for sources emitting 25,000 metric tons per year, or more, of $\mathrm{CO}_{2 \mathrm{e}}{ }^{647}$ On May 12, 2016, EPA issued a draft Information Collection Request ("ICR") to require oil and natural gas companies to provide the information needed to regulate existing sources of methane emissions, including facilities that are not currently regulated. ${ }^{648}$ This could have resulted in hundreds of thousands of existing oil and gas sources with methane emissions being subject to new requirements. ${ }^{649}$ In March 2017, the draft ICR was withdrawn by EPA. ${ }^{650}$

\footnotetext{
${ }^{639}$ Oil and Natural Gas Sector: Emission Standards for New, Reconstructed, and Modified Sources, 81 Fed. Reg. 35,824 (June 3, 2016) (to be codified at 40 C.F.R. pt. 60).

${ }^{640}$ Clean Air Council v. Pruitt, 862 F.3d 1 (D.C. Cir. 2017).

${ }^{641}$ Andrew Childers, Methane Emissions Standards Frozen as EPA Mulls Appeal, BLOOMBERG ENV'T (July 13, 2017, 3:05 PM), https://bnanews.bna.com/environment-and-energy/methane-emissions-standardsfrozen-again-as-epa-mulls-appeal.

${ }^{642}$ Clean Air Council, supra note 640.

${ }^{643}$ Jennifer A. Diouhy et al., Court Rebukes EPA for Shelving Obama-Era Methane Regulation, BloOMBERG BNA: ENERGY AND ClimATE ReP. (July 3, 2017).

${ }^{644}$ EPA Submits Plan to Stay Methane NSPS to White House for Review, InSIDE EPA (Sept. 25, 2017), https://insideepa.com/daily-feed/epa-submits-methane-nsps-stay-plan-review.

${ }^{645}$ Abby Smith, Delaying Methane Rules Needs More Consideration, EPA Says, Bloomberg EnV'T ReP (Nov. 3, 2017).

${ }^{646}$ Abby Smith, EPA Slashes Social Cost of Methane in Bid to Delay Oil and Gas Limits, BLOOMBERG ENERGY AND CLIMATE REP. (Nov. 2, 2017), https://bnanews.bna.com/environment-and-energy/epa-slashessocial-cost-of-methane-in-bid-to-delay-oil-and-gas-limits.

${ }^{647}$ Mandatory Reporting of Greenhouse Gases: Petroleum and Natural Gas Systems, 75 Fed. Reg. 74,458 (Nov. 30, 2010) (to be codified at 40 C.F.R. pt. 98).

${ }^{648}$ EPA's Actions to Reduce Methane Emissions from the Oil and Natural Gas Industry: Draft Information Collection Request for Existing Sources, U.S. ENVTL. PROT. AGENCY,

https:/www3.epa.gov/airquality/oilandgas/may2016/icr-fs.pdf. The draft is available at https://www3.epa.gov/airquality/oilandgas/methane.html.

${ }^{649} I d$.

${ }^{650}$ Anthony Lacey, EPA Quickly Withdraws Oil \& Gas Methane ICR After GOP State Criticisms, INSIDE EPA (Mar. 2, 2017, https://insideepa.com/daily-news/epa-quickly-withdraws-oil-gas-methane-icr-aftergop-state-criticisms; David Schultz, Pruitt Kills Methane Query One Day After Request from Allies, 48 BLOOMBERG ENV'T REP. 457 (2017).
} 
This action prevents the acquisition of information that was expected to be the basis for more stringent regulation of existing oil and gas operations. ${ }^{651}$

On August 2, 2016, the White House Council on Environmental Quality ("CEQ") released final guidance on considering climate change in environmental reviews, which includes federal land management agencies. ${ }^{652}$ On December 12, 2016, the_Bureau of Land Management ("BLM") amended its regulations on the preparation of land use plans to include the effect of the proposed action on climate change and the effect of climate change on the proposed action. ${ }^{653}$ The Trump Administration withdrew the CEQ's guidance document for further consideration on April 5, 2017. ${ }^{654}$

On November 18, 2016, BLM promulgated its Waste Prevention Rule that imposes various requirements on oil and gas producers working on federal lands. ${ }^{655}$ The rule aims to reduce waste and prevent the release of methane into the atmosphere. It prohibits venting of natural gas with few exceptions, including emergency venting, requires producers to reduce wasteful flaring of gas by capturing it for sale, and requires producers to use an instrument approach to leak detection in order to reduce gas leaks during oil and gas production. ${ }^{656}$ In June 2017, the Interior Department suspended compliance with those parts of the rule that were not already in effect. ${ }^{657}$ This led to a lawsuit filed on July 5, 2017, by the State of California and New Mexico challenging BLM's effort to postpone the Waste Prevention Rule. ${ }^{658}$ California and New Mexico claimed that BLM lacks authority under section 705 of the Administrative Procedure Act to postpone compliance dates after a rule has gone into effect. ${ }^{659}$ On October 4, 2017, the Federal District Court for the Northern District of California ruled that BLM could not postpone compliance with the

${ }^{651}$ Dawn Reeves, Early Chaos Raises Doubts on Trump's Ability to Enact EPA Agenda, INSIDE EPA (Mar. 24, 2017), https://insideepa.com/daily-news/early-chaos-raises-doubts-trumps-ability-enact-epa-agenda. ${ }^{652}$ The White House, Fact Sheet: White House Council on Environmental Quality Releases Final Guidance on Considering Climate Change in Environmental Reviews, THE WhITE House: President BARACK OBAmA (Aug. 2, 2016), https://obamawhitehouse.archives.gov/the-press-office/2016/08/02/fact-sheetwhite-house-council-environmental-quality-releases-final.

${ }^{653}$ Resource Management Planning, 81 Fed. Reg. 89,580 (Dec. 12, 2016) (to be codified at 43 C.F.R. $1600)$.

${ }^{654}$ See Withdrawal of Final Guidance for Federal Departments and Agencies on Consideration of Greenhouse Gas Emissions and the Effects of Climate Change in National Environmental Policy Act Reviews, 82 Fed. Reg. 16,576 (Apr. 5, 2017). See also Dawn Reeves, Drumpf Faces Murky Process to Revoke NEPA Climate Guide, Source Says, INSIDE EPA (Mar. 13, 2017), https://insideepa.com/dailynews/trump-faces-murky-process-revoke-nepa-climate-guide-source-says.

${ }^{655}$ Waste Prevention, Production Subject to Royalties, and Resource Conservation, 81 Fed. Reg. 83,008

(Nov. 18, 2016) (to be codified at 43 C.F.R. pt. 3100, 3160, 3170).

${ }^{656} \mathrm{Id}$. at $83,010-11$.

${ }^{657}$ Alan Kovski, Methane Hot Spot in West Troubles Regulators and Industry, BloomBERG BNA: ENV'T REP. (Aug. 4, 2017).

${ }^{658}$ Carolyn Whetzel, Methane Leak Rule in Effect Can't Be Halted, Lawsuit Says, BloomBerg BNA: ENERGY AND Climate ReP. (July 5, 2017, 6:40 AM).

${ }^{659} \mathrm{Id}$. 
limitations on methane emissions on public lands without following the required administrative procedures, including public notice and comment. ${ }^{660}$

When Donald Trump was a presidential candidate his advisors pledged to end the joint EPA and California GHG/fuel economy standards for light duty vehicles. ${ }^{661}$ In 2011, EPA and California agreed to have the same fuel economy standards that would lead to an average fuel efficiency of 50.8 miles per gallon by 2025 . Until 2025 , it is unlikely that either side can unilaterally breach this agreement. ${ }^{662}$ However, the post-2025 regulatory climate is in play. California is moving forward to achieve $40 \%$ of the state's vehicle sales to be zero emission vehicles or gas-electric plug-ins by $2030 .{ }^{663}$ This could result in substantial reductions in emissions, especially if vehicles are powered by electricity generated from renewable sources.

The California Air Resources Board is also developing post-2025 motor vehicle emissions standards. ${ }^{664}$ This potentially puts the present EPA leadership and California on a collision course. If California is to have post-2025 regulations that are more stringent than federal regulations, it will require a waiver from EPA, and that could trigger a political and legal battle. California's mid-term review has concluded that the current standards "are readily feasible at or below the costs estimated back in 2012." ${ }^{665}$ California will continue to maintain its current GHG emission standards even if EPA does not. ${ }^{666}$ California does not believe the federal government has the power to legally terminate its CAA waiver. ${ }^{667}$

Meanwhile, on March 15, 2017, President Trump announced a plan to cancel EPA's decision to keep the GHG emission standards that were made at the end of the Obama Administration's time in office. ${ }^{668} \mathrm{GHG}$ emission standards set by EPA have the same effect as fuel economy standards promulgated by the National Highway Traffic Safety Administration (NHTSA). EPA and NHTSA are engaged in a mid-term review of the fuel economy requirements for 2022-2025. ${ }^{669}$ In March 2017, the Trump Administration indicated it would not retain the light-duty vehicle GHG standards for model year 2022-

\footnotetext{
${ }^{660}$ See California v. Bureau of Land Mgmt., 277 F. Supp. 3d 1106 (N.D. Cal. 2017). See also Senators Seek Answers from Pruitt on Enforcement of Methane NSPS, INSIDE EPA (Sept. 19, 2017), https://insideepacom.gwlaw.idm.oclc.org/clean-air-report/senators-seek-answers-pruitt-enforcement-methane-nsps. ${ }^{661}$ CARB Faces Inevitable Battles with Trump EPA Over Vehicle Air Rules, InsIDE EPA (Nov. 29, 2016), https://insideepa.com/clean-air-report/carb-faces-inevitable-battles-trump-epa-over-vehicle-air-rules. ${ }^{662}$ John Lippert, California Prepares Go-It-Alone Path on Automobile Emissions for Trump Era, 47 ENV'T REP. 4113 (2016).

${ }^{663}$ Id.

${ }^{664} \mathrm{Id}$.

${ }^{665}$ Curt Barry, CARB Vows to Retain Vehicle GHG Limits in Face of Planned Trump Review, InsIDE EPA (Jan. 19, 2017), https://insideepa.com/daily-news/carb-vows-retain-vehicle-ghg-limits-face-planned-trumpreview.

${ }^{666} \mathrm{Id}$.

${ }^{667}$ California's Existing Vehicle Waivers Safe from Trump, State Senators Told, InSIDE EPA (Mar. 7 , 2017), https://insideepa.com/clean-air-report/californias-existing-vehicle-waivers-safe-trump-state. ${ }^{668}$ Doug Obey \& Lee Logan, EPA's Reopening of Vehicle GHG Decision Opens Door for Industry Pitch, INSIDE EPA (Mar. 15, 2017), https://insideepa.com/daily-news/epas-reopening-vehicle-ghg-decision-opensdoor-industry-pitch.

${ }^{669}$ Id.
} 
2025 vehicles, but the mid-term review will not end until mid-2018. ${ }^{670}$ On August 10, 2017, EPA announced it was seeking comment on whether its fuel economy standards for model year 2021 should be changed too. ${ }^{671} \mathrm{EPA}$ is also revisiting its fuel economy standards for medium and heavy-duty vehicles. ${ }^{672}$ By 2027, these regulations are projected to prevent 1.1 billion metric tons of $\mathrm{CO}_{2}$ emissions, reduce fuel costs by $\$ 170$ billion, and reduce petroleum consumption by up to 2 billion barrels. ${ }^{673}$ On October 20, 2017, EPA sent its proposal to terminate parts of the heavy-duty truck GHG emission standards to the White House for review. ${ }^{674}$ The EPA plans to end the regulation of truck trailers and allow used engines and transmissions to be installed in new chassis and cab assemblies, which will prevent the benefits of the truck rules to be realized. ${ }^{675}$

While the GOP seeks to reduce the fuel efficiency of the motor vehicle fleet, it also seeks to terminate the federal tax credit for electric cars. ${ }^{676}$ The federal tax credit is $\$ 7,500$ for the first 200,000 electric and alternative-fuel vehicles sold by a manufacturer. Plug-in hybrids get less. After sales reach that threshold the credit continues for the rest of the quarter and then is reduced by $50 \%$ for the next two quarters and then is reduced to $25 \% .{ }^{677}$ Tesla and General Motors are expected to soon reach the cap. ${ }^{678}$ The GOP's efforts to end these tax credits are predicted to lead to a major diminution in the sales of alternative vehicles and the environmental benefits from the use of such vehicles, while also making it difficult for the ten states with an electric vehicle mandate to meet their sales goal. ${ }^{679}$

Improving visibility, which is a statutory mandate, requires reductions in emissions from almost all sources of air pollution. However, as the examples discussed above show, the Trump Administration is committed to ending Obama Era emission controls on the electric power industry, the oil and gas production industry, and the automotive industry.

\footnotetext{
${ }^{670}$ Abby Smith \& Doug Obey, Trump EPA Poised to Reverse Course on Obama Vehicle GHG Decision, INSIDE EPA: CLEAN AIR REPORT (Mar. 7, 2017), https://insideepa.com/clean-air-report/trump-epa-poisedreverse-course-obama-vehicle-ghg-decision.

${ }^{671}$ Ryan Beene \& John Lippert, Auto Mileage Rules Could Change Earlier Than Planned, BLOOMBERG BNA: ENERGY AND CLIMATE REP. (Aug. 10, 2017), https://news.bloombergenvironment.com/environmentand-energy/automileage-rules-could-change-earlier-than-planned-1.

${ }^{672}$ Greenhouse Gas Emissions and Fuel Efficiency Standards for Medium- and Heavy-Duty Engines and Vehicles_-Phase 2, 81 Fed. Reg. 73,478 (Oct. 25, 2016) (to be codified at 40 C.F.R. pts. 9, 22, 85, 86, 600, 1033, 1036, 1037, 1039, 1042, 1043, 1065, 1066, 1068). See generally Arnold W. Reitze, Jr., Federal Control of Air Emissions from Heavy-Duty Road Vehicles, 44 ENVTL. L. REP. 10216 (2014).

${ }^{673}$ Anthony Adragna, Obama Administration Tightens Truck Emissions Limits, BLOOMBERG: ENERGY AND ENV'T BLOG (Aug. 16, 2016), https://www.bna.com/obama-administration-tightens-b73014446417/.

${ }^{674}$ Abby Smith, EPA Plans to Repeal Parts of Truck Greenhouse Gas Limits, BLOOMBERG DAILY REP. FOR EXECUTIVES (Oct. 23, 2017), https://www.bna.com/epa-plans-repeal-n73014471276/.

${ }^{675}$ Abby Smith, Truck Industry Awaits EPA Rewrite After Trailer Rule Paused, BLOOMBERG BNA DAILY REP. FOR EXECUTIVES (Oct. 30, 2017),

http://dailyreport.bna.com/drpt/display/batch print_display.adp?searchid=31295411.

${ }^{676}$ David Welch, Telsa, GM Electric Cars May Start Losing Their Tax Credits, BLOOMBERG

ENVIRONMENT (Nov. 2, 2017, 8:30 AM), https://bnanews.bna.com/environment-and-energy/tesla-gm-

electric-cars-may-start-losing-their-tax-credits; Ryan Beene et al., Tax Credit for Telsa, Other Electric Cars

Axed in GOP Bill, BlOOMBERg DaILy REP. FOR EXECUtIVES (Nov. 3, 2017).

${ }^{677}$ Welch, supra note 676

${ }^{678} \mathrm{Id}$. at 1 .

${ }^{679}$ Beene \& Lippert, supra note 671.
} 
This and other efforts of the Trump Administration to expand production and use of fossil fuel will make it more difficult to achieve the 2064 visibility goals.

\section{Conclusion}

The CAA's visibility program differs from most programs under both the CAA and the other pollution control programs administered by EPA. It targets the protection of important ecosystems rather than being based on protection of public health. This makes the program more vulnerable to political pressure to minimize its scope. The science underlying visibility protection also is a barrier to implementation because visibility is seriously reduced by small amounts of particulates in the atmosphere. This means that maintaining pristine visibility effectively limits economic development. Many sources contribute to visibility degradation, but much of the compliance burden falls on the fossilfueled electric power industry, particularly coal burning power plants. This brings "deep pockets" into the decision-making concerning visibility programs as the coal-burning electric power industry, in particular, seeks to avoid expensive retrofits that threaten the economic wellbeing of an industry concerned with its survival. Despite these obstacles, the visibility program continues to make headway. 
